\title{
HYLIFE-II Tritium Management System
}

\author{
G. R. Longhurst and T. J. Dolan \\ Idaho National Engineering Laboratory \\ EG\&G Idaho, Inc. \\ P.0. Box 1625 \\ Idaho Falls, ID 83415-3880, USA \\ Phone 208-526-9950, 208-526-1384 \\ FAX 208-526-0528 \\ Internet: gxi@inel.gov tjdeinel.gov
}

Work supported by the U.S. Department of Energy, Office of Energy Research, under DOE Contract DE-AC07-76ID01570 


\section{Contents}

HYLIFE-II Tritium Management System........................

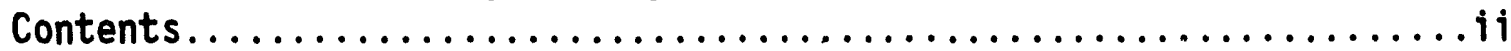

Abstract................................................ ii

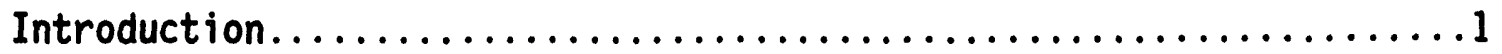

Tritium Flow Rates...............................

Basic System Functions.............................

Blast Chamber Vacuum Pumping................................9

Tritium Removal from Flibe.................................17

Flibe and Tritium Chemistry..........................17

Tritium Removal Methods..............................18

Tritium Release from Flibe Oroplets.....................19

Diffusion and Mass Transport Coefficients................23

Diffusion of Tritium Gas out of Flibe Spray..............27

Vacuum Disengager Parameters..........................39

Flibe Pumping Power................................44

Vacuum Pumping...................................46

Conductance...................................48

Orifice Plates.................................. 51

Need for Intermediate Coolant Loop....................51

Secondary Containment System.............................52

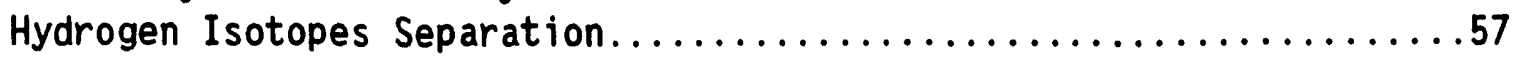

Tritium Removal from Containment Building Air.................60

Release of Non-Hazardous Gases through the Stack...............62

Disposal of Hazardous Effluents...........................62

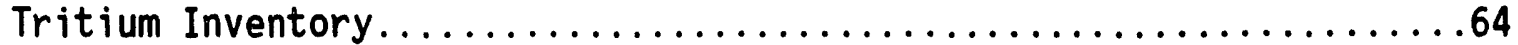

Blast Chamber...................................64

Drain Tanks.....................................65

Vacuum Disengagers...............................66

Inventory quantities.............................67

Tritium Loss Rate.................................. 70

Loss through the Steam Generators.....................70

Loss through the Secondary Containment..................73

Cost Estimate........................................75

Summary ......................................... 81

Acknowledgements .......................................

References....................................... 


\section{Abstract}

The tritium management system performs seven functions: (1) tritium gas removal from the blast chamber, (2) tritium removal from the Flibe, (3) tritium removal from helium sweep gas, (4) tritium removal from room air, (5) hydrogen isotope separation, (6) release of non-hazardous gases through the stack, (7) fixation and disposal of hazardous effluents.

About $2 \mathrm{TBq} / \mathrm{s}$ ( $5 \mathrm{MCi} /$ day) of tritium is bred in the Flibe ( $\mathrm{Li}_{2} \mathrm{BeF}_{4}$ ) molten salt coolant by neutron absorption. Tritium removal is accomplished by a two-stage vacuum disengager in each of three steam generator loops. Each stage consists of a spray of $0.4 \mathrm{~mm}$ diameter, hot Flibe droplets into a vacuum chamber $4 \mathrm{~m}$ in diameter and $7 \mathrm{~m}$ tall. As droplets fall downward into the vacuum, most of the tritium diffuses out and is pumped away. A fraction $\Phi \approx 10^{-5}$ of the tritium remains in the Flibe as it leaves the second stage of the vacuum disengager, and about $24 \%$ of the remaining tritium penetrates through the steam generator tubes, per pass, so the net leakage into the steam system is about $4.7 \mathrm{MBq} / \mathrm{s}$ ( $11 \mathrm{Ci} /$ day). The required $\mathrm{Flibe}$ pumping power for the vacuum disengager system is $6.6 \mathrm{MW}$. With Flibe primary coolant and a vacuum disengager, an intermediate coolant loop is not needed to prevent tritium from leaking into the steam system. An experiment is needed to demonstrate vacuum disengager operation with Flibe. A secondary containment shell with helium sweep gas captures the tritium permeating out of the Flibe ducts, limiting leaks there to about $1 \mathrm{ci} /$ day. The tritium inventory in the reactor is about $190 \mathrm{~g}$, residing mostly in the large Flibe recirculation duct walls. The total cost of the tritium management system is $92 \mathrm{M} \$$, of which the vacuum disengagers cost $=56 \%$, the blast chamber vacuum system $=15 \%$, the cryogenic plant $=9 \%$, the emergency air cleanup and waste treatment systems each $=6 \%$, the protium removal system $=3 \%$, and the fuel storage system and inert gas system each $=2 \%$. 


\section{Introduction}

The HYLIFE-II inertial confinement fusion reactor uses 5-MJ heavy ion beams to compress and ignite fuel pellets yielding $350 \mathrm{MJ}$ per pulse, at a repetition rate of $8.1 \mathrm{~Hz}$ in a single blast chamber.1,2 Falling jets of Flibe $\left(\mathrm{Li}_{2} \mathrm{BeF}_{4}\right)$ molten salt protect the blast chamber wall. The use of Flibe affords some safety and environmental advantages, provided that tritium loss through the steam system can be limited to $<17 \mathrm{MBq} / \mathrm{s}$ ( $40 \mathrm{Ci} /$ day). ${ }^{3}$ The blast chamber vacuum pumping system can remove most of the tritium remaining unburned from fuel pellets, but practically none of the tritium present in the Flibe. Tritium is removed from the Flibe coolant by spraying tiny Flibe droplets into a vacuum in a "vacuum disengager." 4,5

In the absence of a tritium management system, the dominant pathway of tritium to the atmosphere is through the steam generator into the steam system. HYLIFE-II will have three steam generator (SG) loops, with a twostage vacuum disengager in each loop. 6

Tritium permeation rates through heat exchanger tubes are estimated using an analogy between turbulent mass transport and heat transport. ${ }^{7} \mathrm{~A}$ secondary containment shell with a helium sweep gas is used around Flibe ducts where the tritium leakage is significant. This report describes the tritium management system, the tritium inventories of each component, the tritium leak rates through various pathways, and the estimated cost of the system.

\section{Tritium Flow Rates}

The original HYLIFE-II design had both primary and intermediate coolant loops, as illustrated in Figure 1. The following parameter definitions will be used: 2

$B=$ tritium breeding ratio $\approx 1.16$

$C=$ tritium consumption rate by fusion reactions (atoms $/ \mathrm{s}$ )

$F=$ rate of tritium injection in fuel pellets (atoms $/ s$ )

$f_{b}=$ pellet burnup fraction $\approx 0.35$ 


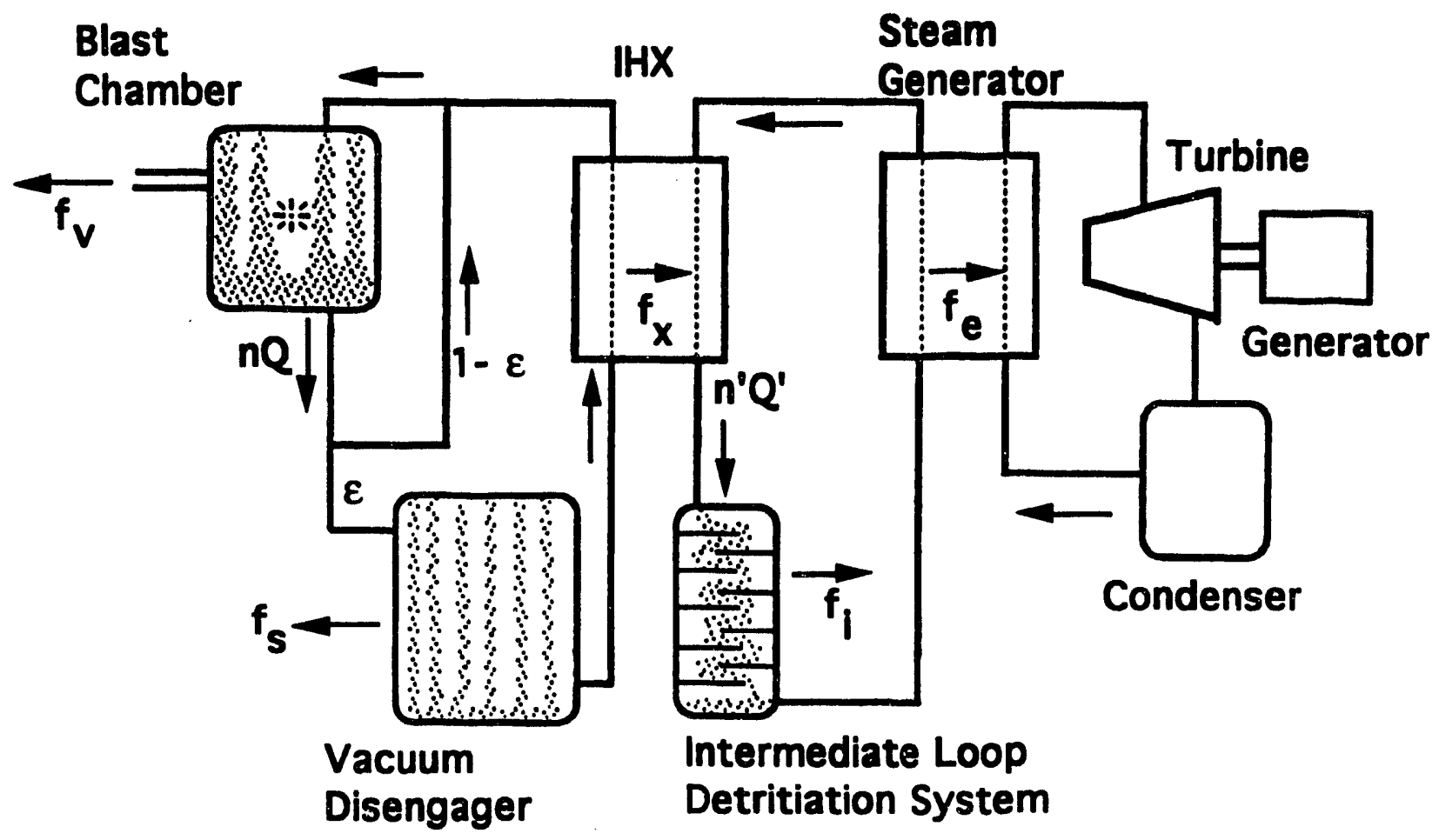

Figure 1. Original HYLIFE-II design with an intermediate coolant loop. (In present designs the intermediate loop is omitted.) 
$f_{e}$ - fraction of tritium atoms leaking into the steam generator per pass of intermediate coolant

$f_{j}$ - fraction of tritium atoms removed by intermediate loop detritiation system

$f_{V}=$ fraction of unburned fuel pellet tritium atoms $(F-C)$ removed by blast chamber vacuum system

$f_{S}=$ fraction of tritium atoms removed by vacuum disengager

$f_{X}=$ fraction of tritium atoms leaking into the intermediate loop per pass of the primary coolant through the intermediate heat exchanger (IHX)

$n=$ tritium concentration in primary coolant leaving the blast chamber $\left(m^{-3}\right)$

$n^{\prime}=$ tritium concentration in secondary coolant leaving the IHX $\left(\mathrm{m}^{-3}\right)$

$P=$ fusion power

$Q=$ primary coolant volumetric flow rate $\left(\mathrm{m}^{3} / \mathrm{s}\right)=85.2 \mathrm{~m}^{3} / \mathrm{s}$

$Q^{\prime}$ - intermediate coolant volumetric flow rate $\left(\mathrm{m}^{3} / \mathrm{s}\right)$

$W=$ energy released per fusion $=2.818 \times 10^{-12} \mathrm{~J}$

$\varepsilon$ = fraction of primary coolant passing through the vacuum disengager $\lambda=$ tritium decay constant $=1.787 \times 10^{-9} \mathrm{~s}^{-1}$.

The tritium consumption rate and tritium fuel injection rate are found from the equations

$$
C=f_{b} F=P / W \text {. }
$$

Assuming a yield of $350 \mathrm{MJ}$ at $8.1 \mathrm{~Hz}$ with $\mathrm{f}_{\mathrm{b}}=0.35$, the fusion power $\mathrm{P}=2835$ MWth, $C=1.01 \times 10^{21}$ atoms $/ \mathrm{s}$, and $F=2.87 \times 10^{21}$ atoms $/ \mathrm{s}$. The activity of the tritium bred in the Flibe is

$$
A_{B}=\lambda B \subset t
$$

where $t$ - time of operation. There is a slight amount of tritium introduced into the Flibe from the unburned fuel not removed by the blast chamber vacuum system, but it is negligible in comparison with the tritium bred in the Flibe by neutrons.

From conservation of tritium atoms, their flow rate in the flibe leaving the blast chamber is found to be 


$$
n Q=\frac{B C+\left(1-f_{v}\right)(F-C)}{\varepsilon\left[1-\left(1-f_{S}\right)\left(1-f_{X}\right)\right]}
$$

Similarly, the tritium flow rate in the intermediate coolant leaving the IHX is

$$
n^{\prime} Q^{\prime}=\frac{\varepsilon f_{x}\left(1-f_{s}\right)}{f_{e}+f_{i}\left(1-f_{e}\right)} n Q .
$$

The tritium loss rate into the steam generator system is then

$$
L=f_{e}\left(1-f_{j}\right) n^{\prime} Q^{\prime}=\frac{f_{e} f_{x}\left(1-f_{i}\right)\left(1-f_{s}\right)\left[B C+\left(1-f_{v}\right)(F-C)\right]}{\left[f_{e}+f_{i}\left(1-f_{e}\right)\right]\left[1-\left(1-f_{s}\right)\left(1-f_{x}\right)\right]}
$$

Various tritium removal strategies have been considered:

- all tritium removal in the primary loop,

- all tritium removal in the intermediate loop,

- tritium removal in both loops.

It is preferable to remove the tritium effectively in the primary loop, because this permits single-wall tubing to be used in the intermediate loop, with substantial savings in design simplicity and cost. It is most effective to remove tritium only in the primary coolant flibe flowing to a heat exchanger, and not in the recirculation path or just below the blast chamber. With effective tritium removal by a vacuum disengager in the primary loop $\left(1-f_{s}\right) \ll 1$, tritium removal in the intermediate coolant loop is unnecessary, so $f_{i} c$ an be set equal to zero. Then Equations ( 3 ) and (5) reduce to

$$
\begin{gathered}
n Q=\left[B C+\left(1-f_{V}\right)(F-C)\right] / \varepsilon \\
L=\varepsilon n Q f_{X}\left(1-f_{s}\right) .
\end{gathered}
$$


In view of the low solubility of tritium in Flibe, it is assumed that $f_{v}=0.99$. Then $n Q=9.80 \times 10^{21}$ atoms $/ \mathrm{s}=40.9 \mathrm{MCi} /$ day. This flow rate is higher than the tritium production rate ( $5 \mathrm{MCi} /$ day), because most of the Flibe recirculates through the blast chamber several times, on the average, before it flows through the steam generator loops, where tritium is removed. With a two-stage vacuum disengager, it is found that $\left(1-f_{s}\right)=10^{-5}$ can be attained. Therefore, the intermediate coolant loop is not necessary for tritium control. If there is 10 intermediate loop, $f_{x}$ in Equation (7) represents the fraction of tritium permeating through the steam generator $(S G)$ tubes, per pass. It is estimated that $f_{X} \approx 0.22$, so the leak rate $L=11 \mathrm{Cl} /$ day. (About $1 \mathrm{C} i /$ day is also lost through Flibe duct walls.) Typical tritium flow parameters are summarized in Table 2. Figure 2 shows the present design of the Flibe coolant loops, with no intermediate loop.

Table 2. Typical tritium parameters in HYLIFE-II with no intermediate coolant loop.

$\begin{array}{ll}\varepsilon & =\text { fraction of Flibe flow going through vacuum disengagers }=0.121 \\ f_{v} & =\text { fraction of unburned fuel tritium removed by vacuum system } \approx 0.99 \\ f_{X} & =\text { fraction of tritium in Flibe permeating through } S G \text { tubes } \approx 0.24 \\ \left(1-f_{s}\right) & =\text { fraction of tritium not removed by vacuum disengager } \\ & =10^{-5} \text { (alculated below for a two-stage vacuum disengager) } \\ n Q & =\text { tritium flow rate leaving blast chamber } \\ & =9.80 \times 10^{21} \text { atoms } / \mathrm{s}=40.9 \mathrm{MCi} / \text { day. } \\ & =\text { rate of tritium introduction into flibe (from breeding }+ \text { fue } 1 \text { ) } \\ & =\text { tritium flow rate into steam generator loops } \\ & =1.19 \times 10^{21} \text { atoms } / \mathrm{s}=4.95 \mathrm{MCi} / \text { day } \\ & =\text { total } \mathrm{Flibe} \mathrm{flow} \mathrm{rate}=85.2 \mathrm{~m} / \mathrm{s} \\ n & =\text { average tritium concentration in Flibe leaving } \mathrm{blast} \mathrm{chamber} \\ \mathrm{L} & =1.15 \times 10^{20} \text { atoms } / \mathrm{m}^{3}\end{array}$




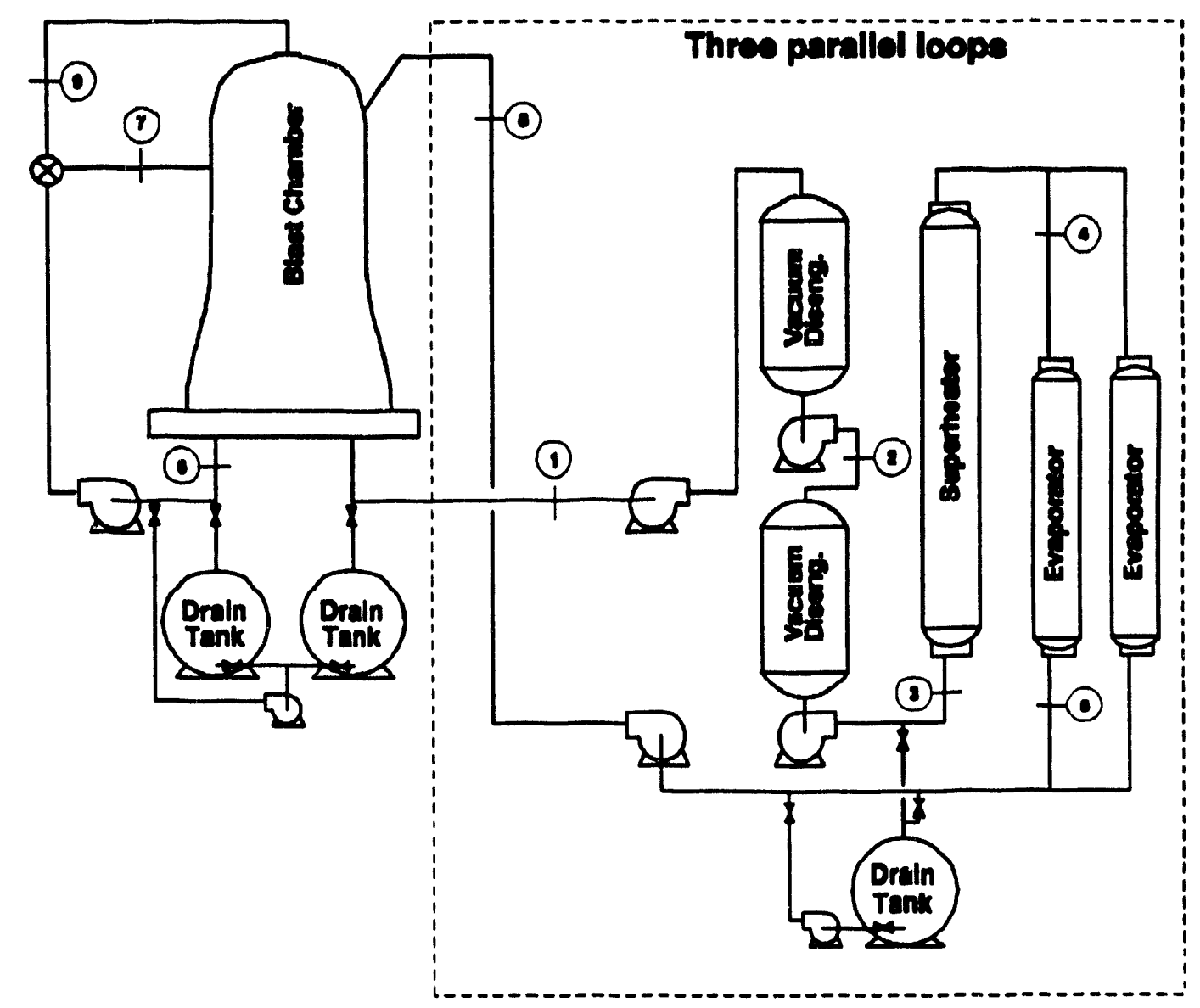

Figure 2. HYLIFE-II Flibe system with no intermediate coolant loop. 


\section{Basic System Functions}

Figure 3 shows the main elements of the HYLIFE-II tritium management system. This system has seven principal functions:

1. Remove unburned tritium coming from the blast chamber.

2. Remove tritium from the Flibe upstream of the steam generators.

3. Process the gas in the secondary containment shell to remove tritium.

4. Remove tritium from room air in the reactor hall in the event of a spill and process any residue from $F$ libe leakage.

5. Separate hydrogen isotopes from other effluents. Remove protium and return analyzed D-T mix to fuel storage system.

6. Release non-hazardous gases to the stack.

7. Provide for fixation and disposal of hazardous effluents processed in the tritium management system.

Each of these will be discussed in order. 


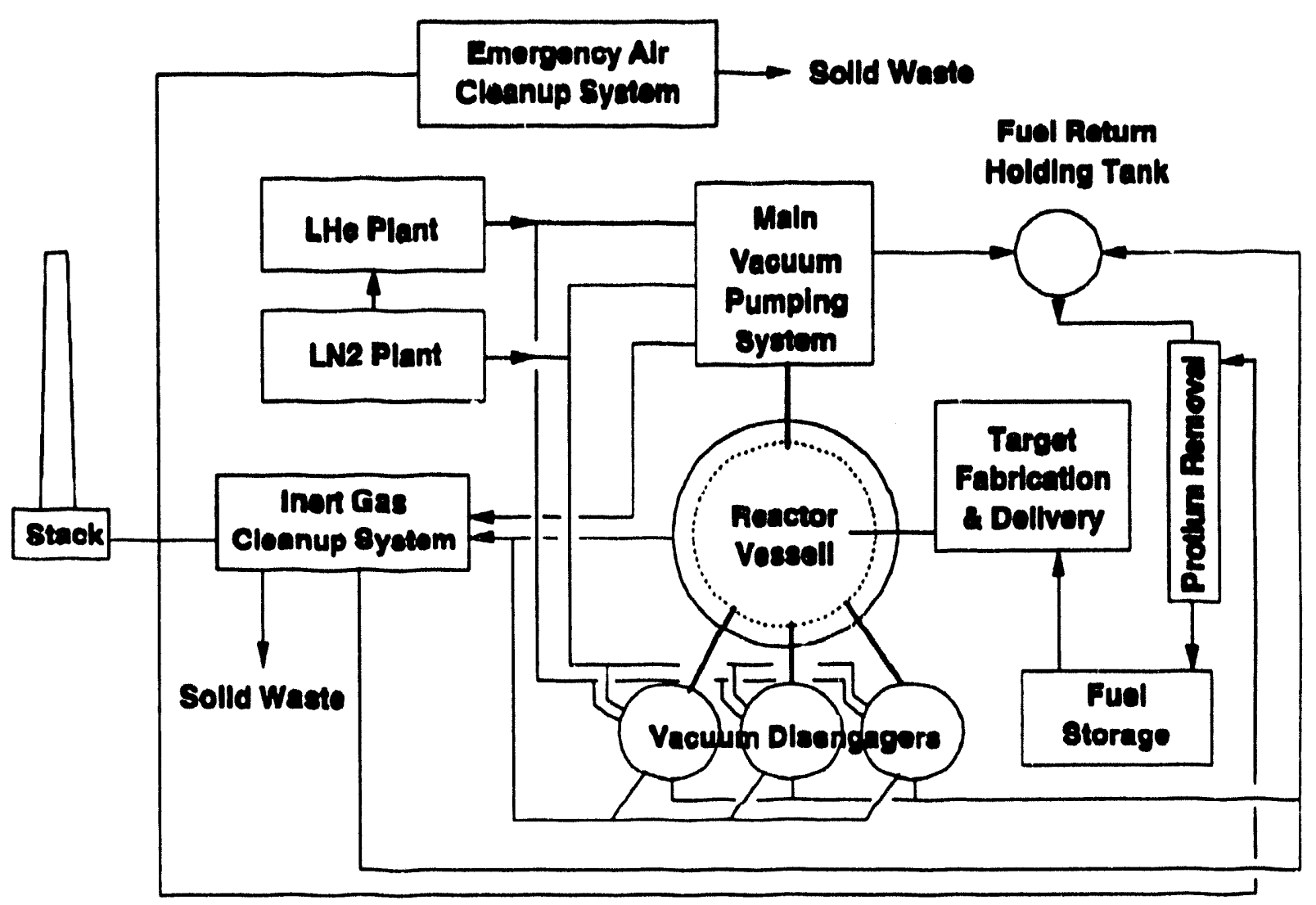

Figure 3. HYLIFE-II tritium management system. 


\section{Blast Chamber Vacuum Pumping}

The main reactor vessel will require considerable pumping to remove unburned fuel, helium ash, and miscellaneous debris. Assuming a DT fusion yield $Y=350 \mathrm{MJ} / \mathrm{pulse}$ and an energy release $\mathrm{W}_{f}-2.818 \times 10^{-12} \mathrm{~J}$ per fusion, there are $\mathrm{NHe}-Y / W_{f}-1.242 \times 10^{20}$ atoms of helium produced per pulse. The number of unburned tritium atonis released into the blast chamber per pulse

$$
N_{T}=N_{H e}(1-f b) / f b \text {, }
$$

where $f_{b}=$ the fuel burnup fraction. If $f_{b}=0.35$, then $N_{T}=N_{0}=$ $2.31 \times 10^{20}$ atoms/pulse, and the total number of $(\mathrm{He}+\mathrm{D}+\mathrm{T})$ atoms added to the chamber per pulse is $\Delta N=5.86 \times 10^{20}$.

For ion beam propagation the required gas density $n<3 \times 10^{19} \mathrm{~m}^{-3}$, which at $923 \mathrm{~K}$ corresponds to a pressure of $0.38 \mathrm{~Pa} .8$ Approximating the blast chamber by a cylinder with radius $3.5 \mathrm{~m}$ and height $12 \mathrm{~m}$, its volume $V=462 \mathrm{~m}^{3}$.

Assuming that about $20 \%$ of this volume is occupied by structure and $\mathrm{Flibe}$, the free volume to be pumped is $V-370 \mathrm{~m}^{3}$. The $(D+T+H e)$ gas pressure added to the chamber per pulse is

$$
\Delta p=\Delta N K T / N=0.020 \mathrm{~Pa} \text { per pulse. }
$$

which is much less than the required pressure. At a repetition rate of $8.1 \mathrm{~Hz}$ the flow rates of $D, T$, and He are

$$
\begin{aligned}
& \mathrm{He} \quad-1.01 \times 10^{21} \text { atoms } / \mathrm{s}=6.71 \mathrm{mg} / \mathrm{s} \\
& D=1.87 \times 10^{21} \text { atoms } / \mathrm{s}=6.24 \mathrm{mg} / \mathrm{s} \\
& \mathrm{T}=1.87 \times 10^{21} \text { atoms } / \mathrm{s}=9.37 \mathrm{mg} / \mathrm{s}
\end{aligned}
$$

Total $\mathrm{dN} / \mathrm{dt}-4.75 \times 10^{21}$ atoms $/ \mathrm{s}$.

There is about $219 \mathrm{mg}$ of Ta per target, or $1774 \mathrm{mg} / \mathrm{s}$. Normally the Ta metal would condense into the Flibe. If all the Ta became fluorinated, the TaF5 (boiling point $504 \mathrm{~K}$ ) would add $5.83 \times 10^{21}$ molecules/s to the gas pumping load. There will also be small quantities of Li, H, HF, DF, TF, LiH, LiT, LID, LiF, 
BeF $_{2}, F_{2}$ and possibly other gases that come from the dissociation and outgassing of the Flibe or the targets.

There are six potential sources of protium:

(1) target debris. This source can be practically eliminated by using targets that do not contain hydrogen. Then only $(n, p)$ reactions in the targets contribute to this source term.

(2) protium diffusion through structural components from the air. The permeation rate of diatomic gases through metals may be estimated from the equation

$$
Q_{p}=K_{p}\left(p_{2} 1 / 2-p_{1} 1 / 2\right) A / d
$$

where $K_{p}=$ permeation coefficient, $\mathrm{P}_{2}=$ external pressure $=0.0507 \mathrm{~Pa}$ for $\mathrm{H}_{2}$ in air, $p_{1}=$ internal pressure, $A=$ surface area of piping, $d=$ tube thickness. For steel at $900 \mathrm{~K}, \mathrm{~K}_{\mathrm{p}} \approx 2 \times 10^{-7} \mathrm{~m}^{2} \mathrm{~Pa}^{1 / 2} / \mathrm{s} .9$ Assuming $\mathrm{p}_{1} \ll \mathrm{p}_{2}, A \approx$ $1000 \mathrm{~m}^{2}$, and $d \approx 0.01 \mathrm{~m}$, the permeation rate is found to be

$$
a_{p} \approx 0.0045 \mathrm{~Pa}-\mathrm{m}^{3} / \mathrm{s} \approx 3.6 \times 10^{17} \text { atoms } / \mathrm{s} \text {. }
$$

The double-wall containment around part of the Flibe system will further reduce protium inflow from the air.

(3) There will also be some hydrogen produced by dissociation of water vapor in the air on hot stainless steel pipes. The partial pressure of water in air is about $720 \mathrm{~Pa}$. A fraction of it dissociating and entering the pipes could substantially increase the $\mathrm{H}_{2}$ source term. However, a balance between the reaction rates for dissociation, recombination, absorption, and diffusion in the presence of an intact or partially depleted oxide film is beyond the scope of the present work. This is a potential source of protium which should be studied further in the future.

(4) protium diffusion through the steam generator from the water and steam. Like protium from water in the air, this source term could be significant, but is left for future study. 
(5) protium from $(n, p)$ reactions in the flibe and in the blast chamber walls. Hydrogen production in the Hastelloy $\mathrm{N}$ blast chamber walls is estimated to be $4305 \mathrm{appm}$ after $30 \mathrm{y}$ irradiation, or about $144 \mathrm{appm} / \mathrm{year} .10$ For Hastelloy $\mathrm{N}(70 \% \mathrm{Ni}, 17 \% \mathrm{Mo}, 7 \% \mathrm{Cr}, 5 \% \mathrm{Fe})$, average molecular weight $63.8 \mathrm{~g} / \mathrm{mole}$, and $\rho \approx 8710 \mathrm{~kg} / \mathrm{m}^{3}$ at $923 \mathrm{~K}$. The chamber wall area is estimated to be about $480 \mathrm{~m}^{2}$. Assuming an effective wall thickness of $0.03 \mathrm{~m}$, the chamber wall mass $M=125$ tonnes, containing about $1.2 \times 10^{30}$ atoms of metal. The protium production rate in the blast chamber walls is estimated to be $5.4 \times 10^{18}$ atoms $/ \mathrm{s}$.

In the $F 1$ ibe $19 F(n, p)$ and $\left(n, n^{\prime} p\right)$ reactions are estimated to produce about 0.0034 protons per $D-T$ reaction. Assuming that reactions in $\mathrm{Li}$ and Be produce a comparable amount, about 0.007 protons/DT reaction is estimated to be produced in the Flibe. At a fusion power level of $2835 \mathrm{MW}$, this would yield $7 \times 10^{18}$ atoms $/ \mathrm{s}$ of protium.

(6) protium produced by $D(d, p)$ fusion reactions. At burn temperatures of 10-20 keV, the $D(d, p)$ fusion reaction rate is a factor of $170 \pm 10$ lower than the DT fusion reaction rate producing helium. Therefore, the protium production rate by fusion reactions $\approx 6 \times 10^{18}$ atoms $/ \mathrm{s}$.

The total protium inflow rate calculated here is about $1.9 \times 10^{19}$ atoms $/ \mathrm{s}$, which is much lower than the flow rates of $D, T$, and He, so it may be ignored. (This situation could change if protium influx from water and water vapor turns out to be significant.) The partial pressure of $\mathrm{He}$ in the air is about $0.53 \mathrm{ia}$, so in principle it could permeate into the vacuum system. However, according to Roth, "The permeation of atmospheric gases through metal walls does not include the rare gases ( $\mathrm{He}, \mathrm{A}, \mathrm{Ne}, \mathrm{Kr}, \mathrm{Xe}$ ) since no rare gas diffuses through metals at any temperature under purely thermal activation." 11

The molecular mean free path $\lambda=k_{1} / p$, where $k_{1}=0.0141 \mathrm{~Pa}-\mathrm{m}$ for $\mathrm{H}_{2}$. (The symbol $\lambda$ is used for both decay constant and mean free path, with distinction to be deduced from context.) For a duct with $D=1 \mathrm{~m}$ at a chamber pressure = $0.38 \mathrm{~Pa}, \lambda / D=0.04$, and the flow is in the transition regime. In the transition region the conductance is nearly the sum of the viscous and molecular conductances. 12 A cooled surface or baffle at $T=770 \mathrm{~K}$ will be located near the vacuum pumbing duct entrance to condense Flibe vapor. For 
the baffles only the molecular flow conductance is used:

$C_{B}=A(k T / 2 \pi m)^{1 / 2} T_{b}$

where $A-\operatorname{area}\left(\mathrm{m}^{2}\right)$ of the port occupied by baffles, $k=$ Boltzmann constant, $\mathrm{m}=$ molecular weight of $T_{2}=1.001 \times 10^{-26} \mathrm{~kg}$, and $T_{b}=$ transmission probability through the baffle. For a well-designed chevron baffle, $T_{b}=0.20 .13$ For tritium molecules at about $770 \mathrm{~K}$ the conductance of the baffle is

$$
C_{B}=82 A=82\left(\pi D^{2} / 4\right) \quad m^{3} / \mathrm{s} \text {. }
$$

where $D=$ diameter of the duct and baffle. If $D=1 \mathrm{~m}$ then $C_{B}=64 \mathrm{~m} 3 / \mathrm{s}$, and if $D=1.5 \mathrm{~m}$, then $C_{B}=115 \mathrm{~m} 3 / \mathrm{s}$. The average duct temperature is assumed to be $600 \mathrm{~K}$. The corresponding total gas throughput is

$$
a=k T(d N / d t)=39.3 \mathrm{~Pa}-\mathrm{m}^{3} / \mathrm{s} .
$$

According to the March 26, 1992 layout of HYLIFE-II, the blast chamber vacuum pumping ducts have length $L \approx 13 \mathrm{~m}, D=1 \mathrm{~m}$, and two 45 degree bends. For bends less than 90 degrees, the tube conductance in the molecular flow regime is roughly equal to that of a straight tube with the same axial length. The conductances of a circular duct for hydrogen isotopes at $600 \mathrm{~K}$ in the molecular and viscous flow regimes are 12

$$
\begin{aligned}
& C_{m}=122(29 / 5)^{1 / 2}(600 / 293)^{1 / 2} D^{3} /(L+1.333 D)=420 D^{3} /(L+1.333 D) \\
& C_{v}=1430(170.5 / 83.5)(293 / 600)^{1 / 2} D^{4} \mathrm{Pav}_{\mathrm{av}} / \mathrm{L}=2040 \mathrm{D}^{4} \mathrm{Pav} / \mathrm{L}
\end{aligned}
$$

where $(29 / 5)=$ mass ratio $($ air/DT), $(600 / 293)=$ temperature ratio, $(170.5 / 83.8)=$ viscosity ratio (air/hydrogen), and $\mathrm{p}_{\mathrm{av}}=$ average pressure in the duct. In the transition regime, the conductance $C_{1}$ of a tube is roughly the sum of the molecular and viscous conductances. These conductances for ducts with $L=13 \mathrm{~m}, \mathrm{P}_{\mathrm{av}}=0.2 \mathrm{~Pa}$, are estimated for two values of diameter:

$\begin{array}{lll}C_{m}= & D=1 \mathrm{~m} & D=1.5 \mathrm{~m} \\ C_{v}= & 29 & 95 \mathrm{~m}^{3} / \mathrm{s} \\ & 31 & 159\end{array}$


$c_{1} \approx c_{m}+c_{v}=$

$C_{B}$

$C-\left(C_{B}^{-1}+C_{1}^{-1}\right)^{-1}-$

31

64

115

Here $C=$ total conductance of the ducts between the chamber and the pumps. Let $S$ - total pumping speed of the pumps. The values of $S$ and $C$ can be estimated from

$$
S C /(S+C)=Q / p \text {. }
$$

Using $Q=39.3 \mathrm{~Pa}-\mathrm{m}^{3} / \mathrm{s}$, and $\mathrm{p}=0.38 \mathrm{~Pa}$, the effective pumping speed is found to be

$$
\mathrm{sC} /(\mathrm{S}+\mathrm{C})=103 \mathrm{~m}^{3} / \mathrm{s},
$$

from which $S=103 \mathrm{C} /(C-103)$. For a case with four ducts, the total conductance $C_{\text {tot }}=4 C$, and the required pumping speed is

$\begin{array}{lll}C=1 \mathrm{~m} & D=1.5 \mathrm{~m} \\ \mathrm{~S}= & 124 & 316 \mathrm{~m}^{3} / \mathrm{s} \\ & 608 & 153 \mathrm{~m}^{3} / \mathrm{s}\end{array}$

In what follows the following values are assumed: 4 ducts, $D=1.5 \mathrm{~m}$, $L=13 \mathrm{~m}, S=200 \mathrm{~m}^{3} / \mathrm{s}\left(50 \mathrm{~m}^{3} / \mathrm{s}\right.$ per duct $)$. For comparison, the pumping speed required for HYLIFE-I with heavy ion beams was $310 \mathrm{~m}^{3} / \mathrm{s} .14$

Cooled baffles reduce the Flibe vapor pressure to low values before the gases reach the vacuum pumps. Turbomolecular pumps can achieve about $5 \mathrm{~m}^{3} / \mathrm{s}$, so the $50 \mathrm{~m}^{3} / \mathrm{s}$ load could be handled by 10 turbopumps on each duct. However, turbopumps are vulnerable to damage by Flibe droplets, and they require periodic replacement. Scroll pumps (Normatex) are expensive and have limited flow capacity. High pumping speeds ( $>1000 \mathrm{~m}^{3} / \mathrm{s}$ ) are available from cryogenic pumps. A set of three cryopumps (one in service, one regenerating, and one in 
standby) would suffice on each duct.

Since He will make up about $21 \%$ of the pumped gas stream, it will be important to have a means of separating the He from the $D / T$ mixture. All species but He would quickly condense in the cryopump, and the He could be Irawn off by a turbomolecular or other dry mechanical pump. Only trace quantities of tritium would be entrained in the effluent flow. That could be scavenged by passing the effluent stream over a getter bed such as uranium or a La-Ni intermetallic.

Hemmerich's cryodiffusion pump could achieve very high pumping speeds, 15 but it is ineffective in the molecular flow regime, which may occur in the HYLIFE-II ducts, so Foster's "snail" cryopump (Figure 1 ) is chosen instead.16 A travelling "snail" (Figure 5) moves over the cryogenic surface, locally heating it and driving off the condensate to a collection duct. One snail cryopump on each duct would suffice. Since this cryopump continually regenerates, it is not necessary to periodically valve it off and warm it up for regeneration. Hydrogen isotopes are drawn off by the turborrolecular pump and sent to the Protium Removal System.

A cryogenic plant producing liquid helium and liquid nitrogen is required for the cryopumping system. The $L N_{2}$ will be used as a thermal buffer for the liquid He. 


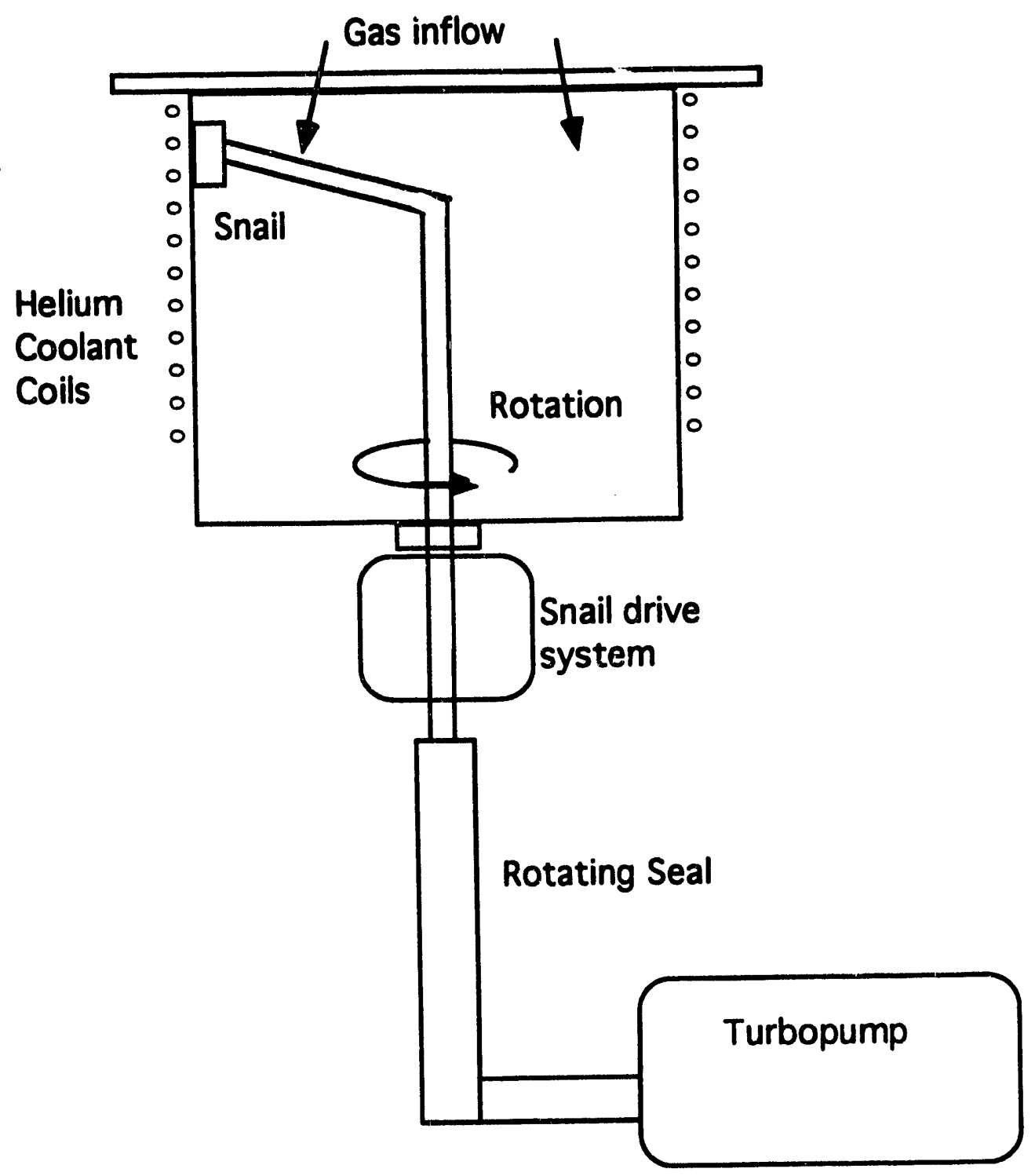

Figure 4. A snail type cryogenic pump. 


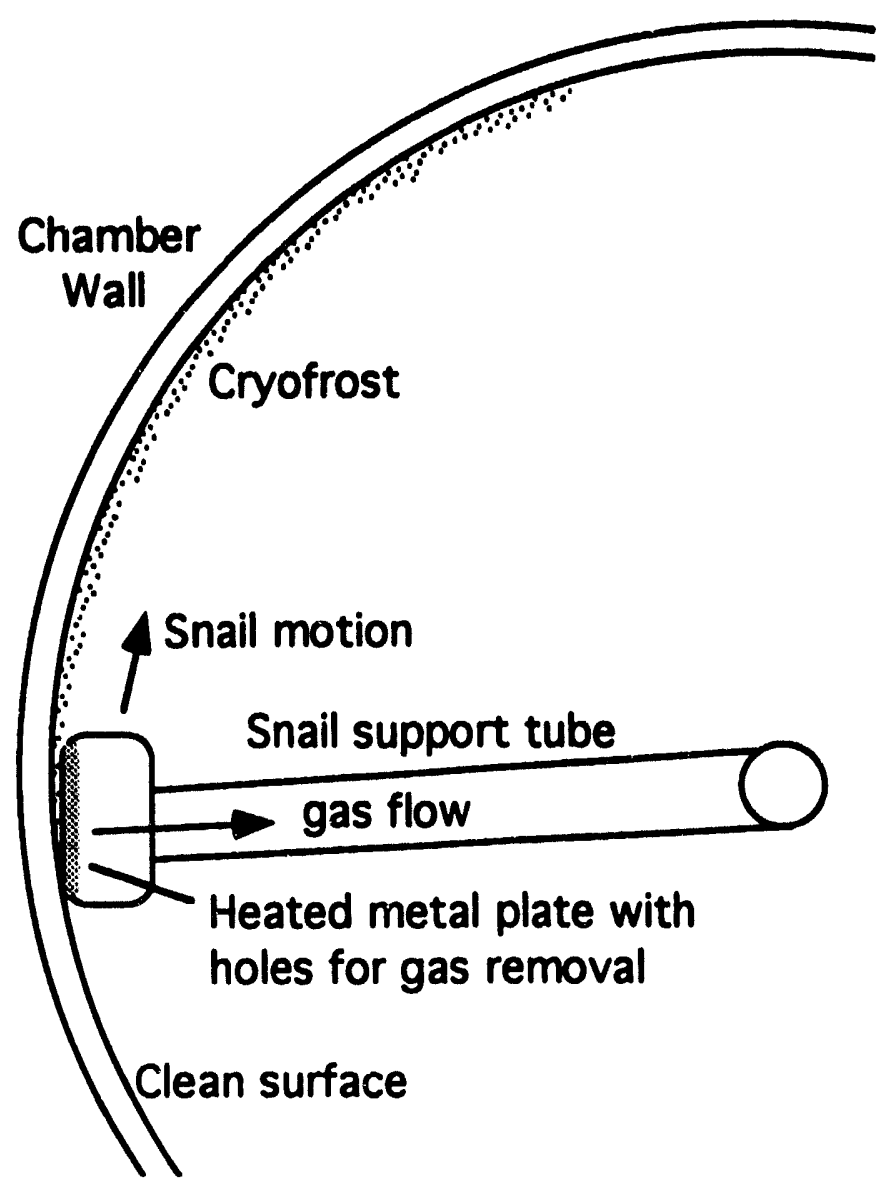

Figure 5. The traveling snail. 


\section{Tritium Removal from Flibe}

\section{Flibe and Tritium Chemistry}

A two-stage vacuum disengager will be needed in each of the three heat transfer loops. Tritium is bred by neutron absorption in lithium in the Flibe. Helium is produced in the Flibe by neutron interactions in $\mathrm{LI}$ and Be. There will be virtually no deuterium in the Flibe, since it is not produced appreciably by nuclear reactions or dissolved much from the gas. The Flibe fractionation products ( $L$ iF and $B e F_{2}$ ) produced by the blast and high temperatures should also be absent when the Flibe arrives at the vacuum disengager.

The Flibe may be passed through a Be screen to remove excess fluorine, and a dilute buffering agent such as Ce may also be added to the Flibe. Many reactions involving fluorine or tritium will be occurring in the Flibe, such as :

$$
\begin{array}{ll}
\mathrm{CeF}_{3}+\mathrm{F} & \rightarrow \mathrm{CeF}_{4} \\
\mathrm{CeF}_{3}+(1 / 2) \mathrm{F}_{2} & \rightarrow \mathrm{CeF}_{4} \\
\mathrm{~F}+\mathrm{T} & \rightarrow \mathrm{TF} \\
\mathrm{T}+\mathrm{T} & \rightarrow \mathrm{T}_{2} \\
\mathrm{~F}+\mathrm{F} & \rightarrow \mathrm{F}_{2} \\
\mathrm{~F}_{2}+\mathrm{T}_{2} & \rightarrow 2 \mathrm{TF} \\
\mathrm{Be}+2 \mathrm{TF} & \rightarrow \mathrm{BeF}_{2}+\mathrm{T}_{2} \\
\mathrm{TF}+\mathrm{CeF}_{3} & \rightarrow \mathrm{CeF}_{4}+(1 / 2) \mathrm{T}_{2} .
\end{array}
$$

Since the tritium bred in the Flibe will be very dilute, the rate of Reaction (15) producing $T_{2}$ directly will be low. The rate of Reaction (14) producing TF will depend upon the amount of free fluorine available, which depends on the rates of the other reactions. The equilibrium concentrations of TF and $T_{2}$ have been computed as functions of the mole fraction $\mathrm{Fe}++$ in the salt. 17 In general, using sufficient $\mathrm{Be}$ and $\mathrm{CeF}_{3}$ will tend to increase the equilibrium concentration ratio of $T_{2} / T F$ to large values. Here it is assumed that all the tritium is in the $T_{2}$ form. The small fraction of tritium in the TF form will be more difficult to remove from the Flibe droplets in the vacuum disengager, but it will also be much less likely to permeate out of the Flibe through the 
heat exchanger tubes.

\section{Tritium Removal Methods}

Tritium may be removed by running the Flibe over baffle plates with counterflowing gas, by bubbling inert gas through the Flibe, and by spraying the flibe into a vacuum or inert gas. The mass transport rate of a bubbling system is better than flow over baffles, and the mass transport rate in a spray is generally a little better than that in a bubbling system. ${ }^{18}$ Therefore, a spray system is chosen for HYLIFE-II.

Our analysis indicates that a vacuum disengager (a molten salt spray into a vacuum) can achieve the required separation. The use of a flowing inert gas (such as argon) in the spray chamber has also been considered. The gas would partially levitate the Flibe droplets, prolonging their flight time; and it would induce internal circulation and oscillations of the droplets, thus increasing the tritium removal rate from the droplets. However, a significant amount of the gas could be carried to the blast chamber, where it would interfere with condensation and beam propagation; some heat would be lost with the gas; and a system to remove tritium from the gas would entail additional complexity and expense. Studies of a flowing-gas spray chamber showed no significant improvements in system size or cost; therefore, the Flibe droplets will be sprayed into a vacuum.

Another tritium control idea, suggested by $D .-K$. Sze, is to maintain the primary loop tritium in the Tritium Fluoride (TF) form by adding excess fluorine to the Flibe (via MoF 6 , for example). ${ }^{19}$ In the TF form tritium has a much lower diffusivity through the Flibe, and it cannot dissociate to penetrate through some types of tube coatings. One potential coating with a high binding energy is TiN, which could be applied by adding nitrogen to the Flibe to interact with $\mathrm{Ti}$ alloy tubes or coatings. However, a vacuum disengager would not work well with the TF form, unless much smaller droplets could be used. 
Several vacuum disengager design probloms must be addressed:

- tritium diffusion out cf Flibe droplets

- tritium diffusion out of the spray region

- $\quad$ optimum droplet siza

- means of spray production

- requitred chamber radius and height

- Flibe pumping power

- vacuum pumping requirements

- attainable tritium removal efficiency.

These will be discussed in the following sections.

\section{Tritlum Release from Flibe Droplets}

There are two diffusion problems to be solved: the tritium diffuses out of Flibe droplets, and then the released tritium gas diffuses out of the spray region to the vacuum pumps.

The distribution of tritium remaining in a Flibe droplet as a function of time during the droplet's fall through a vacuum is illustrated in Figure 6 . 

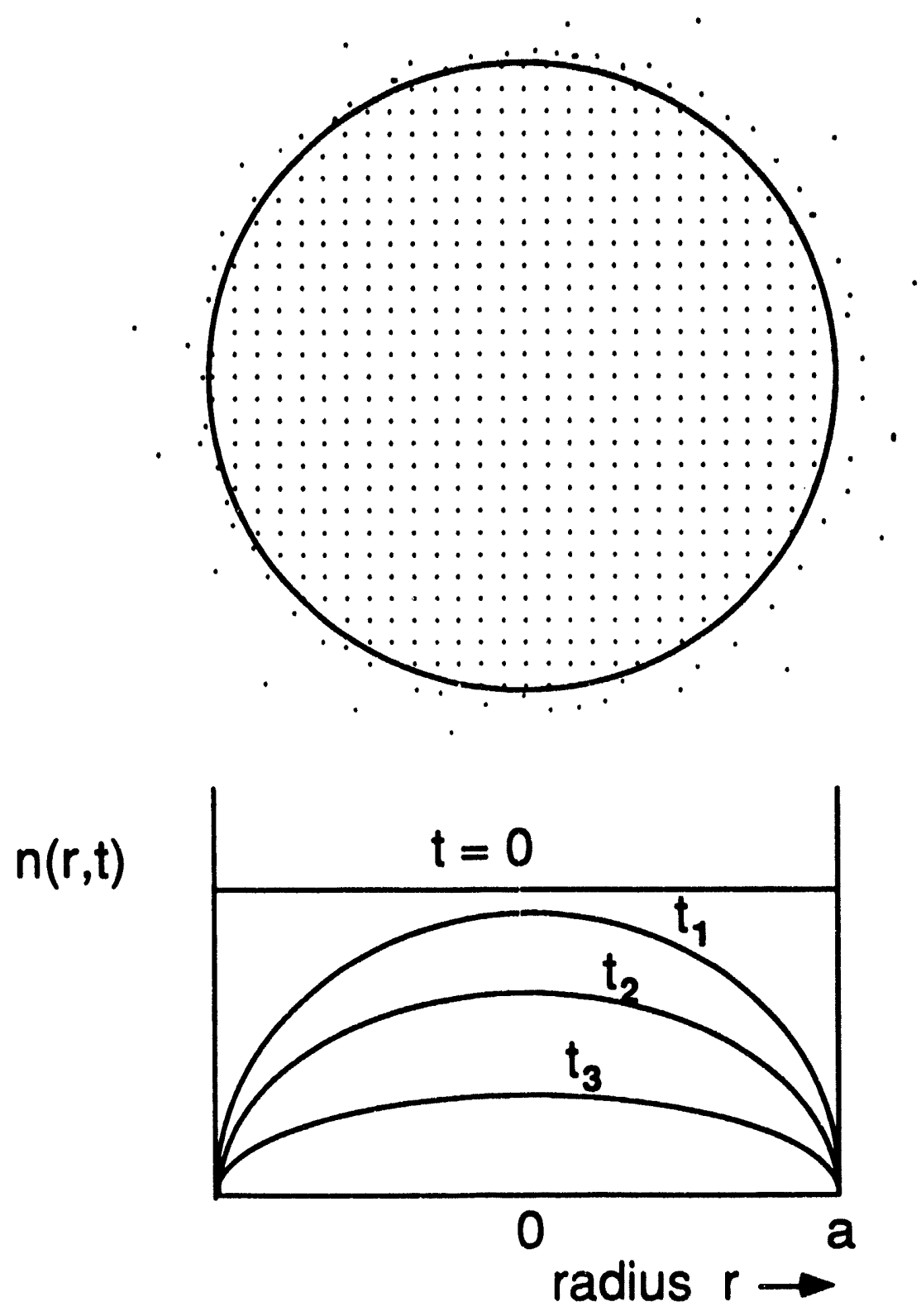

Figure 6. Hypothetical tritium density profiles in a spherical flibe droplet at various times during the droplet's fall through a vacuum. 
A constant external pressure boundary condition is assumed in calculating the tritium release from Flibe droplets. In fact, as the droplets fall they move into a region of lower external tritium pressure, so the ultimate limiting pressure is that at the bottom of the spray. This varying boundary condition is accounted for by calculating the two-dimensional pressure distribution in the spray region and using an intermediate pressure (at $z-0.67 \mathrm{~h}$ ) for the boundary value. Tritium in Flibe has an experimentally measured Henry's law solubility relating pressure to concentration. The fraction of tritium remaining in a liquid droplet after a fall time $t$ is given by the equation 20

$\Phi=p_{a d} p_{0}+6\left(1-p_{0 \alpha} p_{0}\right) \sum_{m=1}^{\infty} \exp \left(-\lambda_{m}^{2} F_{0}\right)\left(\sin \lambda_{m}-\lambda_{m} \cos \lambda_{m}\right)^{2} / \lambda_{m}{ }^{3}\left(\lambda_{m}-\sin \lambda_{m} \cos \lambda_{m}\right)$

where $F_{0}=D_{F} t / a^{2}-$ Fourier number, $D_{F}-$ diffusion coefficient of tritium in the liquid droplet $\left(\mathrm{m}^{2} / \mathrm{s}\right), a-$ droplet radius, $p_{-}=$tritium pressure in the surrounding gas, $p_{0}=$ initial tritium pressure in the droplet, and the $\lambda_{m}$ are eigenvalues found from the equation

$$
\begin{aligned}
& \lambda_{m} \cot \lambda_{m}=1-B i, \\
& B i=a h_{m} / D_{F}=B i \text { ot number }
\end{aligned}
$$

and $h_{m}=$ mass transport coefficient at the droplet surface into the surrounding gas or vacuum $(\mathrm{m} / \mathrm{s})$. The effect of tritium backpressure outside the droplet enters through the po term. The fraction of tritium remaining in the droplet is shown in Figure 7 as a function of $\mathrm{Bi}$ and $\mathrm{Fo}$. 


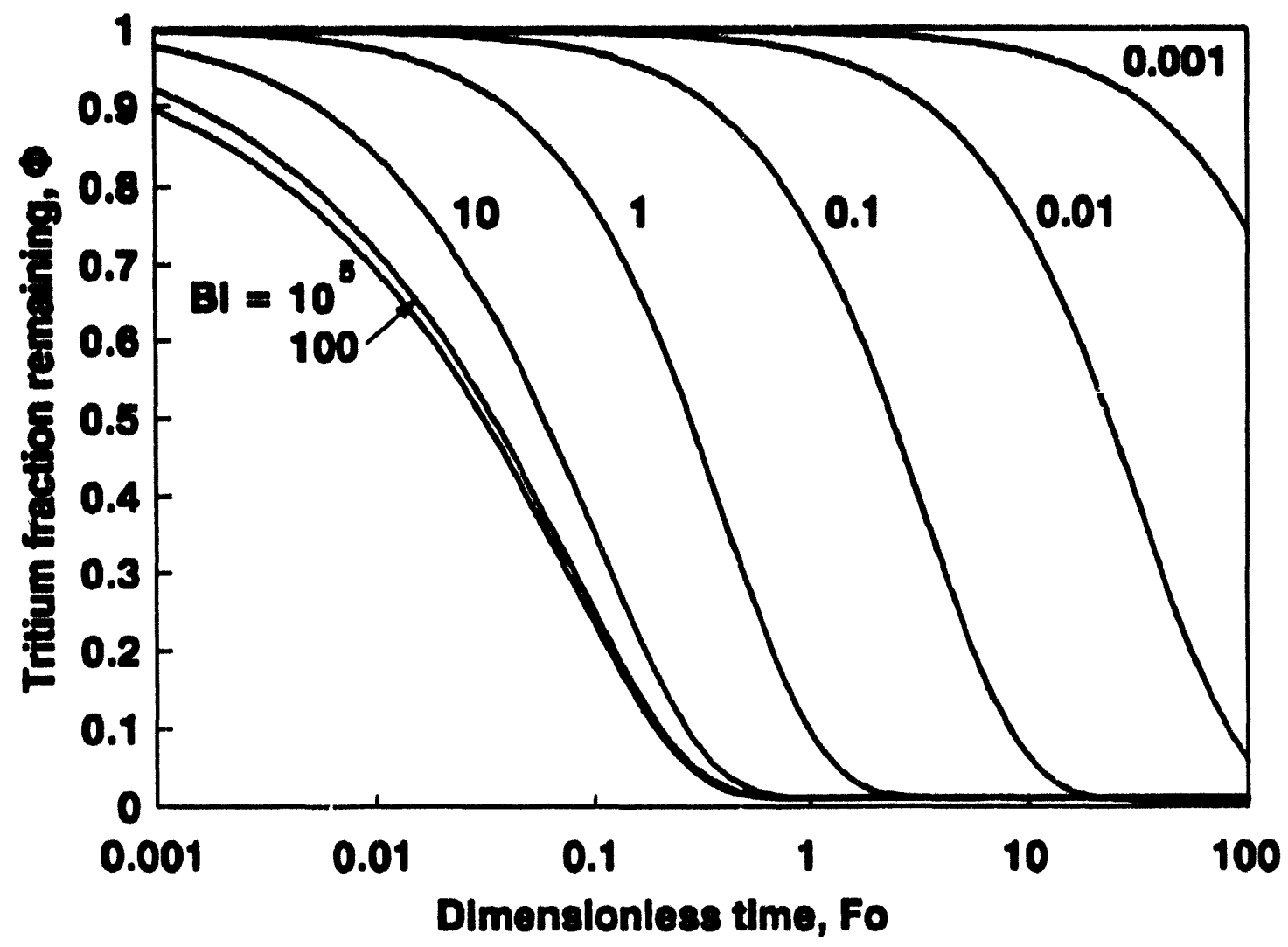

Figure 7. Tritium fraction remaining in a Flibe droplet as a function of Biot and Fourier numbers, for a case with $p_{a}-p_{0}=0.01$. 
Internal recirculation and droplet oscillations, induced by flow through an orifice and by friction with gas, could increase transport rates by factors of 2-10.21,22 However, the recirculation and oscillations of tiny droplets may dissipate in times shorter than the flight time, and there is no friction with gas to sustain them in a vacuum, so credit is not taken for these potential enhancements.

\section{Diffusion and Mass Transport Coefficlents}

For the case of TF in Flibe at $T-923 \mathrm{~K}$, the experimentally measured diffusion coefficient is $O_{F}=6.3 \times 10^{-9} \mathrm{~m}^{2} / \mathrm{s} .{ }^{23}$ According to $\mathrm{H}$. Moriyama (Kyoto University), the HT or $T_{2}$ form has a diffusivity 10 times higher than the TF form, as expected by analogy from the measured mass transport coefficients, so it is assumed that $D_{F}=6.3 \times 10^{-8} \mathrm{~m}^{2} / \mathrm{s}$. Further experimental work is needed to clarify the value of this key parameter.

The mass transport coefficient $h_{m}$ for release of tritium at the flibe droplet surface enters only into computation of the Biot number. The value of $h_{m}$ can be inferred from experimental data of 0 ishi et al,23 but the experimental technique tends to underestimate its value. There are three potential resistances to tritium flow near a droplet surface:

(1) a diffusion layer just inside the liquid surface. This effect is accounted for separately by the diffusion terms in Equation (20).

(2) a surface barrier. In the absence of chemical reactions or surface binding, there is no barrier. This effect is expected to be negligible for tritium leaving the flibe, unless impurities cause chemical binding.

(3) a diffusion layer through gas just outside the droplet surface, as illustrated in figure 8 . In a vacuum system with very low pressures surrounding the droplet, this flow resistance is small. 


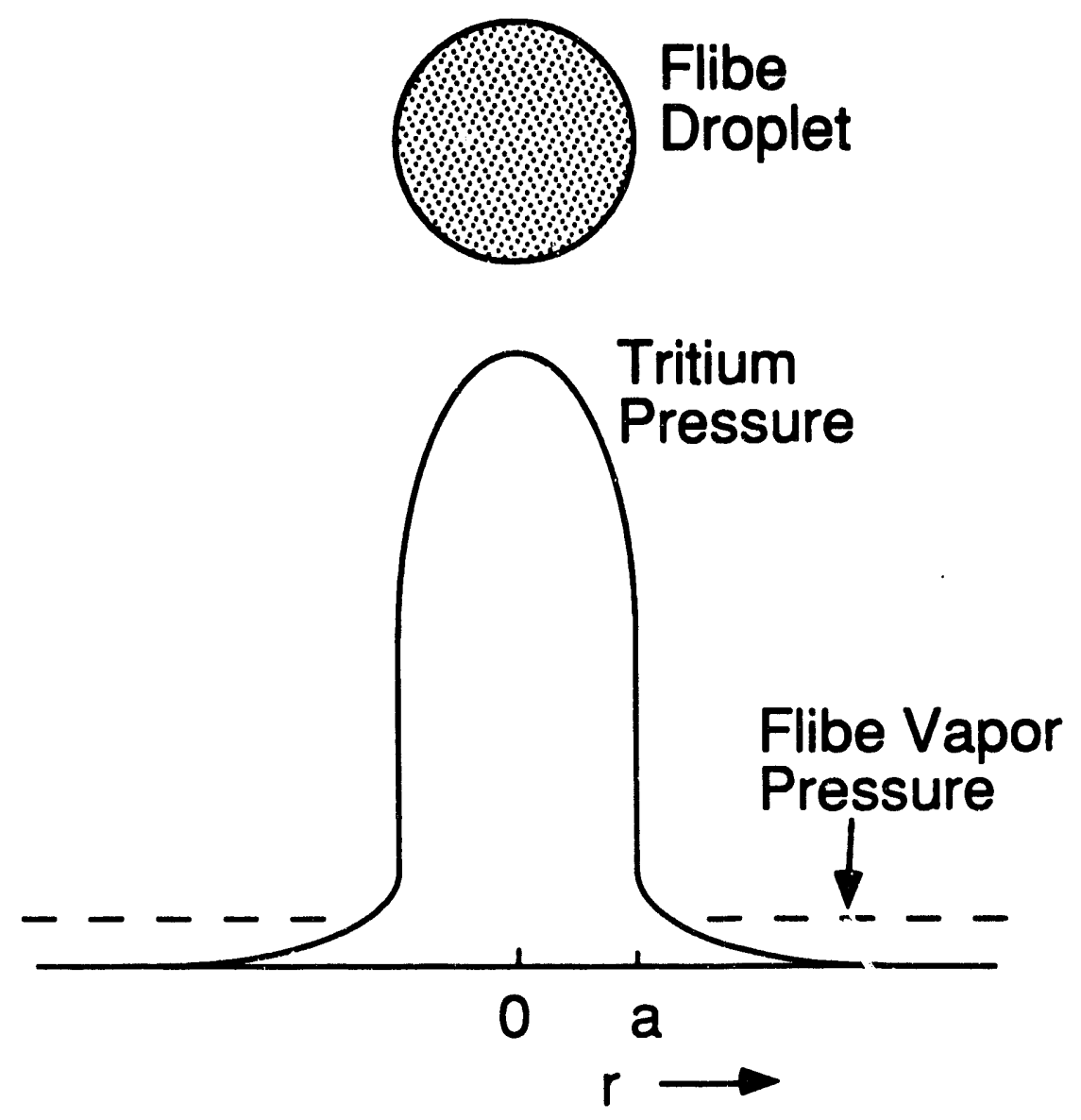

Figure 8. Distribution of tritium pressure and Flibe vapor pressure near a Flibe droplet.

The value of the surface mass transport coefficient can be estimated by analogy with the surface $i$ ilm convective heat transfer coefficient $h$, replacing the Prandtl Number Pr with the Schmidt Number Sc. For the case of spherical Flibe droplets falling at a velocity $v$, the appropriate correlation may be that for convective heat transfer to a fluid flowing past a sphere. Setting $h_{m}=k_{x} / c_{f}$ in Eq.(21.2-25) of Bird, Stewart, and Lightfoot (BSL), ${ }^{24}$ the result is

$$
h_{m}=\left(D_{A B} / D\right)\left(2.0+0.060 \operatorname{Re}^{1 / 2} \mathrm{Sc}^{1 / 3}\right)
$$

where 


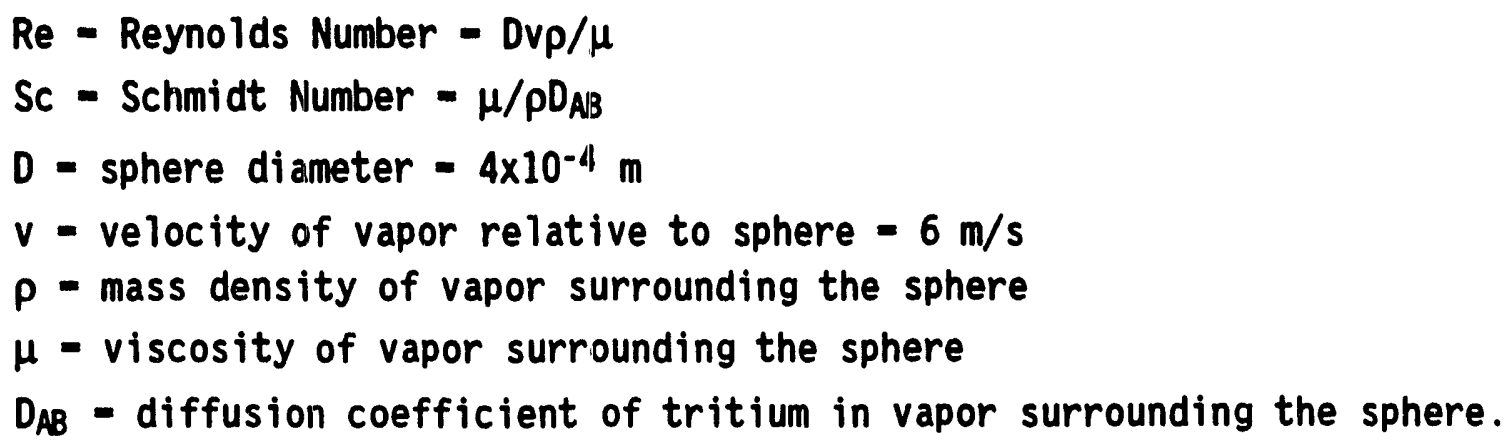

Both Flibe vapor and low-pressure tritium comprise the vapor surrounding the droplet. The tritium pressure at the outside of the droplet in the first stage of the vacuum disengager is estimated to be on the order of $1 \mathrm{~Pa}$. (The internal pressure is initially $290 \mathrm{~Pa}$ ). The mass densities and viscosities are estimated to be

$\rho=0.79 \times 10^{-6} \mathrm{~kg} / \mathrm{m}^{3}$ for tritium at $1 \mathrm{~Pa}, 923 \mathrm{~K}$

$=2.9 \times 10^{-6} \mathrm{~kg} / \mathrm{m}^{3}$ for saturated Flibe vapor at $923 \mathrm{~K}$

$\mu=3.3 \times 10^{-5} \mathrm{~kg} / \mathrm{m}-\mathrm{s}$ for tritium at $1 \mathrm{~Pa}, 923 \mathrm{~K}$

$\approx 5 \times 10^{-5} \mathrm{~kg} / \mathrm{m}-\mathrm{s}$ for Flibe vapor at $923 \mathrm{~K}$.

The diffusivities of tritium in Flibe vapor and in tritium gas are estimated from Eq.(16.4-12) of BSL:

$D_{A B}=2.26 \times 10^{-5}\left[T\left(1 / M_{A}+1 / M_{B}\right)\right]^{1 / 2} / \sigma_{A B}{ }^{2} \Omega_{D A B} C$

where

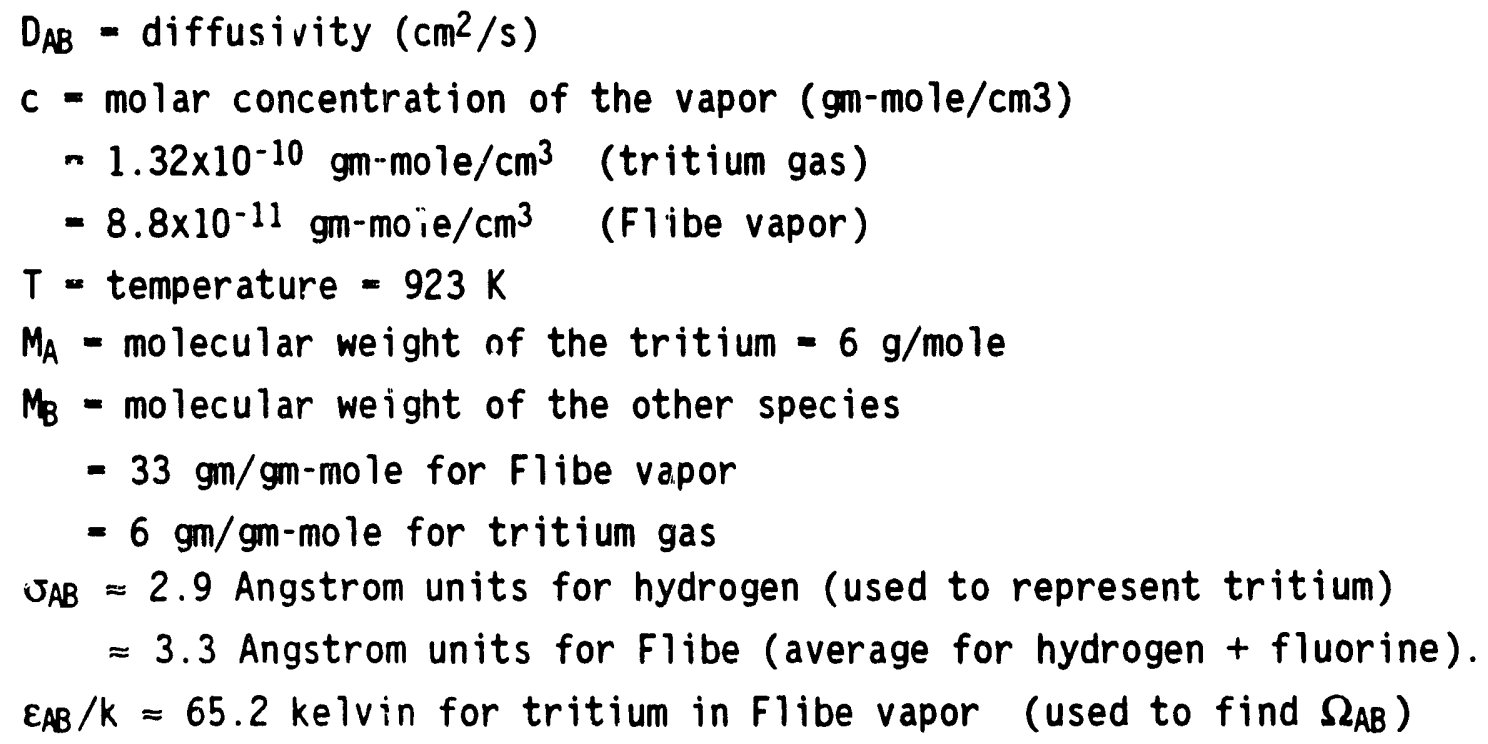


- 112 kelvin for tritium in tritium gas

$\Omega_{A B} \approx 0.55$ for tritium in Flibe vapor at $923 \mathrm{~K}$

$\Omega_{A B}=0.65$ for tritium in tritium gas at $923 \mathrm{~K}$.

The resulting values of diffusivity are

$$
\begin{aligned}
D_{A B} & =5.8 \times 10^{5} \mathrm{~cm}^{2} / \mathrm{s}=58 \mathrm{~m}^{2} / \mathrm{s} \text { (in Flibe vapor) } \\
& =5.5 \times 10^{5} \mathrm{~cm}^{2} / \mathrm{s}=54 \mathrm{~m}^{2} / \mathrm{s} \text { (in tritium gas) } .
\end{aligned}
$$

Approximate composite values of density, viscosity and diffusivity for the two vapors (Flibe and tritium gas) are

$$
\begin{array}{ll}
\rho=3.7 \times 10^{-6} \mathrm{~kg} / \mathrm{m}^{3} & \text { (sum) } \\
\mu=4.6 \times 10^{-5} \mathrm{~kg} / \mathrm{m}-\mathrm{s} & \text { (mass-weighted average) } \\
D_{A B}=28 \mathrm{~m}^{2} / \mathrm{s} & \text { (rec' 'rocal sum). }
\end{array}
$$

The resulting Reynolds and Schmidt Numbers are

$$
\begin{aligned}
& \operatorname{Re}=1.9 \times 10^{-4} \\
& S c=0.44
\end{aligned}
$$

from which

$$
h_{m}=1.5 \times 10^{5} \mathrm{~m} / \mathrm{s} \text {. }
$$

This value exceeds the tritium molecular speed $u=1820 \mathrm{~m} / \mathrm{s}$, so it is probably unphysically large. Its large value indicates that tritium penetration through the surface vapor film is probably not a rate-limiting process. In numerical computations a value $h_{m}=100 \mathrm{~m} / \mathrm{s}$ was used. For all $h_{m}>1 \mathrm{~m} / \mathrm{s}$ the Biot number is effectively infinite, and the predicted value of $\Phi$ is insensitive to the value of $h_{m}$. 


\section{Diffusion of Tritium Gas out of Flibe Spray}

Hollow-cone or swirl-chamber nozzles are often used for spraying liquids into gases, but the spray diverges, and the average droplet size increases as the gas pressure decreases. ${ }^{25}$ If the Flibe sprays diverge, as in Figure 9, then droplets will tend to coalesce, and tritium diffusion will be impeded. Therefore, orifice plates are chosen to produce parallel jet sprays. For flow into a vacuum, the droplet size will typically be about twice the orifice hole size, as illustrated in Figure 10.26

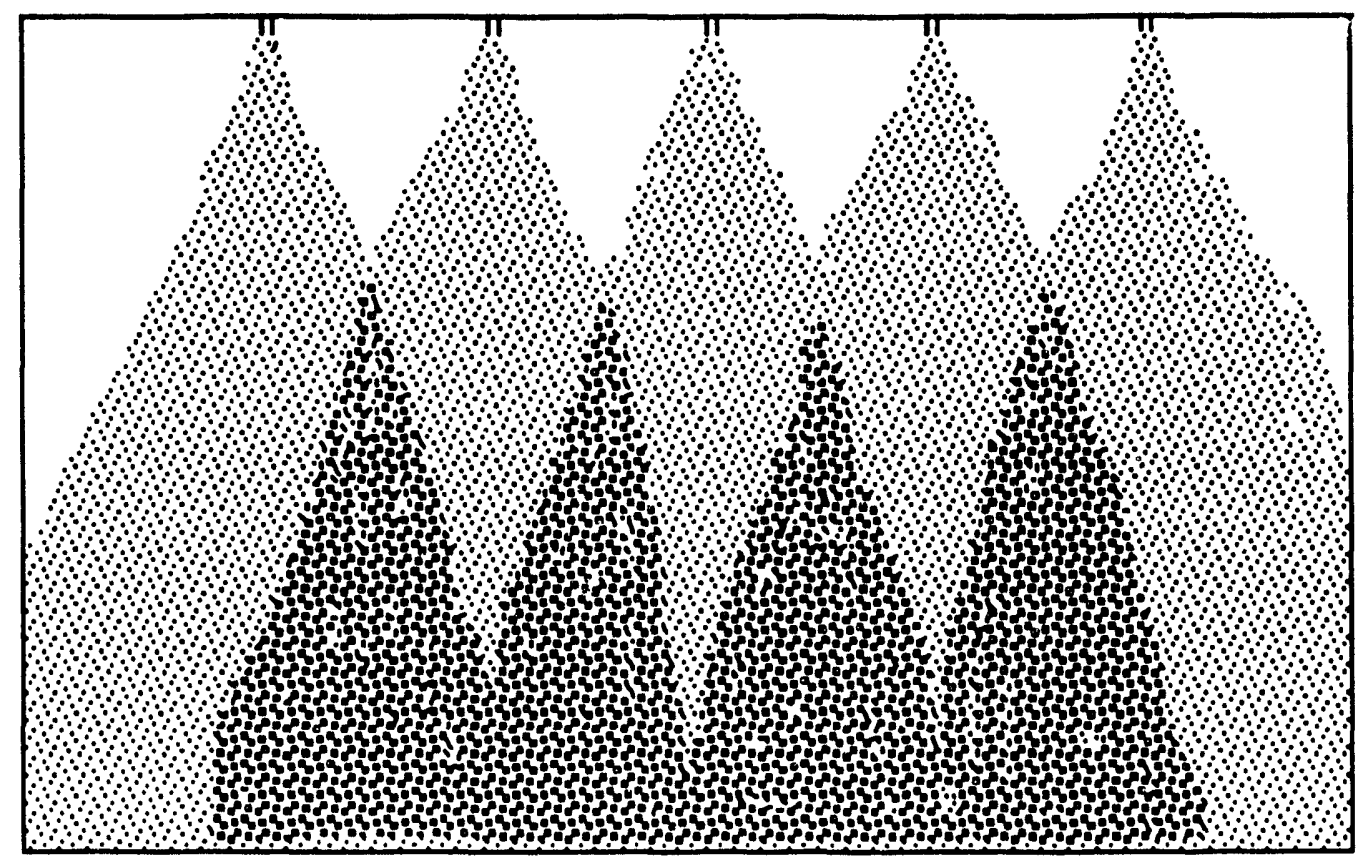

Figure 9. Overlapping of nonparallel sprays. 

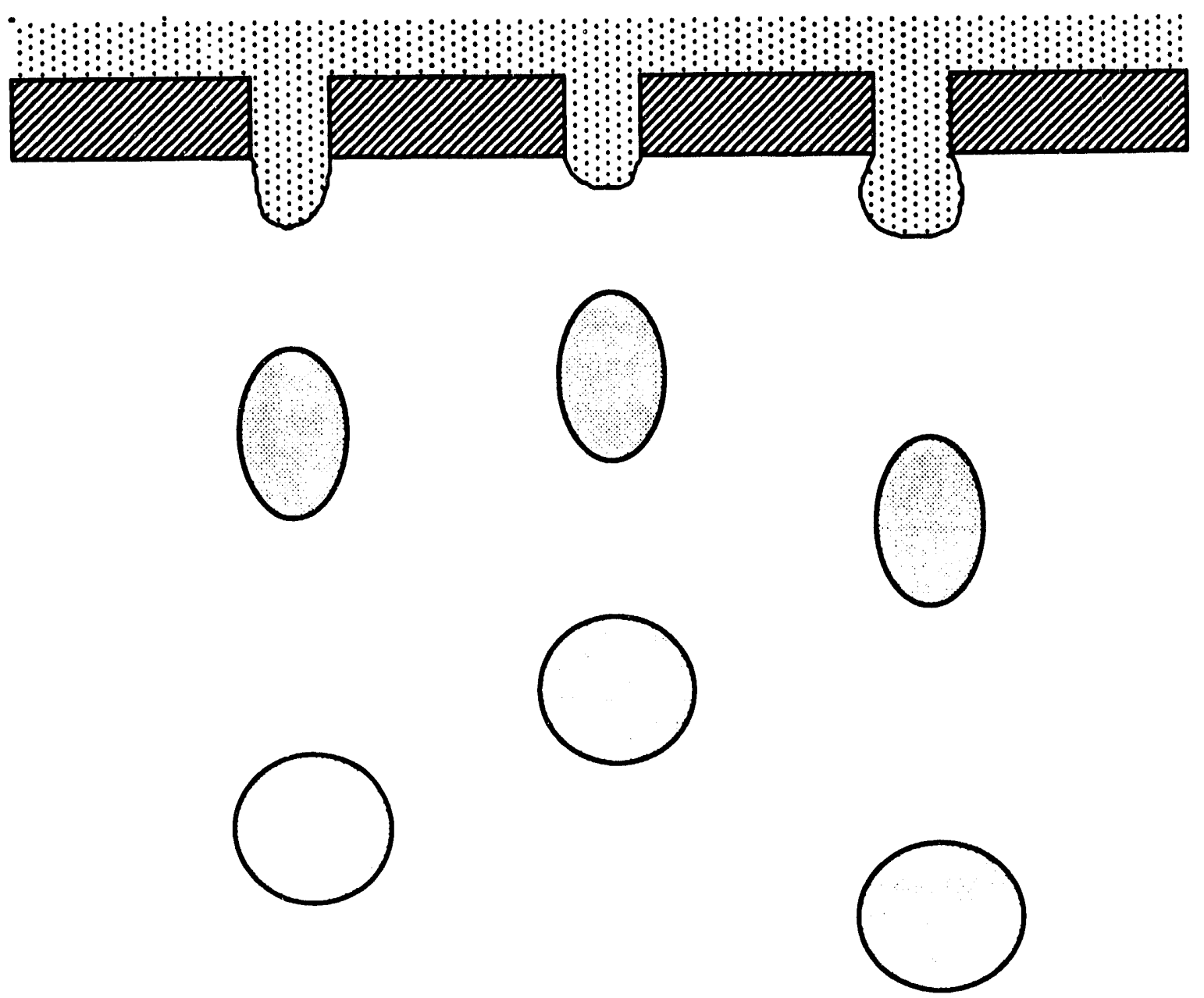

Figure 10. Flibe jet and spray droplets forming during flow through an orifice plate. 
If the Flibe droplets in the spray are close together, then a substantial tritium backpressure can build up, which limits the tritium release rate from the droplets via the $p_{\infty}$ terms in Equation (20). In the coordinate system of Figure 11 , the droplets are falling in the $z$ direction, and the tritium gas diffuses through the spray in the radial direction to reach the vacuum pumps.

The spray will be produced by pumping the Flibe through orifice plates containing millions of tiny holes in a triangular array, as in Figure 12 . Let $p=$ pitch - distance between hole centers, $d_{0}$ - hole diameter, and $\varepsilon_{v}(?)$ - fraction of the spray volume occupied by Flibe droplets at position $z$. The fraction of surface area occupied by holes is

$$
f_{h}=\pi d_{0} 2 / 2(3)^{1 / 2} p^{2} \text {. }
$$

Droplets with radii of $10-500 \mu \mathrm{m}$ can readily be produced with a variety of liquids (water, alcohol, acetone, oxygen, ether, molten salts, etc.). An orifice piate containing $30050-\mu \mathrm{m}$ diameter holes has demonstrated production of multiple parallel streams of droplets. ${ }^{27}$ According to C. D. Hendricks (Lawrence Livermore National Laboratory), the minimum practical ratio of droplet pitch/diameter is about 1.5, in order to prevent drop let coalescence, so the minimum ratio of $P / d_{0}$ for the holes is about 3 . The corresponding value of $f_{h}=0.10$. At the orifice plate exit $\varepsilon_{v}(0)=f_{h}$. As the droplets are accelerated by gravity, their local volume fraction decreases, since they spread apart as they fall. From the continuity equation

$$
\varepsilon_{v}(z) v(z)=\text { constant }=\varepsilon_{v}(0) v_{0}
$$

where $z$ is the distance the droplet has fallen, $v(z)=v_{0}\left(1+2 g z / v_{0}{ }^{2}\right)^{1 / 2}$, $g=$ acceleration of gravity, and $v_{0}$ - initial velocity through the orifice. 

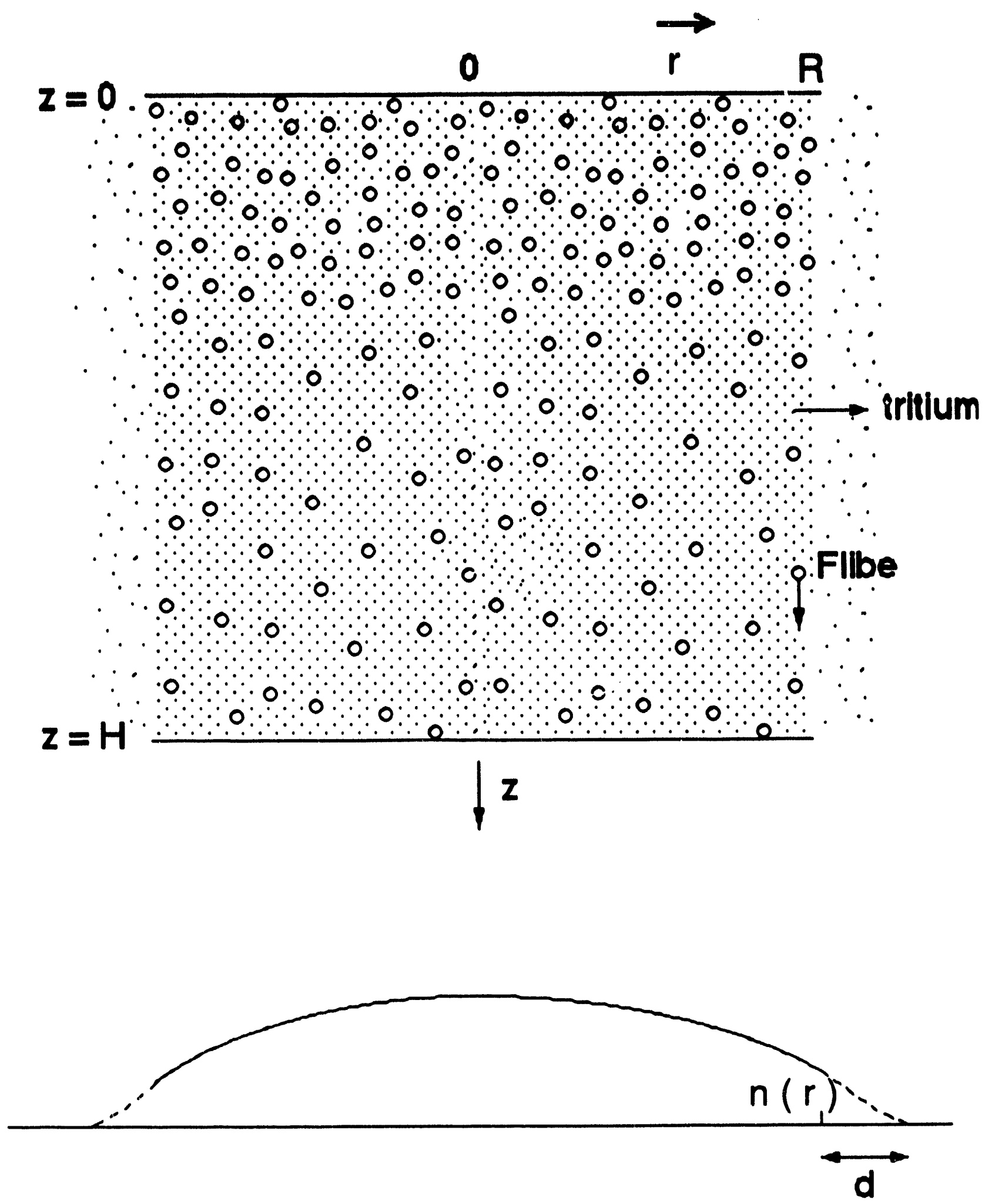

Figure 11. Coordinate system for tritium gas diffusion out of Flibe spray. 


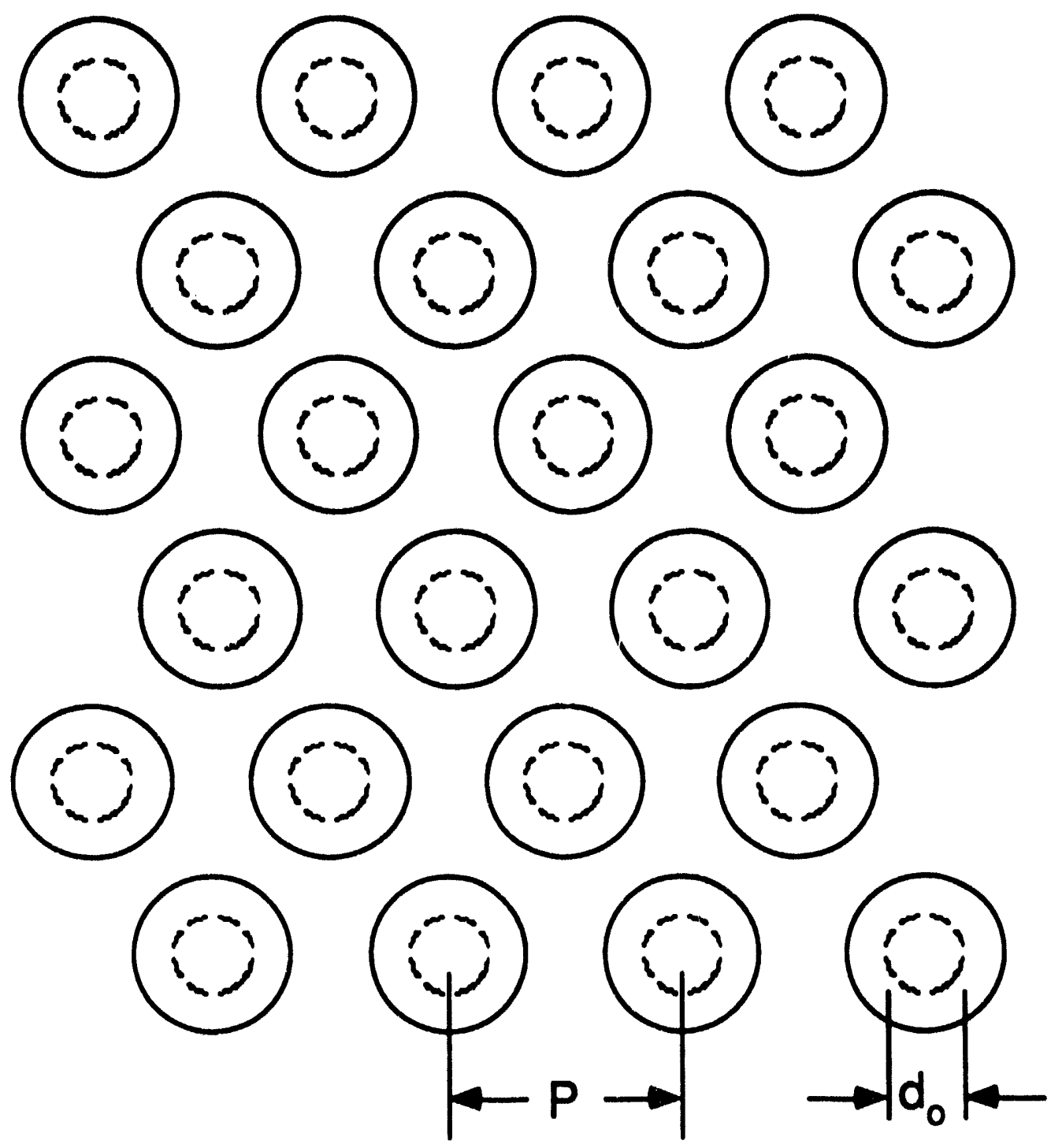

Figure 12. A triangular array of Flibe droplets (circles) emerging from holes (dashed circles) in a Flibe spray orifice plate. 
The droplets form within a few $m$ of the orifice plate, which is a negligible distance compared to the spray height. Thus, the volume fraction at any position $z$ is given by

$$
\begin{aligned}
& \varepsilon_{v}(z)-f_{h} / \beta \\
& \beta=\left(1+2 g z / v_{0}^{2}\right)^{1 / 2},
\end{aligned}
$$

as 1llustrated in Figure 13. For the case with $v_{0}=5 \mathrm{~m} / \mathrm{s}, \varepsilon_{v}(z)$ decreases from 0.1 (at $z-0$ ) to $0.045($ at $z-h$ ).

Tritium gas molecules interact with Flibe droplets and with Flibe vapor in the spray region. The diffusion coefficient of tritium gas out of the spray region was estimated from

$$
\begin{aligned}
& D_{s}=v_{t} \lambda / 3 \\
& \lambda=\left(1 / \lambda_{d}+1 / \lambda_{f}+1 / \lambda_{t}\right)^{-1} \\
& \lambda_{d}=a / 3 \varepsilon_{v} \\
& \lambda_{f}=1 /\left(\sigma_{f} n_{f}\right) \\
& \lambda_{t}=1 /\left(\sigma_{t} n_{t}\right)
\end{aligned}
$$

Where $v_{t}=$ tritium molecular speed $-1820 \mathrm{~m} / \mathrm{s}$ at $923 \mathrm{~K}, \lambda_{d}=$ mean free path of tritium molecules among the Flibe spray droplets, $\lambda_{f}=$ mean free path of tritium molecules in Flibe vapor, $\lambda_{t}$ - mean free path of tritium molecules interacting with other tritium molecules, a = droplet radius, $n_{f}=$ Flibe vapor density in spray region $=5.2 \times 10^{19} \mathrm{~m}^{-3}$ at $923 \mathrm{~K}, \mathrm{n}_{\mathrm{t}}$ - tritium gas molecular density $<6 \times 10^{20} \mathrm{~m}^{-3}$ (at $923 \mathrm{~K}$ and $7 \mathrm{~Pa}$, an estimated maximum pressure), $\sigma_{f}=$ cross section for interaction of tritium molecules with LiF or BeF2 molecules - $3 \times 10^{-19} \mathrm{~m}^{2}$ (Based on known mean free paths for similar sized molecules 28 ; and on measured cross sections for $\mathrm{He}+$ with $\mathrm{He}$ and for $\mathrm{Ne}+$ with Ne extrapolated to low energies $\left.{ }^{29}\right)$, and $\sigma_{t}=$ cross section for interaction of tritium molecules with other tritium molecules - $10^{-20} \mathrm{~m}^{2}$ (the approximate size of the hydrogen molecule). From these values $\lambda_{f}-64 \mathrm{~m}$ and $\lambda_{t}>110 \mathrm{~mm}$. If $a=0.2 \mathrm{~mm}$ and $\varepsilon_{v}-0.1$ to 0.045 (varies with vertical position), then $\lambda_{d}=0.7 \mathrm{~mm}$ to $1.5 \mathrm{~mm}$. Thus, $\lambda \approx \lambda_{d}$ and $D_{s} \approx v_{t} a / 9 \varepsilon_{v}$, which varies vertically from $0.4 \mathrm{~m}^{2} / \mathrm{s}$ (top) to $0.9 \mathrm{~m}^{2} / \mathrm{s}$ (bottom). 


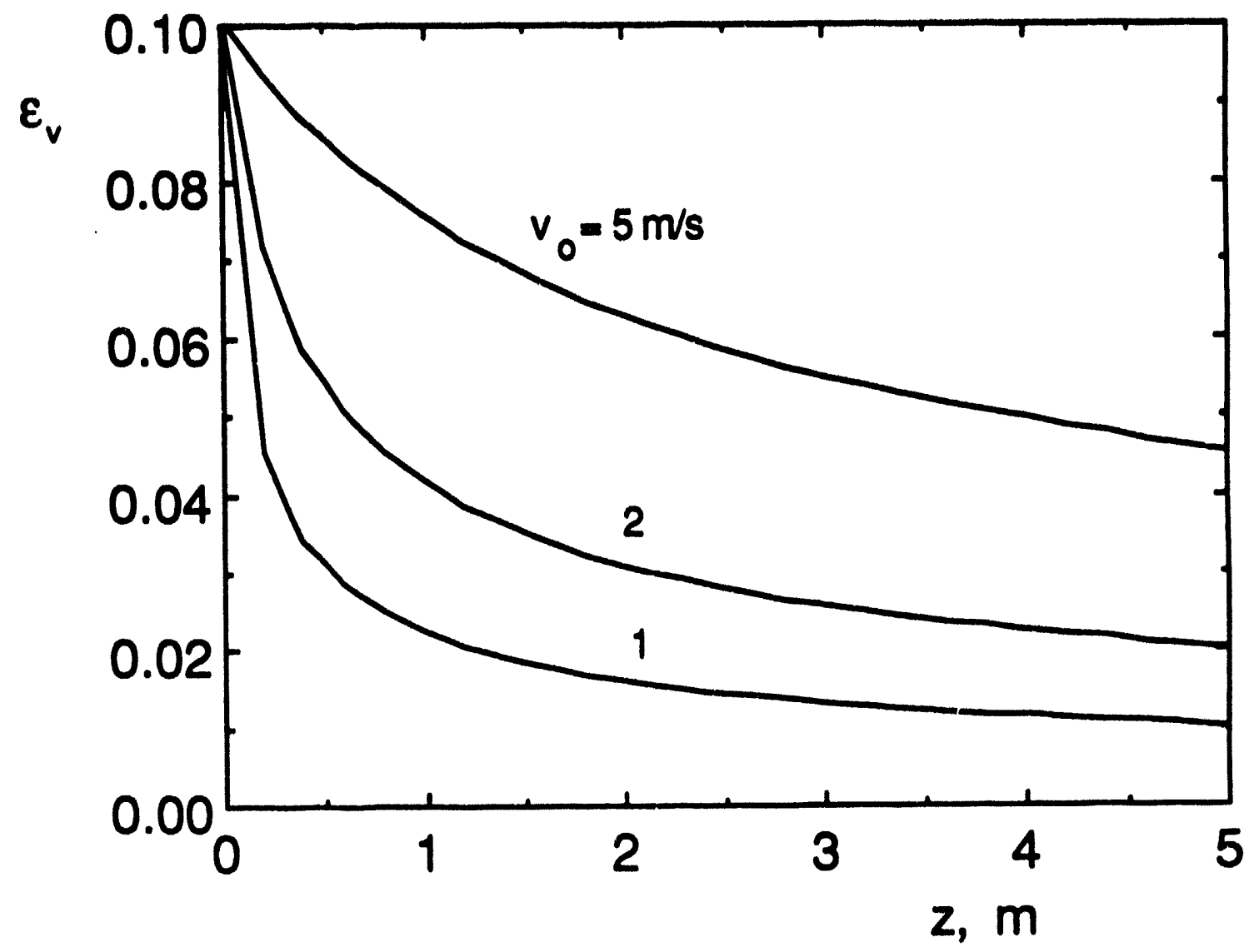

Figure 13. Variation of $\varepsilon_{v}$ with distance $z$ the droplets have fallen. 
If ${ }^{n_{10}}$ - concentration of tritium in the Filbe at spray chamber inlet, then the source term of tritium gas released from the droplets is found to be $S-\varepsilon_{V} n_{T 0} \partial \Phi / \partial t$

$$
\begin{aligned}
& S-\left(6 f_{h} n_{T 0} D_{F} / a^{2} \beta\right)\left(1-p_{\infty} / p_{0}\right) \sum_{m=0}^{\infty} \frac{\exp \left(-\lambda_{m}^{2} F_{0}\right)\left(\sin \lambda_{m}-\lambda_{m} \cos \lambda_{m}\right)^{2}}{\lambda_{m}\left(\lambda_{m}-\sin \lambda_{m} \cos \lambda_{m}\right)} \\
& { }^{\star} \exp \left[-\lambda_{m}^{2} D_{F} V_{0}(1-\beta) / a^{2} g\right]
\end{aligned}
$$

which is roughly proportional to exp(-constant* $\left.z^{1 / 2}\right)$.

The diffusion equation for the tritium gas is

$$
D_{s}\left[\partial^{2} n / \partial r^{2}+(1 / r)(\partial n / \partial r)+\partial^{2} n / \partial z^{2}\right]+\left(\partial D_{s} / \partial z\right)(\partial n / \partial z)+s=0 \text {, }
$$

The following boundary conditions are assumed:

- Symmetry exists at the centerline

$$
\partial n / \partial r=0 \text { at } r=0 \text {. }
$$

- The tritium pressure is maintained at a value $p_{w}$ at the chamber edge by vacuum pumps

$$
n(R, z)-P_{W} / k T
$$

- Tritium permeation into the top and bottom plates is negligible: $\partial n / \partial z=0$ at $z=0$ and at $z-h$.

The diffusion coefficient and source term are both nonlinear. The diffusion equation has been solved using a simultaneous overrelaxation technique with a finite difference approximation. 30 The resulting twodimensional profiles of tritium gas pressure are shown in Figure 14. 


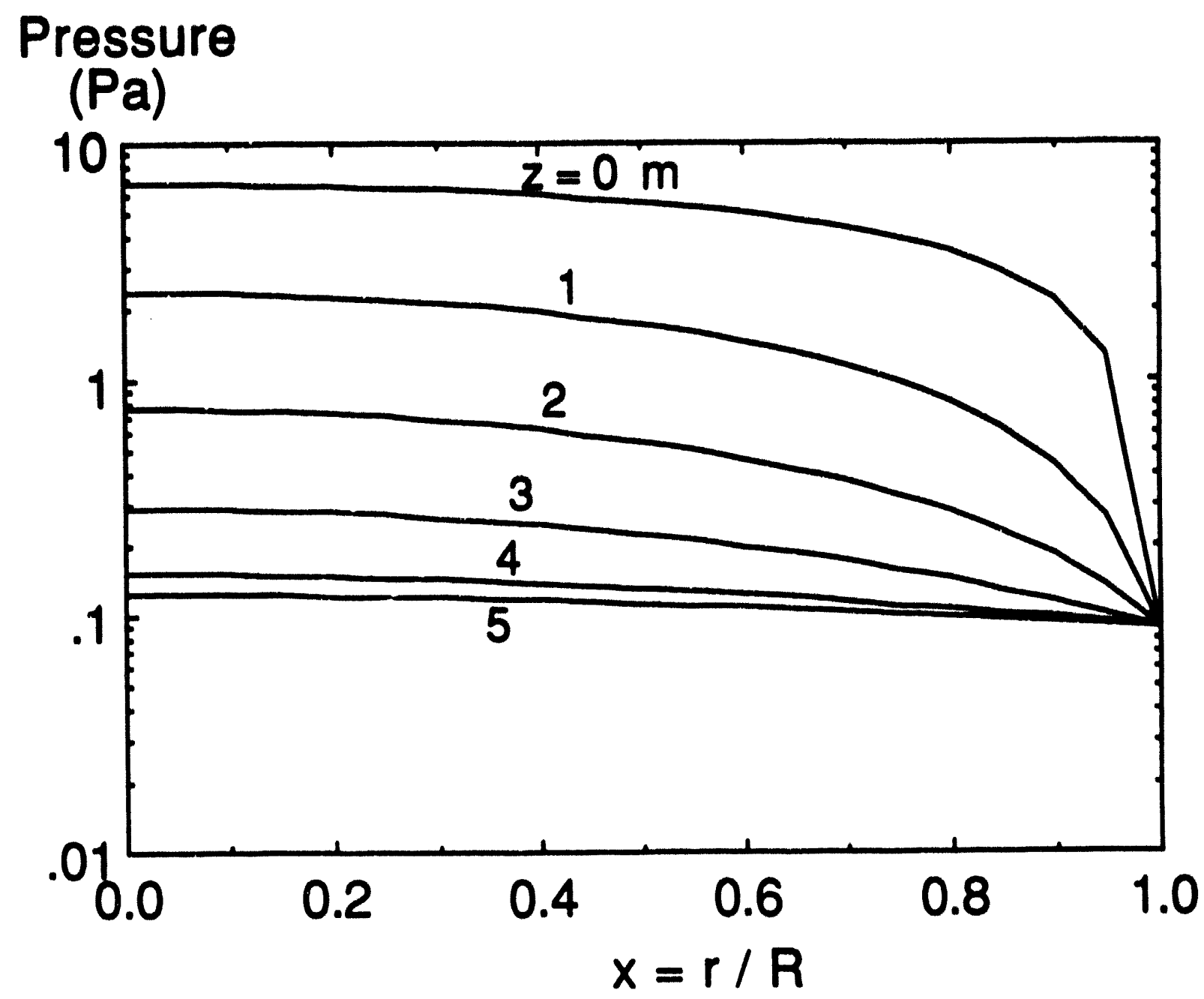

Figure 14. Two-dimensional distribution of tritium gas pressure in Flibe spray region, assuming $p_{0}=294 \mathrm{~Pa}, p_{w}=0.0003 p_{0}, R=2 \mathrm{~m}, h=5 \mathrm{~m}$. 
For comparison, ane-dimensional diffusion equation was solved analytically at each 2 position, with the result

$$
n(r, z)-\left[S(z) R^{2} / 20\right]\left(1-r^{2} / R^{2}\right)+p_{w} / k T .
$$

Although the one-dimensional and two-dimensional solutions have the same general magnitudes, the one dimensional solution falls sharply with $z$, while the two-dimensional solution is smoothed out by axial diffusion. Thus, anedimensional solution would not suffice for design of the vacuum disengager.

Assuming $P / d_{0}-3$, the pressure profiles were computed for a varlety of droplet radif and spray heights, in order to determine the boundary conditions for Equation (20). The results are shown in Figure 15. Greater accuracy could be attained by a numerical solution of the tritium diffusion equation in a Flibe droplet using time-dependent boundary conditions (instead of a constant value of $\left.P_{\infty} / P_{0}\right)$.

The tritium back pressure inside the spray region and attainable values of $\Phi$ can be further reduced by including flow channels free of spray droplets (Figure 16), as suggested by R. W. Moir. Since three-dimensional calculations for flow channels have not been done, credit for this effect is not assumed here. 


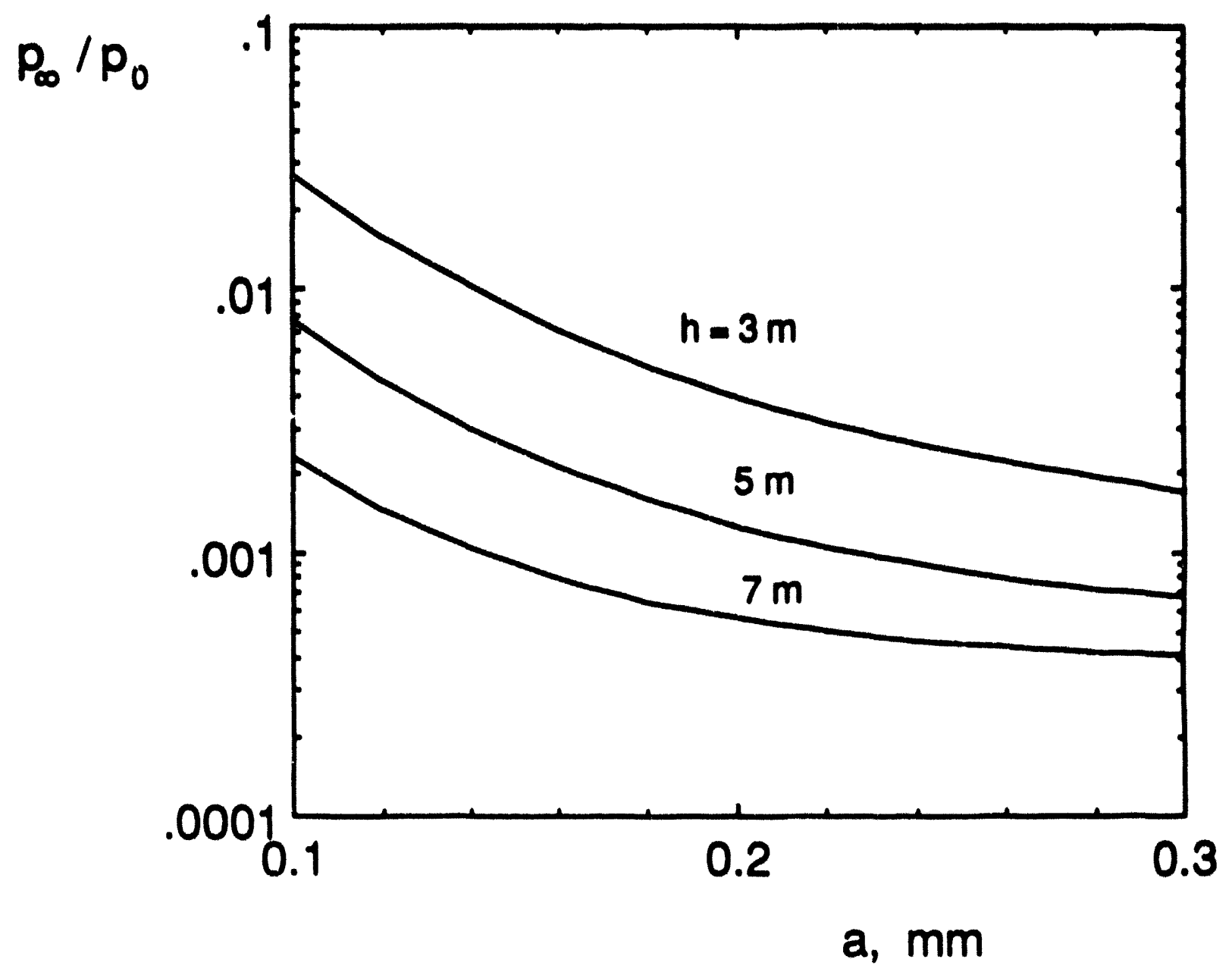

Figure 15. Variation of tritium pressure at center of spray $h / 3$ from the bottom with droplet size a and spray height $h$. 


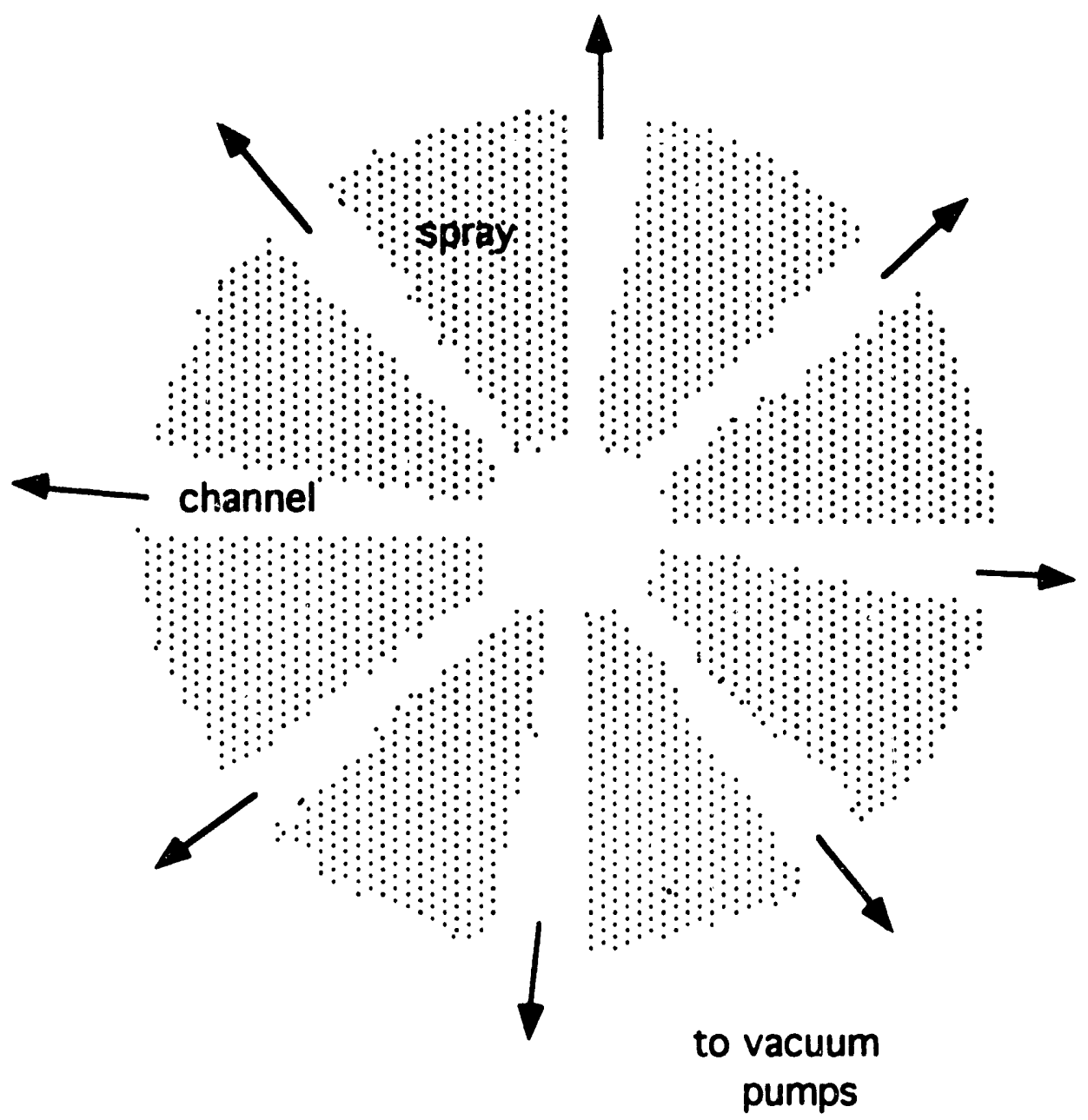

Figure 16. The use of tritium gas flow channels to reduce tritium backpressure in the spray region. 


\section{Vacuum Disengager Parameters}

The volumetric flow rate of Flibe in the three steam generator loops $\varepsilon Q=10.3 \mathrm{~m}^{3} / \mathrm{s}$. Each of the three two-stage vacuum disengagers handles one-third of this amount, or $a_{s}=3.5 \mathrm{~m}^{3} / \mathrm{s}$.

Either downward sprays or upward sprays could be used, as illustrated in Figure 17. Although the upward sprays would have much lower chamber height and pumping power, the jets would overlap and coalesce, unless the velocities were carefully tailored, so a downward spray is chosen for the vacuum disengagers. If the droplets are sprayed downward with an initial velocity $v_{0}$, then the i:ime to fall a distance $z=h$ is

$$
t=(\beta-1) v_{0} / g
$$

where $\beta=\left(1+2 g z / v_{0}^{2}\right)^{1 / 2}$. For the reference design $v_{0}=5 \mathrm{~m} / \mathrm{s}, \mathrm{h}=5 \mathrm{~m}$, and $t=0.62 \mathrm{~s}$

The required spray region volume $V_{s}$ can be estimated from the equation

$$
v_{s}=a_{s} t /\left\langle\varepsilon_{v}\right\rangle
$$

where $\left\langle\varepsilon_{v}\right\rangle=$ the average fraction of chamber volume occupied by the Flibe droplets $\approx 0.06$. (The variation of $\varepsilon_{v}$ with $z$ was shown in Figure 8.) Thus, $V_{s} \approx 36 \mathrm{~m}^{3}$. The total orifice plate area

$$
A=1.2 a_{s} / f_{h} v_{0}
$$

where the factor 1.2 provides additional area for extra plates and for structure supporting the plates. If $v_{0}=5 \mathrm{~m} / \mathrm{s}$, then $A=8.3 \mathrm{~m}^{2}$, from which the spray radius $R=1.6 \mathrm{~m}$. To allow for inlet and outlet pipes at the top 

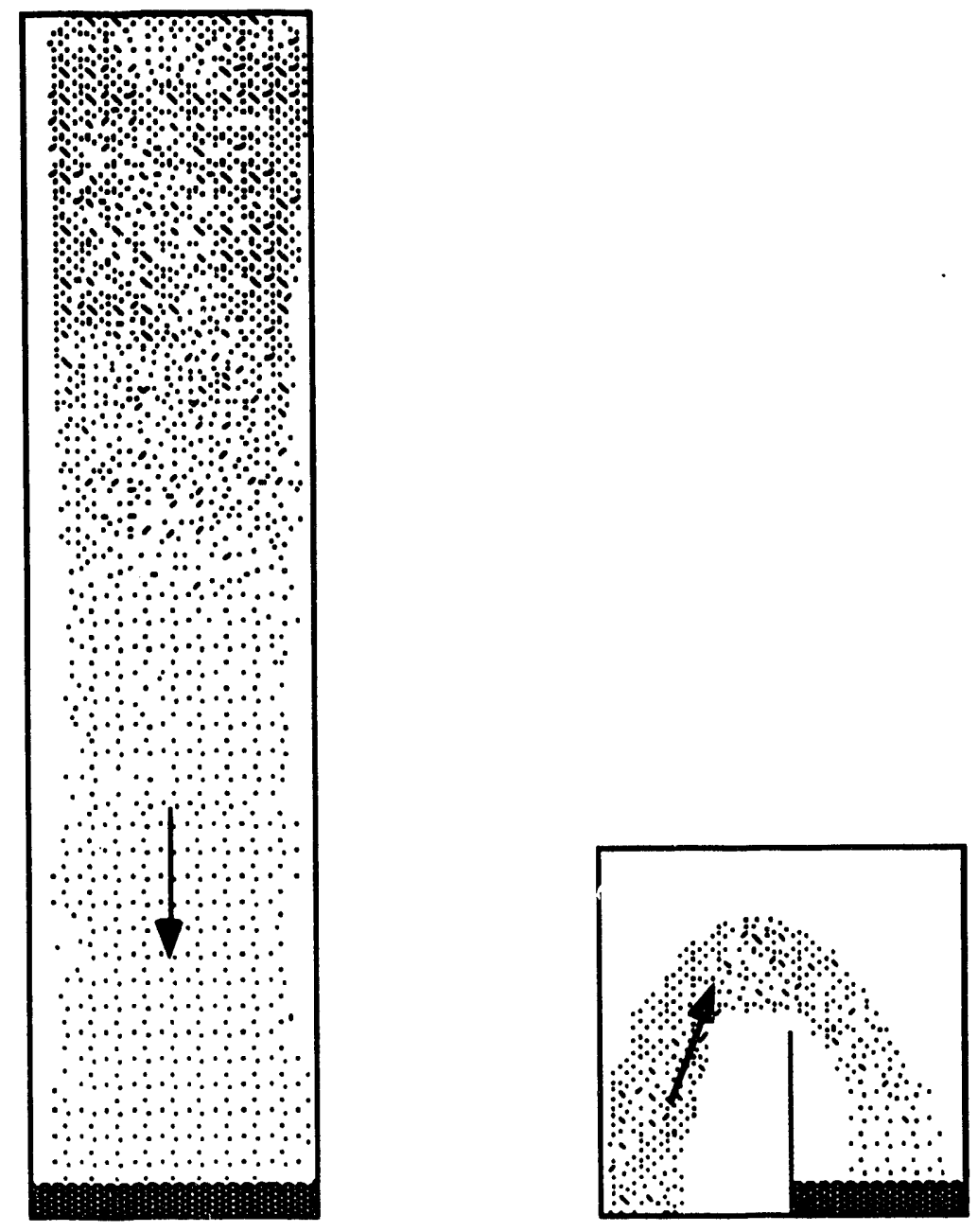

Figure 17. Downward and upward sprays of Flibe droplets. 
and bottom, the total spray chamber height

$H=h+2 D_{t}$,

where $h=$ spray height and $D_{t}=$ Flibe tube diameter.

Assuming a constant $P / d_{0}=3$, there is an optimum droplet size at each spray chamber height, as shown in Figure 18. If the droplet is smaller than optimum, then $D_{S}$ is low, the tritium gas diffusion out of the spray region is slow, and backpressure inhibits tritium release from the droplets. If the droplet is larger than optimum, then diffusion within the droplet becomes the limiting process. Two stages are needed to satisfy vacuum pumping requirements at reasonable cost. For a two-stage vacuum disengager, it is desirable to achieve $\Phi=0.003$ for each stage. A spray height $h=3 \mathrm{~m}$ is inadequate (Figure 18), and $h=7 \mathrm{~m}$ is unnecessary. Therefore, $h=5 \mathrm{~m}$ and $a \approx 0.2 \mathrm{~mm}$ are choseri for the present design. This combination theoretically achieves $\Phi=0.0015$ per stage, which gives us a safety factor of 2 relative the design goal per stage, to compensate for uncertainties of material parameters, three dimensional flow, etc. The spray chamber parameters are listed in Table 3 . 


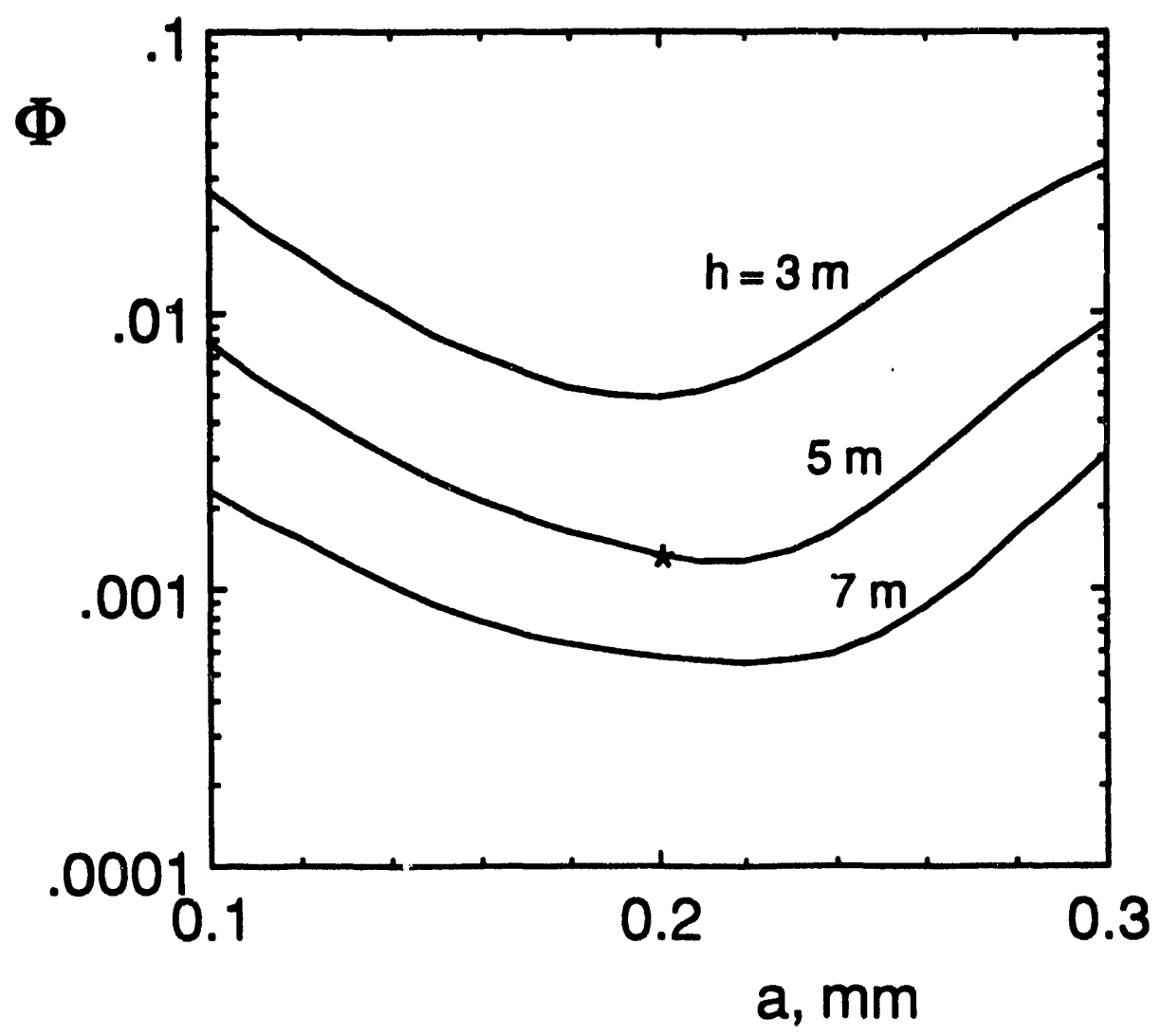

Figure 18. Tritium fraction remaining in droplet as a function of droplet radius for various spray heights. The operating point is denoted by an asterisk. 
Table 3. Spray chamber parameters.

Flibe flow rate per vacuum

$$
\text { disengager }
$$

Tritium flow rate per vacuum disengager

$a_{s} \quad-3.5 \mathrm{~m}^{3} / \mathrm{s}$

\begin{tabular}{|c|c|c|}
\hline disengager & $\operatorname{enQ} / 3$ & $\begin{array}{l}=4.0 \times 10^{20} \text { tritium molecules } / \mathrm{s} \\
=1.65 \mathrm{MCi} / \text { day, }\end{array}$ \\
\hline Chamber radius & $\mathbf{R}$ & $-2 \mathrm{~m}$ \\
\hline Spray height & h & $-5 m$ \\
\hline Droplet radius & a & $=0.2 \mathrm{~mm}$ \\
\hline $\begin{array}{c}\text { Droplet velocity through } \\
\text { orifice plate }\end{array}$ & $v_{0}$ & $-5 \mathrm{~m} / \mathrm{s}$ \\
\hline Hole fraction of orifice plate & $f_{h}$ & -0.10 \\
\hline Flibe temperature & $\mathrm{T}$ & $-923 \mathrm{~K}$ \\
\hline $\begin{array}{l}\text { Tritium diffusion coefficient } \\
\text { in Flibe at } 923 \mathrm{~K}\end{array}$ & $D_{F}$ & $=6.3 \times 10^{-8} \mathrm{~m}^{2} / \mathrm{s}$ \\
\hline $\begin{array}{c}\text { Tritium gas diffusion coefficient } \\
\text { among spray droplets }\end{array}$ & $D_{s}$ & $=0.4-0.9 \mathrm{~m}^{2} / \mathrm{s}$ \\
\hline $\begin{array}{l}\text { Henry's Law Tritium solubility } \\
\text { in Flibe }{ }^{31}\end{array}$ & $\mathrm{~s}$ & $=2.5 \times 10^{19} \exp (-3534 / \mathrm{T})\left(\right.$ atoms $\left./ \mathrm{m}^{3} \mathrm{~Pa}\right)$ \\
\hline
\end{tabular}


There will be a two-stage vacuum disengager achieving $\Phi=\left(1-f_{s}\right)=10^{-5}$ in each of the three heat exchanger loops.

\section{Flibe Pumping Power}

The required pumping power per vacuum disengager stage is

$P=$ gravity head + friction in pipe + friction in orifice + surface tension + kinetic energy

$P=\left[\rho g z+f L \rho u^{2} / 2 D_{t}+f_{0} L_{0} \rho v_{0} 2 / 2 d_{0}+3 \sigma / a+\rho v_{0}^{2} / 2\right] Q_{s} / \eta$

where $f$ - friction factor in Flibe tube, $L$ - total Flibe tube length (including equivalent lengths of $20 D_{t}$ for each right angle bend), $f_{0}=$ friction factor in orifices, and the other relevant parameters are defined in Table 4. (Additional Flibe pumping power is required for the blast chamber and steam generators.) 
Table 4. Flibe pumping parameters

\begin{tabular}{|c|c|c|c|}
\hline Flibe temperature & $T$ & - & $923 k$ \\
\hline Flibe surface tenston 32 & $\boldsymbol{\sigma}$ & - & $0.185 \mathrm{~J} / \mathrm{m}^{2}$ at $923 \mathrm{~K}$ \\
\hline Flibe mass density & $\rho$ & - & $1970 \mathrm{~kg} / \mathrm{m}^{3}$ \\
\hline Flibe specific heat & $c_{p}$ & $=$ & $2.38 \mathrm{~J} / \mathrm{g}-\mathrm{K}$ \\
\hline Flibe viscosity & $\mu$ & - & $0.0068 \mathrm{~Pa}-\mathrm{s}$ \\
\hline Orifice plate hole diameter & $\infty_{0}$ & $=$ & $0.2 \mathrm{~mm}$ \\
\hline Orifice plate thickness & L & - & $2 \mathrm{~mm}$ \\
\hline Pump effictency & $\eta$ & 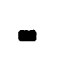 & 0.8 \\
\hline Flibe tube diameter & $D_{t}$ & $=$ & $1.0 \mathrm{~m}$ \\
\hline Flibe tube length & $L$ & - & $\begin{array}{l}75 \mathrm{~m} \text { per heat exchanger loop } \\
(35 \mathrm{~m}+2 \text { elbows) }\end{array}$ \\
\hline Flibe volumetric flow rate & $a_{s}$ & - & $3.5 \mathrm{~m}^{3} / \mathrm{s}$ \\
\hline Flibe velocity in tube & $u$ & - & $4.46 \mathrm{~m} / \mathrm{s}$ \\
\hline \multicolumn{4}{|l|}{ Flibe velocity through } \\
\hline orifice plate & $v_{0}$ & - & $5 \mathrm{~m} / \mathrm{s}$ \\
\hline Approximate pumping head & $\mathbf{z}$ & $=$ & $8 m$ \\
\hline Pumping power per stage & $\mathbf{P}$ & - & $1.09 \mathrm{MW}$ \\
\hline Total Flibe pumping power & $p$ & - & $6.6 \mathrm{MW}$ \\
\hline
\end{tabular}




\section{Vacuum Pumping}

At equilibrium the tritium removal rate by the vacuum disengagers will equal the tritium introduction rate into the Flibe:

$$
\mathrm{dN} / \mathrm{dt}-\mathrm{enQ}-1.19 \times 1021 \mathrm{atoms} / \mathrm{s}-4.95 \mathrm{MCl} / \mathrm{day} .
$$

At $T=923 \mathrm{~K}$, the total throughput is

$$
a=k T(d N / d t)=15.2 \mathrm{~Pa}-\mathrm{m}^{3} / \mathrm{s} \text {. }
$$

Thus, each of the three vacuum disengagers should be able to remove at least $5.1 \mathrm{~Pa}-\mathrm{m}^{3} / \mathrm{s}$ of tritium. Assuming a wall pressure of $0.09 \mathrm{~Pa}$ in a vacuum disengager first stage, the required effective pumping speed in the first stage of one disengager is

$$
S C /(S+C)=Q / p-57 \mathrm{~m}^{3} / \mathrm{s}
$$

For the second stage the throughput and pumping pressure are each reduced by a factor of about 0.003 , so $Q / p$ remains about the same. Thus, the total vacuum pumping requirement of three two-stage vacuum disengagers $-342 \mathrm{~m}^{3} / \mathrm{s}$ is greater than that of the blast chamber $\left(155 \mathrm{~m}^{3} / \mathrm{s}\right)$.

Each spray chamber will be pumped by four vacuum ports, as illustrated in Figure 19. 


\section{Flibe Vacuum Disengager $\quad \begin{gathered}\text { vacuum } \\ \text { pumping }\end{gathered}$}
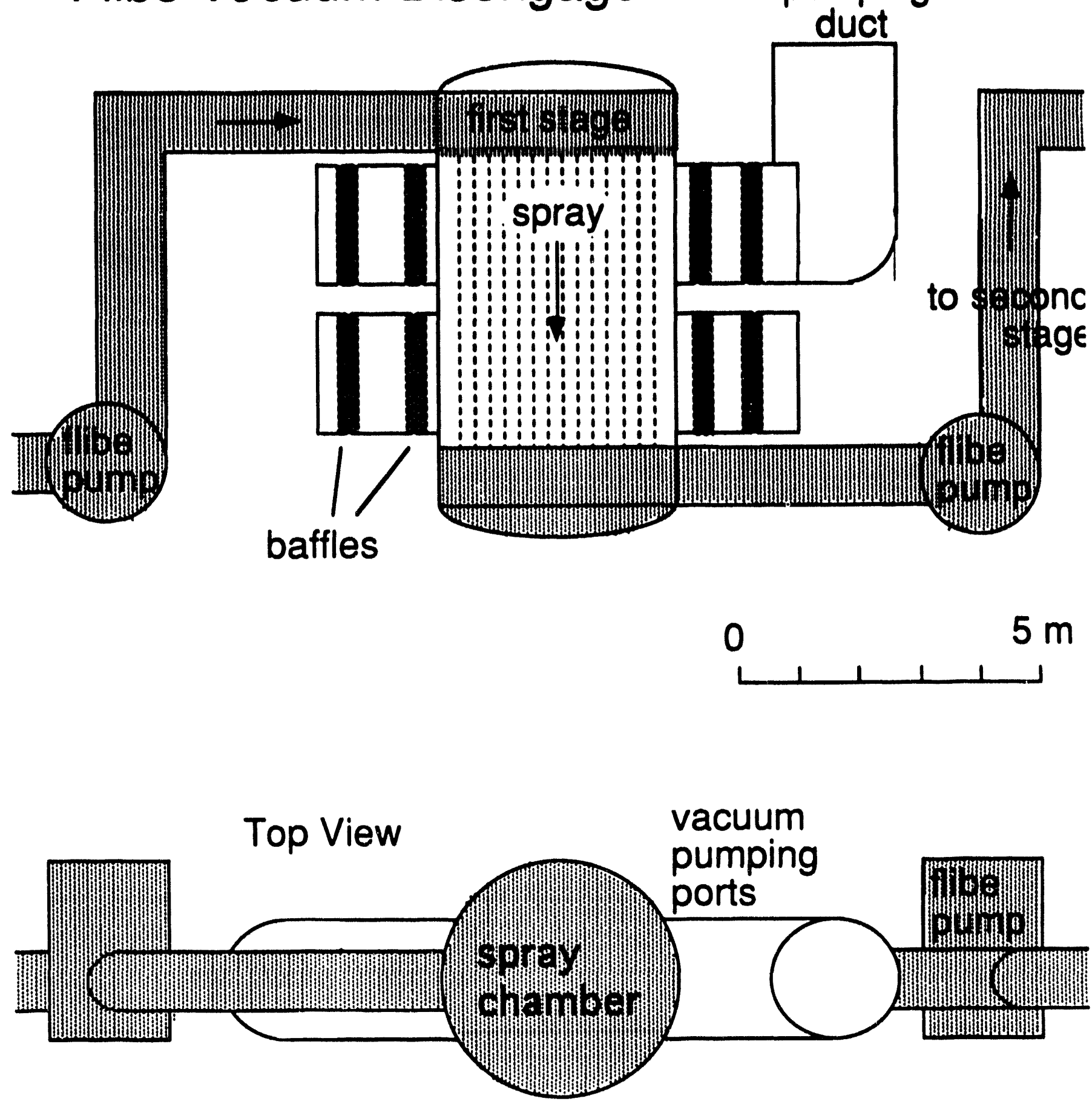

Figure 19. Layout of the vacuum disengager. 


\section{Conductance}

A representative pumping duct is 1llustrated in Figure 20 . Each duct will contain two baffles and a gate valve. The first baffle will operate near $773 \mathrm{~K}$, to condense and drain liquid Flibe. This baffle must be well above the freezing temperature of Flibe, to avoid bulldup of frozen Flibe. A second baffle will cool the gases to about $400 \mathrm{~K}$, which reduces the required pumping speed.

The $T_{2}$ flow rate per heat exchanger loop $(\mathrm{dN} / \mathrm{dt})_{1}-2 \times 0^{20}$ molecules $/ \mathrm{s}$. At $400 \mathrm{~K}$ duct temperature, the required throughput

$$
Q-k T(d N / d T)_{1}-1.1 \mathrm{~Pa}-\mathrm{m} 3 / \mathrm{s} \text {. }
$$

The tritium molecule mean free path at the port entrance may be estimated from Equation (25) without the $\lambda_{d}$ term, since the port is outside the spray region. Thus

$$
\lambda=\left(n_{f} \sigma_{f}+n_{t} \sigma_{t}\right)^{-1}
$$

where $n_{f}=$ Flibe vapor density near the baffle $-10^{19} \mathrm{~m}^{-3}, \mathrm{n}_{t}$ - tritium molecule density near the baffle $\approx 8 \times 10^{18} \mathrm{~m}^{-3}$ (at $\mathrm{p}-0.1 \mathrm{~Pa}$ ), $\sigma_{f}-3 \times 10^{-19} \mathrm{~m}^{2}$, and $\sigma_{t}-10-20 \mathrm{~m}^{2}$. Since $\lambda / D_{p} \approx 0.17$, the flow is in the transition region between viscous and molecular flow. For the baffles only the molecular flow conductance is used:

$$
C=A(k T / 2 \pi m)^{1 / 2} T_{D}
$$

where $A=$ area $\left(\mathrm{m}^{2}\right)$ of the port occupied by baffles, $k$ - Boltzmann constant, $m=$ molecular weight of $T_{2}=1.001 \times 10^{-26} \mathrm{~kg}$, and $T_{b}=$ transmission probability through the baffle $=0.20$. For tritium molecules at about $848 \mathrm{~K}$ (the average of the inlet and exit temperatures), the conductance of the first baffle

$$
C_{1}=86 \mathrm{~A}=68 \mathrm{~m}^{3} / \mathrm{s} \text {. }
$$

For the second baffle at an average temperature of $587 \mathrm{~K}$, the conductance

$$
C_{2}=72 \mathrm{~A}=56 \mathrm{~m}^{3} / \mathrm{s} \text {. }
$$




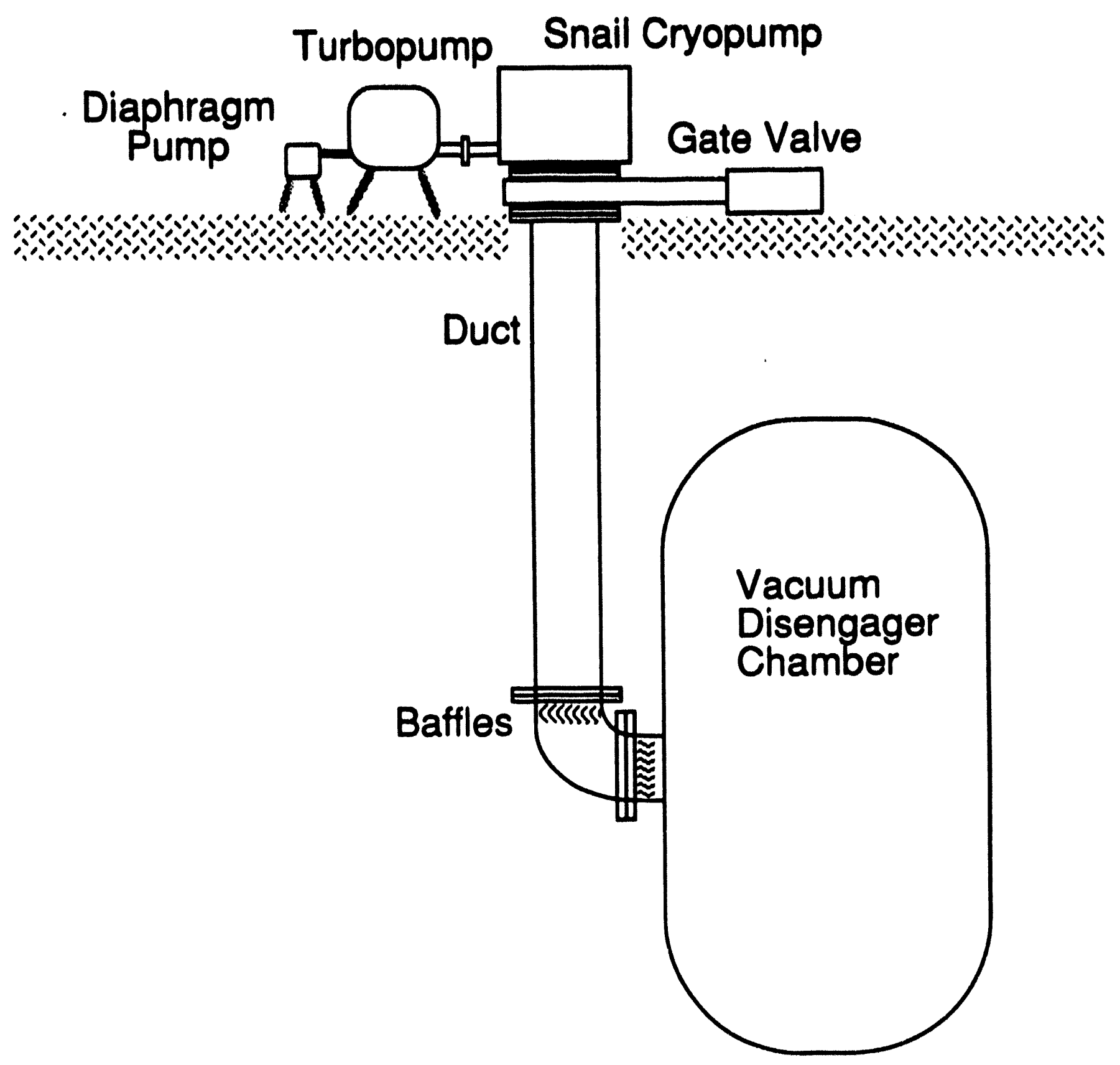

Figure 20. Arrangement of one vacuum disengager vacuum duct. 
Each duct has $L \sim 20 \mathrm{~m}, D-1 \mathrm{~m}, \mathrm{Pav}=0.2 \mathrm{~Pa}$. In the transition regime, the conductance $C_{1}$ of a tube is roughly the sum of the molecular and viscous conductances. The conductance of the vacuum duct is estimated from

$$
\begin{aligned}
& C_{m}-122(29 / 5)^{1 / 2}(400 / 293)^{1 / 2} D^{3} /(L+1.3330)-16 \mathrm{~m}^{3} / \mathrm{s} \\
& C_{v}-1430(170.5 / 83.5)(293 / 400)^{1 / 2} D^{4} \mathrm{Pav}_{\mathrm{av}}-25 \mathrm{~m}^{3} / \mathrm{s} \\
& C_{L}=C_{m}+C_{v}-41 \mathrm{~m}^{3} / \mathrm{s}
\end{aligned}
$$

where (29/5) - mass ratto (air/OT), (400/293) - temperature ratio, $(170.5 / 83.8)$ - viscosity ratio (air/hydrogen), and $\mathrm{p}_{\mathrm{av}}$ - average pressure in the duct $-0.2 \mathrm{~Pa}$. The net conductance of the duct and baffles is

$$
C=\left(1 / C_{1}+1 / C_{2}+1 / C_{L}\right)^{-1}-17 \mathrm{~m}^{3} / \mathrm{s} \text {. }
$$

\section{Cryogentc Pumps and Turbonolecular Pumps}

The required first stage chamber edge pressure $\mathrm{P}_{W}=0.09 \mathrm{~Pa}$. Using snail cryopumps rated at $S-50 \mathrm{~m}^{3} / \mathrm{s}$, the maximum attainable throughput is

$$
Q=P_{w} S C /(S+C)=1.1 \mathrm{~Pa}-\mathrm{m}^{3} / \mathrm{s} \text {, }
$$

which matches the required throughput. Two-dimensional calculations are needed to determine whether azimuthal pressure asymmetry will be a problem when using only two ducts at each level.

It is assumed that $p$ (cryopump) $=0.1 p_{w}=0.009 \mathrm{~Pa}$. The pressure inside the heated snail is chosen to be $p($ snail) $=100 p$ (cryopump) $=0.9 \mathrm{~Pa}$. This pressure is determined by the rate at which the snatl heats the surface and by the snall velocity across the surface. If the snall operated at higher pressures, more gas would leak around the snail edges back into the cryopump, and if the snail operated at much lower pressures, the gas would be removed more slowly from the cryopump surface, which would reduce its effective pumping speed. It is assumed that $p$ (turbopump inlet) $=p($ snail $) / 3=0.3 \mathrm{~Pa}$. At $300 \mathrm{~K}$ turbopump temperature, the throughput $Q=0.83 \mathrm{~Pa}-\mathrm{m}^{3} / \mathrm{s}$ per pump. 
The required turbopump speed $S-Q / p-2.8 \mathrm{~m}^{3} / \mathrm{s}$, which is avallable commercially for tritium service.

\section{Orffice Plates}

Individual $0.1 \times 0.1 \times 0.002 \mathrm{~m}$ orifice plates will be suspended from a stainless steel lattice like suspended colling panels. The orifice place assembly will have excess panels to compensate for holes that may becone clogged or enlarged.

The orifice plates will have hole diameters of $0.2 \mathrm{~mm}$ (half the droplet diameter). It will be necessary to run the flibe through a cleanup system initially to remove all the particulates larger than the hole diameter. A Flibe side stream will be processed to maintain its chemical composition and to remove particulates that may arise during operation. Since the orifice plates are in a hot part of the loop, mass transport and deposition there will probably not be a problem. Corrosion may erode away some of the holes and enlarge them, with transport of the corrosion products to cooler surfaces. The dissolution rates of metals such as $\mathrm{Cr}$ depend upon their diffusion rates to the surface. Since $\mathrm{Ni}$ is highly corrosion resistant in flibe, stainless steel or nickel alloy orifice plates should endure well.

\section{Need for Intermediate Coolant Loop}

Since the vacuum disengager appears to provide good tritium control in the Flibe primary coolant, it may be possible to eliminate the intermediate coolant loop. A double-wall steam generator will be used to isolate the Flibe primary coolant loop from the steam system, without the need for an intermediate loop. The use of double-wall tubes greatly increases the steam generator reliability. Although the double-wall steam generator will cost more than an ordinary steam generator, elimination of the intermediate coolant loop will result in substantial net savings. 


\section{Secondary Containment System}

The primary loop will have a double-wall containment of tritium. The inner wall will be the vacuum boundary, and the outer wall will be a $2 \mathrm{~mm}$ thick welded stainless steel shell, with a helium sweep gas flowing in the annulus between the walls, as illustrated in Figure 21 . With the sweep gas pressure slightly subatmospheric, leaks in the system will tend to result in an influx of air into the system rather than the escape of tritium. Silica aerogel insulation $(k=0.02 \mathrm{~W} / \mathrm{m}-\mathrm{K}) 0.1 \mathrm{~m}$ thick around the inner Flibe duct will reduce the outside temperature to about $350 \mathrm{~K}$, with a heat loss of 0.52 MW, assuming that it can operate at $T \sim 900 \mathrm{~K}$. If not, a layer of other hightemperature insulation would be required inside the aerogel.

Components downstream of the vacuum disengagers, such as the steam generators and their return ducts, will not require secondary tritium containment, and neither will the vacuum pumping ducts of the blast chamber and vacuum disengagers.

Tritium may be removed from the helium sweep gas by use of palladium windows or by oxidation and trapping on a catalyst bed. There will be removable insulaticin and shells around flanges of the flibe duct, as shown in Figure 22, and a mechanical guard over any parts of the shell that are likely to be bumped by people or manipulators. The tritium leak rate via the sweep gas will be calculated in a later section. 


\section{HYLIFE-II Secondary Tritium Containment}

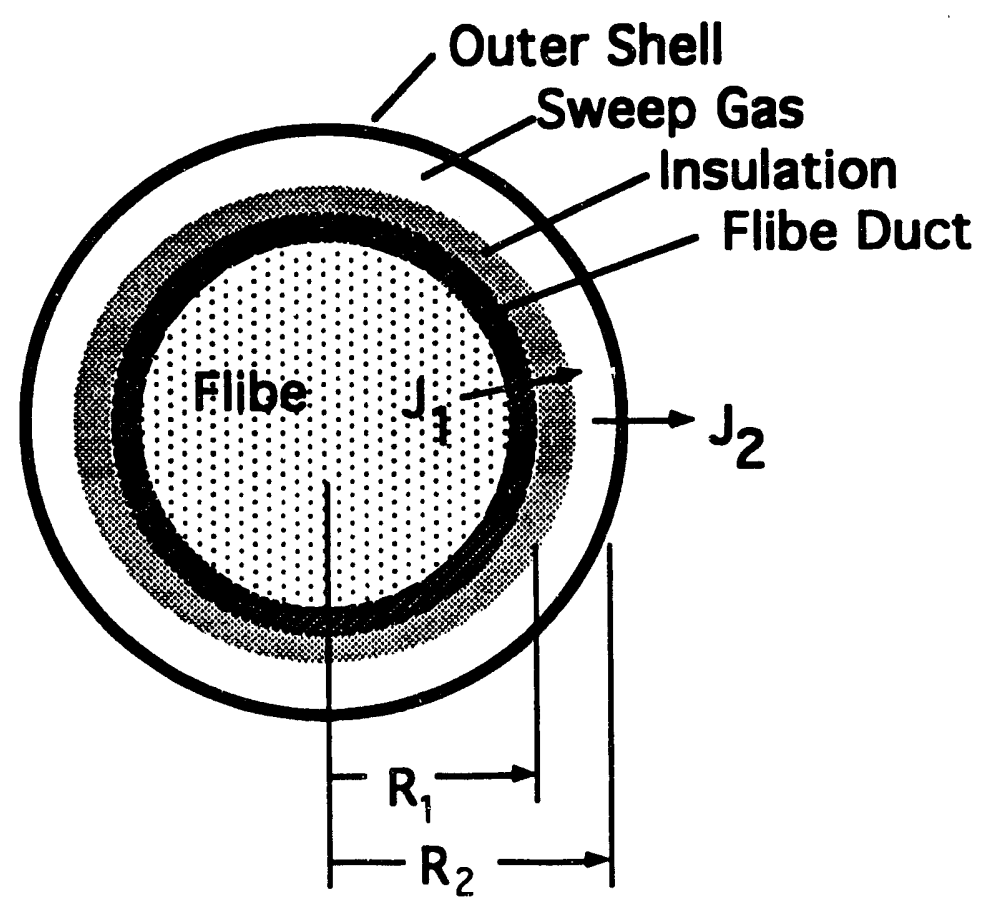

Figure 21. An insulated Flibe duct 


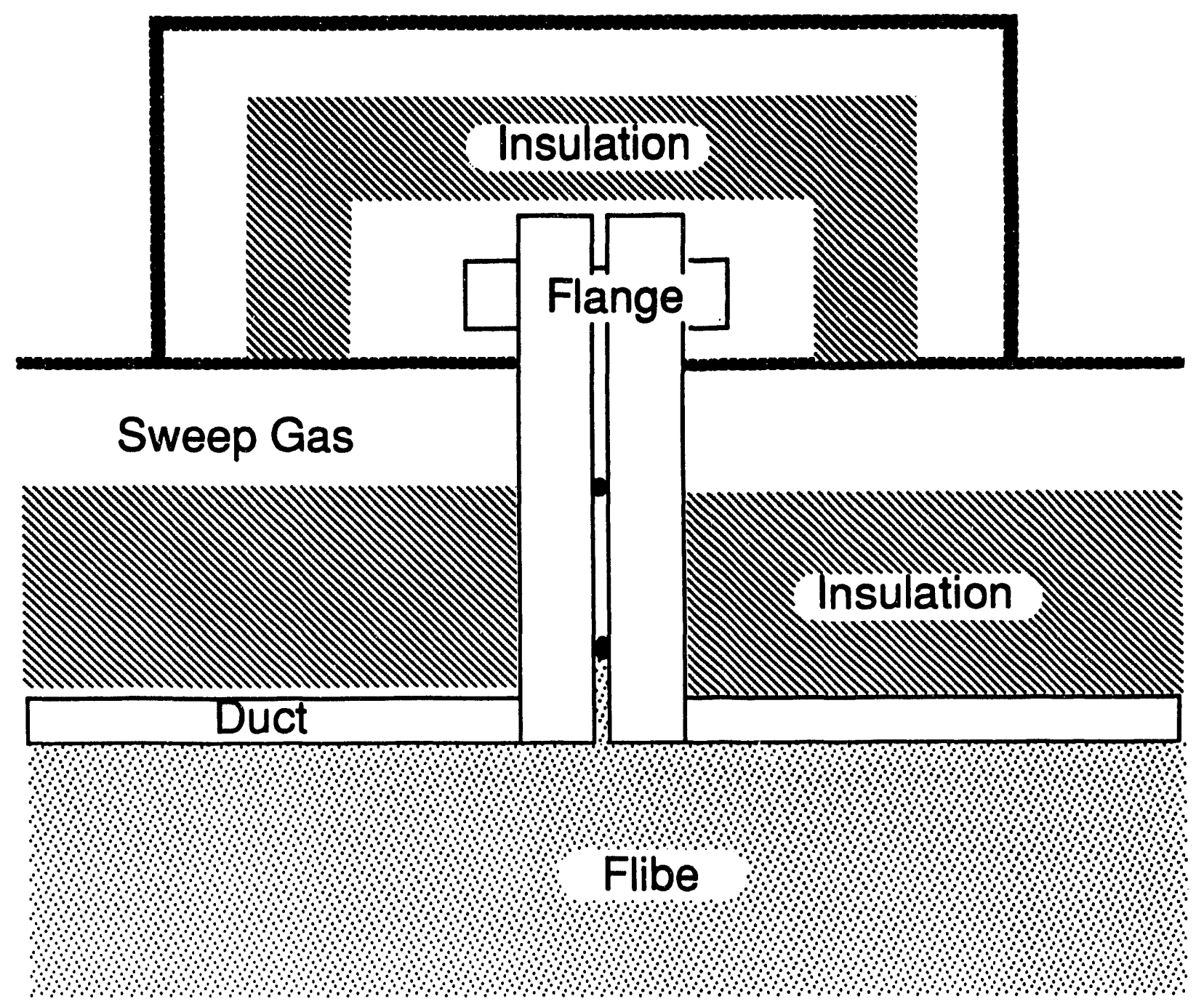

Figure 22. Thermal insulation and stainless steel outer shell around a flange. Sweep gas ports are not shown. 
The inert gas cleanup system is illustrated in Figure 23. The inert gas will flow through an array of tritium getter beds prior to recycle. Tritium and deuterium will be reversibly absorbed by these beds. Reactive gas impurities such as nitrogen or oxygen will react irreversibly with the getter material. If the gas stream contains more complex molecules such as methane or water, those molecules will be cracked and the hydrogen absorbed and other constituents combined with the bed metal. The beds will require periodic replacement. Bed life is extended by operating the first getter bed at a sufficiently high temperature $\left(\sim 500{ }^{\circ} \mathrm{C}\right)$ that hydrogen will not be absorbed, but reactive gases will be scavenged. After removal of other gases by the getter beds, the helium sweep gas will be recycled to the secondary containment system. 
HYLIFE-II Inert Gas Cleanup System

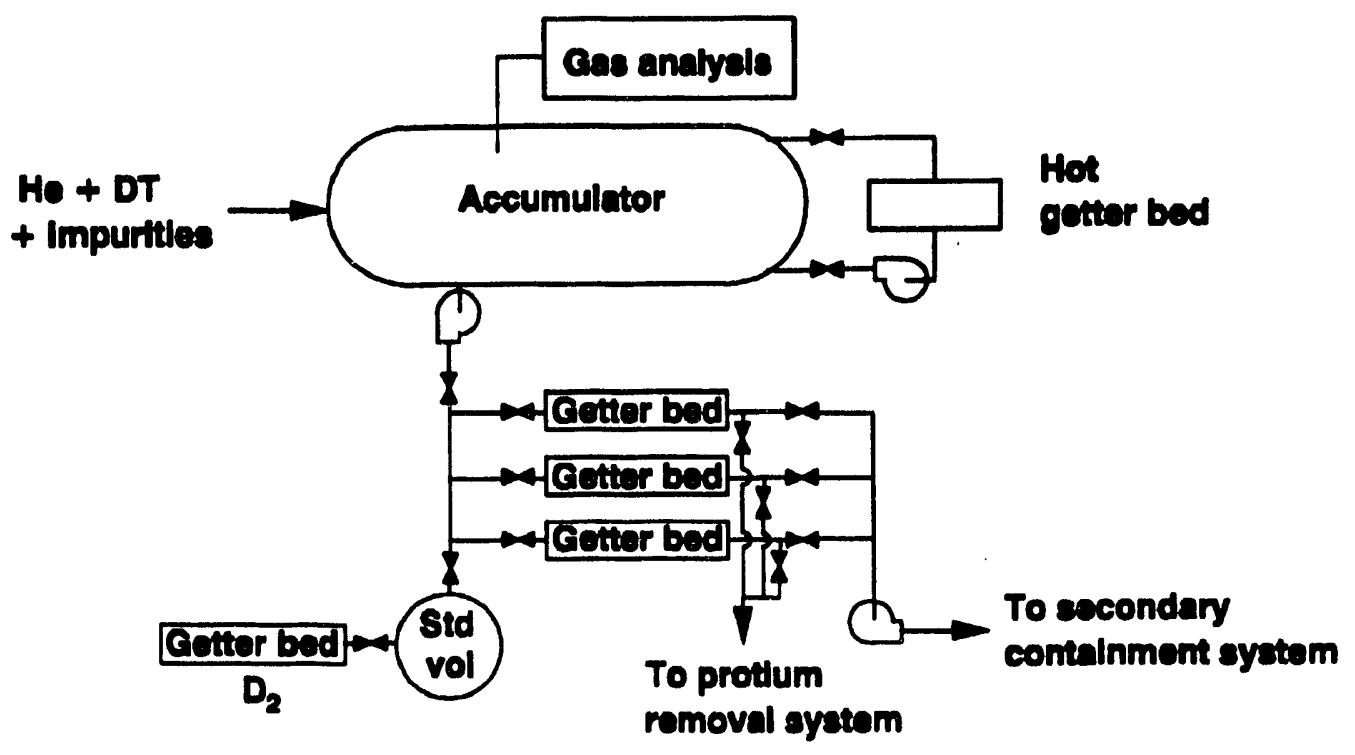

Figure 23. Inert Gas Cleanup System. 
When a getter bed has absorbed between $1 / 2$ and $3 / 4$ of its capacity for hydrogen, the bed would be taken off line and heated to return the purified hydrogen isotopes to the fuel storage system. An analyzing station would determine the D-T mix as well as the $H$ content enroute. If the $H$ content were too high, it would be necessary to send the gas through an isotopic separation system.

These gases may be handled and processed at nearly atmospheric pressure. Because tritium contamination levels will be relatively low, pumping may be done with diaphragm pumps, dry piston pumps, or roots blowers. Any gas surviving processing in this way will be inert, $D / T$ free, and suitable for return to the secondary containment system.

Each bed's capacity for hydrogen isotopes can be periodically measured by connecting the active bed with a standard volume of deuterium whose temperature and pressure are known. This process is repeated until the bed will hold no more deuterium. The amount of gas absorbed is a measure of its capacity. The bed is then regenerated to make it ready for service. Deuterium is chosen as the calibration gas because of the desire to avoid tritium (to minimize tritium inventory) and protium (a nonfuel gas).

The calibration deuterium is stored on a larger getter bed, which can be heated to generate the gas and fill the standard volume. Then, it can be cooled to retrieve the deuterium when the active bed is regenerated.

\section{Hydrogen Isotopes Separation}

It is necessary to determine the isotopic composition of the hydrogenic mixture recovered from the vacuum systems and sweep gas system, in order to ensure that protium $(H)$ levels are low enough $(<0.3 \%)$, and to determine how much deuterium needs to be added to bring the mixture to the desired $D / T$ composition for new targets. 
Hydrogen isotopic separation may be done most readily with cryogenic distillation columns. Such columns typically produce very high purity effluent streams, $>99 \%$ pure of the various hydrogen isotopes. This system should maintain the $H$ content of the return gas stream below $0.3 \%$, in order to avoid reduction of the target energy gain. Since the protium source term estimated above is only about $0.3 \%$ of the tritium flow rate in the blast chamber vacuum system, it might be unnecessary to provide a hydrogen isotopes separation system. However, more thorough calculations would be required to justify its omission.

Inputs to the isotope separation system include the effluent streams from the blast chamber vacuum systems, the accelerator vacuum system, the vacuum disengager vacuum system, and the inert gas cleanup system.

A two-column system is anticipated, as illustrated in Figure 24 . The feed stream enters the first column, where the $\mathrm{H}_{2}$ comes out and is released to the stack. Heavier isotopic molecules including $H D, H T, D_{2}, D T$, and $T_{2}$ (in order of descending volatility) come from the reboiler end of the column and pass through a catalyst bed equilibrator. This causes the reformation of $\mathrm{H}_{2}$ molecules from the HD and HT and a general redistribution of the mole fractions of the other molecules. That becomes the feed for the second column in which $\mathrm{H}_{2}, H D$, and $H T$ are taken out at the top and $D_{2}, D T$, and $T_{2}$ are taken from the bottom of the column and returned to the fuel storage system. The lighter molecules are again passed through a catalyst bed equilibrator to induce the formation of $D_{2}, D T$, and $T_{2}$ molecules, and the stream reenters the first column. The second column adds only about $10 \%$ to the cost of the system. It provides a much more complete removal of protium from the fue 1 return stream and a greatly reduced tritium fraction in the gas steam released through the stack. 


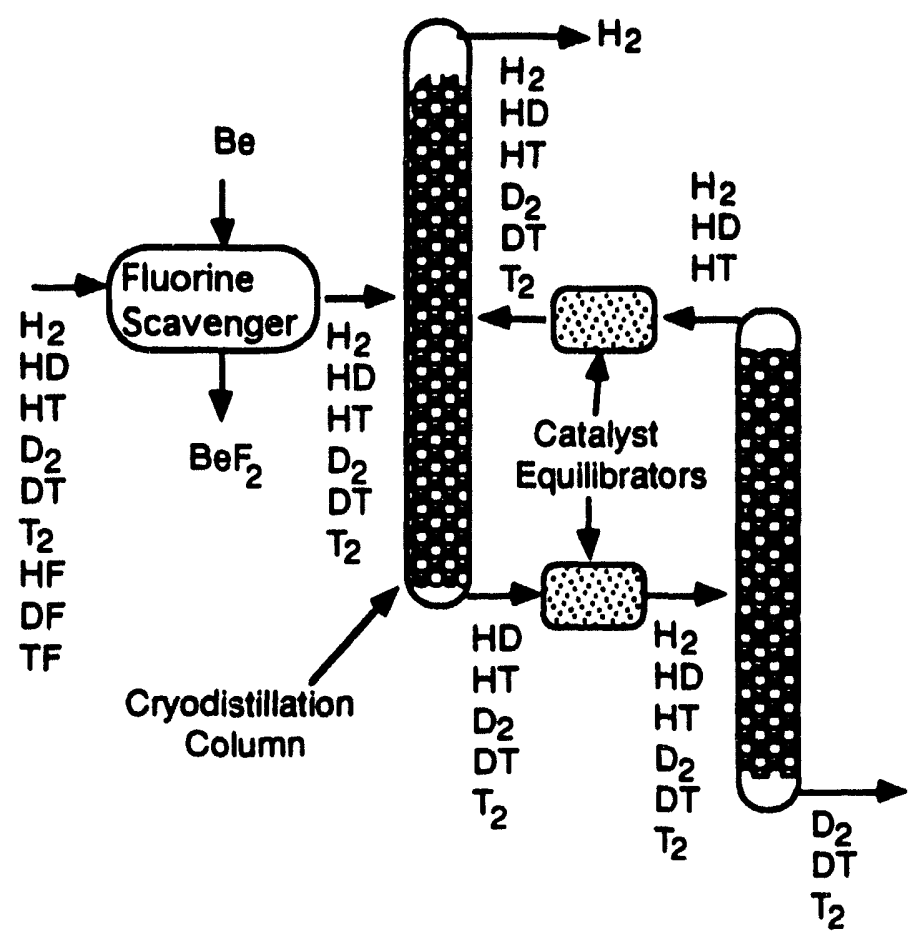

Figure 24. Cryodistillation system for separation of hydrogen isotopes. 
Mass spectrometers or gas chromatographs will be used to determine the isotopic composition of the effluent. The power requirements for the tritium management system are estimated to be: Flibe pumping - $6.6 \mathrm{MW}$, cryogenic system - 1 MW, sum (helium sweep gas system + air cleanup system + hydrogen (sotope system) $<1$ MW.

\section{Tritlum Removal from Containment Bullding Air}

With the exception of the secondary heat transfer loop in which water is boiled to drive the turbines, the HYLIFE-II system will be water free. Hence, seepage of tritiated water (the prime pathway for tritium loss from fission reactors) will not be a problem. The vacuum disengager system should prevent tritium escape to the secondary coolant, but it is conceivable that it could fail, resulting in tritiation of the steam loop. Continuous measurement of the tritium content in the secondary loop water will give an early indication of any such occurrence and allow shutdown before any significant inventory of tritium can accumulate in the water.

The prospect of a flibe duct rupture with release of tritium and Flibe contaminants such as beryllium compounds to the reactor hall must also be anticipated. In the case of such a spill, an emergency air cleanup system would be needed to purify the reactor hall air before releasing it to the environment. Air cleanup systems are usually based on remoral of contaminants that may injure a catalyst bed, followed by catalyzed oxidation of hydrogenous molecules and collection of the water thus formed on molecular sieve beds or alternative driers. In this case, only ambient air moisture would be expected to become tritiated. The Flibe and its dissociation products should condense at ambient temperatures. Thus, the main tritium load in the room air would be $T_{2}$ coming out of the Flibe. Unless there is an ignition source, this should not react substantially before being processed. If coming from the Flibe may react to produce metallic fluoride salts and $T_{2} 0$ or HTO, but there would be very little TF present in the Flibe, because $\mathrm{Be}$ 
buffers are used to keep most of the tritium in the $T_{2}$ form. The emergency air cleanup system consists of a set of bag-filters followed by HEPA filters, a catalyst bed, and a drier bed, as 1llustrated in Figure 25. This system is sized to allow processing of the entire reactor hall volume in 8 hours.

The tiny amount of tritiated water normally collected by this system could be fixed in concrete for burial as radioactive waste. However, if a substantial amount of tritium were collected, then the tritiated water could be removed from the drier bed, electrolyzed, and processed by the isotope separation system.

\section{HYLIFE-II Emergency Alr Cleanup System}

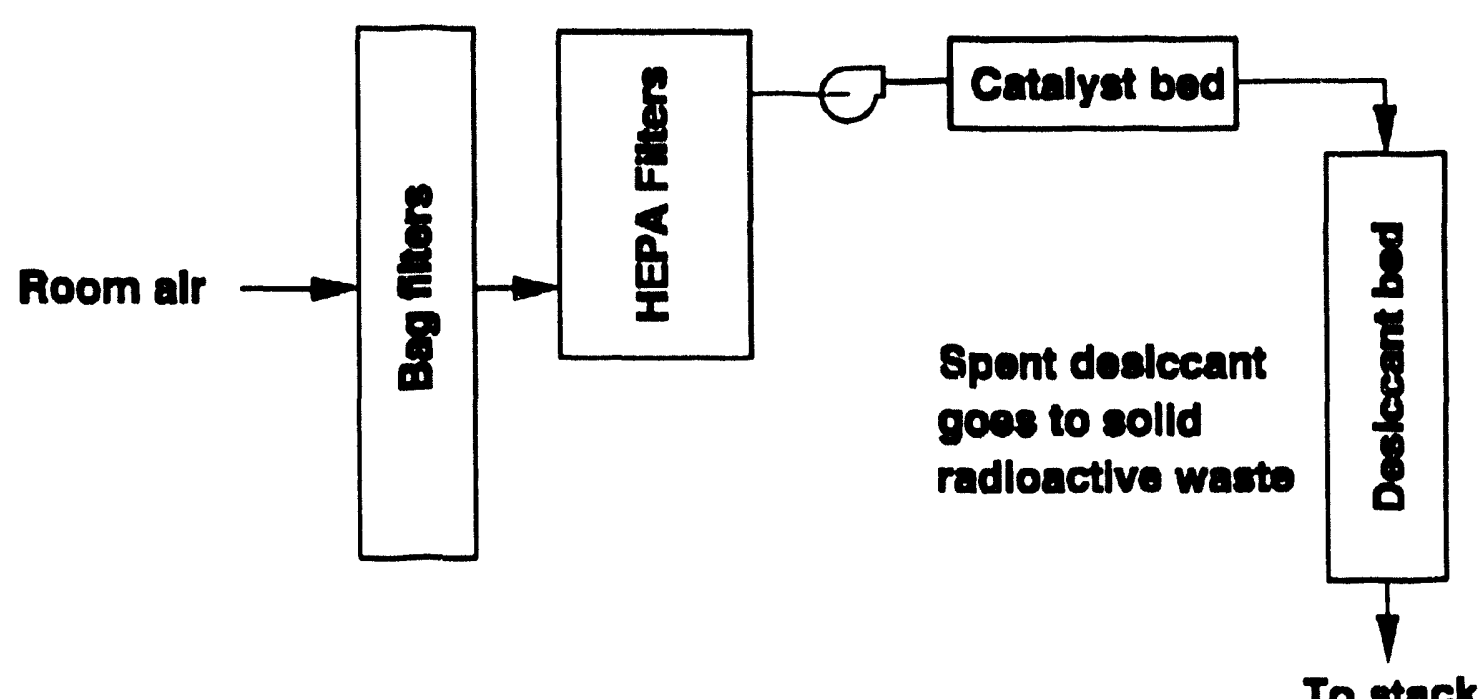

Figure 25. HYLIFE-II air detritiation system. 


\section{Release of Non-Hazardous Gases through the Stack}

Protium isolated from the fuel return stream and certain other gases not hazardous to the environment will be released through the plant stack. Helium ash collected by the blast chamber vacuum system will be sent to the inert gas cleanup system that processes secondary enclosure gas. This additional helium will help compensate for helium losses from the sweep gas and cryogenic systems.

Protium from the isotopic separation column in the fuel return stream and other gases generated during the regeneration of the cryopumps will be released through the stack. Cryopump warming will be done gradually, so that the hydrogen isotopes come off before the other species. Because the highertemperature condensates will contain some tritiated molecules (such as methane), it will be necessary to pass that stream over getter beds to crack those molecules and then to separate the hydrogen isotopes. An alternative means of hydrogen separation, use of a palladium-silver diffuser, is not chosen, because

(1) carbon and other elements that may be cracked from the higher-temperature condensate tend to poison the diffuser, and

(2) hydrogen isotopes passing through the diffuser are purified, but the filtrate on the upstream side would not necessarily be sufficiently low in tritium to release through the stack.

\section{Disposal of Hazardous Effluents}

Solid wastes produced by the tritium management system will include consumed getter bed material and tritiated compounds. Liquid wastes will be containerized and hence fall under the same regulations as solid wastes for disposal. All of these must be considered radioactive waste. Additionally, depending on what material is used for the getter beds, they may also be classified as hazardous waste. The latter classification is far less likely if the material has been processed to take it to its state of lowest chemical energy, thus removing the flammable or reactive characteristic classification. 
The remaining problem would be characteristic toxicity, which may require encapsulation or calcining to a form where the leach test used to establish toxicity potential would fall to determine toxicity. At the least, a facility will be needed for packaging such wastes. Because these will probably be radioactive from the low neutron fields that may be present at their service locations, it may be necessary to do this work in a remote handing facility. Such a facflity will probably be needed for maintenance functions as well.

Metal getter beds used for gas purification and separation can be reacted to completion with air, closed up and sealed, and disposed of as radioactive waste. If waste minimization is an issue, or if there is uncertainty about the ability to ensure that the reactive characteristics of the getter material have been fully removed, the beds may be disassembled and refilled with new getter material. That will require special considerations in bed design. 


\section{Tritium Inventory}

To assess the tritium inventory we need to consider parts of the HYLIFE-II system beyond the tritium management system. These are now discussed.

\section{Blast Chanber}

The current design for the blast chamber is summarized by Moir ${ }^{2}$ and House. ${ }^{33}$ It is essentially a cylindrical chamber about $3 \mathrm{~m}$ in radius and $14 \mathrm{~m}$ high with a domed top closure and a flat bottom. Three flibe circults enter the upper part of the blast chamber, and the liquid fall distance is about $8 \mathrm{~m}$.

The first circuit is the flibe flow to provide the shield for the blast. This flow is divided into a large number of jets, many of which are mechanically oscillated to provide a cavity within which the explosion takes place. The volumetric flow rate of Flibe through this channel is $57.1 \mathrm{~m}^{3} / \mathrm{s}$. Flow paths inside the blast chamber are complex. An average vertical velocity of $16 \mathrm{~m} / \mathrm{s}$ is estimated. All of this Flibe comes from the catch assembly at the bottom of the blast chamber (legs 6 and 9 in Figure 2). The volume of Flibe from this circuit in the blast chamber at any time is about $50 \mathrm{~m}^{3}$, and it is assumed to be isothermal at $923 \mathrm{~K}$ outside the blast chamber.

The second major flibe circuit feeds several internal paths including the shielding tray, horizontal and vertical beam shielding flow, shell 1 tubes, and channels between the shells 1 and 2 of the main enclosure, with a total flow rate of $17.8 \mathrm{~m}^{3} / \mathrm{s}$. This flow also comes from the main recirculating flow (leg 7 in Figure 2), and is assumed to be at $923 \mathrm{~K}$ outside the blast chamber. The pool at the bottom of the reactor contains Flibe from 3 shots, so adding the one in progress, this flow's contribution to the volume of flibe in the blast chamber at any time is $8.8 \mathrm{~m}^{3}$.

The third flibe circuit is a condensing spray that is injected into the outer part of the central chamber to accelerate condensation of Flibe vaporized by the explosion. The flow in that channel is $9.7 \mathrm{~m}^{3} / \mathrm{s}$, and it 
comes from the cold side of the heat exchanger loop (1eg 8 in Floure 2). It also provides $0.6 \mathrm{~m}^{3} / \mathrm{s}$ of Flibe for cooling the space between shells 2 and 3 . Hence, the total flow through this channel is $10.3 \mathrm{~m}^{3} / \mathrm{s}$, the same as the flow through the three heat exchanger loops. The temperature at which it enters the blast chamber is $857 \mathrm{~K}$. The volume of flibe in the blast chamber from this strean is $5.1 \mathrm{~m}^{3}$.

Tritium left over from the fusion explosion is highly unlikely to enter the Flibe in any quantity, because of the large Filbe droplet sizes expected from the blast. 34 The chemical potentials favor evolution of tritium bred in the flibe to the gas phase. That tritium will become mixed with the contributions from all Flibe flows in the collection pool and will be pumped with the Flibe throughout the plant. Since the main avenue of escape for this tritium from the flibe is through the vacuum disengager, it will rise in concentration unt 11 the removal rate in that system equals the production rate in the blast chamber. The tritium concentration in the flibe leaving the blast chamber is $1.15 \times 10^{20}$ atoms $/ \mathrm{m}^{3}$ (Table 2 ).

With clean, cool flibe providing cooling at the outside of the blast chamber, 35 only she 112 and the structures interior to that will be highly tritium contaminated. It is assumed for tritium loss rate and inventory calculations that the contaminated metal consists of the volume of a shell $25 \mathrm{~mm}$ thick over the entire surface of the blast chamber

\section{Drain Tanks}

A number of drain tanks will be needed to receive the Flibe during system maintenance or during an accident. These drain tanks must be capable of heating the Flibe well into the liquidus, and they should accomodate flibe expansions and contractions without damage. The tanks serving the blast chamber and recirculation loop will become loaded with tritium from the hot Flibe. However, only the tritium carried by the flibe into the tanks will be able to reach the tank walls. The solubility of tritium in the tank materials will greatly exceed its solubility in Flibe, so it is assumed for conservatism that all the tritium from the drained flibe enters the tank walls. The 
maximum tritium inventory in the tanks would be that corresponding to the number of times the tanks are filled, which is assumed to be ten.

It is assumed that 4 drain tanks serve the blast chamber and the main recirculation loop. Taking 10 times the inventory of the tritium in the flibe that would go to those tanks, a tritium inventory in the tanks of $5 \mathbf{g}$ is estimated. The drain tanks serving vacuum disengager/steam generator loops will be filled with Flibe that is essentially free of tritium, so the inventory there is negligible.

\section{Vacuum Disengagers}

These devices are nominally right-circular cylinders of radius $2.5 \mathrm{~m}$ and height $9 \mathrm{~m}$. A shell thickness of $3 \mathrm{~cm}$ is assumed. Internally, $2 \%$ of the volume is assumed to be taken up by structure. At any instant $4.4 \mathrm{~m}^{3}$ of Flibe is assumed to be present in the chamber. The chambers are assumed to be well insulated so that the Flibe does not lose thermal energy during the vacuum separation of tritium from the Flibe. Since solution of tritium in Flibe is endothermic, when the tritium emerges the sensible heat recovered is about $(0.3 \mathrm{eV} /$ molecule $)\left(10^{21}\right.$ molecules $\left./ \mathrm{s}\right)\left(1.6 \times 10^{-19} \mathrm{~J} / \mathrm{eV}\right)=48 \mathrm{~W}$, which is negligible.

Two vacuum disengagers are provided for each of the three heat transfer loops. Each is assumed to remove $99.7 \%$ of the tritium from the Flibe entering it. Hence, the tritium in the second disengager would be only $0.3 \%$ of that in the first and may be neglected for inventory accountancy purposes here. The average tritium content of Flibe in the disengager is assumed to be half that with which it entered. Because most of the chamber is exposed to a vacuum, there will be little tritium uptake in most of the structure. Only that structure in the first stage upper plenum and orifice plates, assumed to be $2 \%$ of the total disengager chamber volume, would become significantly contaminated. It would contain tritium in equilibrium with Flibe at the incoming tritium concentration, assuming surface-limited kinetics. 


\section{Inventory Quantities}

A list of Flibe ducts and estimated tritium inventories is shown in Table 6, based on the layout diagram of March 26, 1992.36 The main base collector manifolds have been reduced to three separate ducts each. The dominant inventory is in the duct walls $(140.8 \mathrm{~g})$. The total inventory of tritium in the Flibe in the various ducts is $0.475 \mathrm{~g}$. The inventory in the blast chamber Flibe is $0.074 \mathrm{~g}$, and in the blast chamber structure, $0.195 \mathrm{~g}$. In the vacuum disengagers, the estimated inventory is $0.92 \mathrm{mg}$ of tritium in the structure, with negligible tritium in the Flibe. Hence, for the entire HYLIFE-II facility, other than the tritium processing system, the inventory is estimated to be approximately $141.5 \mathrm{~g}$, mostly in the Flibe recirculation duct walls. 
Table 6. Estimates of tritium contents in HYLIFE-II Flibe ducts.

\begin{tabular}{|c|c|c|c|c|c|c|c|c|c|c|}
\hline Ref & Description & $N$ & $\begin{array}{c}\mathrm{L} \\
\text { (m) }\end{array}$ & $\begin{array}{l}R \\
\text { (m) }\end{array}$ & $\begin{array}{l}\text { Thick } \\
\text { (m) }\end{array}$ & $\begin{array}{c}Q \\
m^{3} / s \\
\end{array}$ & $\begin{array}{c}v \\
(\mathrm{~m} / \mathrm{s})\end{array}$ & $T(K)$ & $\begin{array}{c}\text { Flibe } \\
\text { Trit (g) } \\
\end{array}$ & $\begin{array}{l}\text { Structure } \\
\text { Trit (g) }\end{array}$ \\
\hline 1 & $\begin{array}{l}\text { Base Collector } \\
\text { Manifold }\end{array}$ & 3 & 30 & 0.8 & 0.03 & 3.43 & 1.71 & 923 & 0.1024 & 13.17 \\
\hline & Pump to Vac Dis 1 & 3 & 25 & 0.5 & 0.02 & 3.43 & 4.37 & 923 & 0.0333 & 6.13 \\
\hline 2 & $\begin{array}{l}\text { Vac Dis } 1 \text { to } \\
\text { Vac Dis } 2\end{array}$ & 3 & $\mathbf{8}$ & 0.5 & 0.02 & 3.43 & 4.37 & 923 & 0.0001 & 4. $4 E-04$ \\
\hline 3 & $\begin{array}{l}\text { Vac Dis } 2 \text { to } \\
\text { Superheater }\end{array}$ & 3 & 23 & 0.5 & 0.02 & 3.43 & 4.37 & 923 & $2.8 E-07$ & $2.3 E-08$ \\
\hline 4 & $\begin{array}{l}\text { Superheater to } \\
\text { Pump }\end{array}$ & 3 & 7.5 & 0.5 & 0.02 & 3.43 & 4.37 & 896 & $8.4 E-08$ & 4.7E-09 \\
\hline & Pump to Evaporator & 6 & 6 & 0.35 & 0.02 & 1.72 & 4.38 & 896 & $6.7 E-08$ & 5.7E-09 \\
\hline 5 & $\begin{array}{l}\text { Evaporator to } \\
\text { Header Junction }\end{array}$ & 6 & 2 & 0.35 & 0.02 & 1.72 & 4.38 & 857 & $2.1 E-08$ & 1.1E-09 \\
\hline 6 & $\begin{array}{l}\text { Base Collector } \\
\text { Manifold }\end{array}$ & 9 & 30 & 0.8 & 0.03 & 8.32 & 4.14 & 923 & 0.3073 & 60.31 \\
\hline & Pump to Junction & 9 & 10 & 0.8 & 0.03 & 8.32 & 4.14 & 923 & 0.0113 & 20.12 \\
\hline 7 & $\begin{array}{l}\text { Junction to Side } \\
\text { Header }\end{array}$ & 9 & 12 & 0.4 & 0.02 & 1.98 & 3.94 & 923 & 0.0034 & 6.87 \\
\hline 8 & $\begin{array}{l}\text { Junction to Spray } \\
\text { Header }\end{array}$ & 3 & 60 & 0.5 & 0.02 & 3.43 & 4.37 & 857 & $2.1 E-07$ & 2. $1 E-08$ \\
\hline 9 & $\begin{array}{l}\text { Junction to Top } \\
\text { Header }\end{array}$ & 9 & 20 & 0.7 & 0.03 & 5.74 & 3.73 & 923 & 0.0174 & 34.21 \\
\hline
\end{tabular}


The inventory in the tritium management system will depend on the details of the design, which have not yet been determined. The inventories of the vacuum systems, sweep gas channels, and room air cleanup system wil? be small. The inventories of the sweep gas getter beds and hydrogen isotopes system will be appreciable, but not large. The dominant inventory will be about one day's supply in the tritium fuel storage beds and target factory. At a given time, about one fourth of that amount could be in the processing system. The tritium mass in one days fuel supply is

$$
M=m_{t} P t / W f_{b}=1.24 \mathrm{~kg}
$$

where $P=2.835 \times 10^{9} \mathrm{~W}, t=86400 \mathrm{~s}, \mathrm{~m}_{\mathrm{t}}=5.01 \times 10^{-27} \mathrm{~kg}, \mathrm{~W}=2.818 \times 10-12 \mathrm{~J}$, and $f_{b}=0.35$.

Hence, the total tritium inventory would be about $1.4 \mathrm{~kg}$, of which most would be in isolated storage beds. 


\section{Tritium Loss Rate}

\section{Loss through the Steam Generators}

To optimize the thermal efficiency, the heat exchangers will have very large surface areas, thin walls, and the highest temperatures tolerable by the materials. These features make them highly permeable to tritium. Tritium transport through the Flibe to the heat exchanger tube walls is duminated by turbulent flow, with slow diffusion of tritium through the boundary layer, and the Reynolds analogy between heat and mass transfer may be applied.24 Calculations with a tungsten barrier on the tubes showed only a slight effect on $f_{x}$. The flow resistance of the Flibe boundary layer is greater than that of the tungsten. Since the tritium concentration at the tube wall is much less than the radial average concentration, the equations previously derived 7 may be simplified to estimate the fraction of tritium permeating through a heat exchanger, with the result

$$
f_{x}=1-\exp \left[-(0.1989 H / R) \int_{0}^{1} d y / \operatorname{Re}^{1 / 8} C f^{+}\right]
$$

where $y=z / H, Z$ is the distance along the tube, $R$ is the tube radius, $H$ is the tube length, $R e$ is the tube Reynolds number, and $c_{f}{ }^{+}$is a radial average of a dimensionless tritium concentration given by

$$
c_{f}^{+}=2 \int_{0}^{1} d x \times c^{+}(x)
$$

with

$$
\begin{array}{ll}
c^{+}(x)=\int_{0}^{\alpha(1-x)} \frac{d s}{(1 / S c)+0.0154 \text { vs[ } 1-\exp (-0.0154 \text { vs })]} & \text { if } \alpha(1-x)<26, \\
c^{+}(x)=c^{+}(26)+\ln [\alpha(1-x) / 26] & \text { if } \alpha(1-x)>26,
\end{array}
$$


$v=\mathbf{s}$

if $s \leq 5$,

$v=4.731 \ln (s)-2.664$ if $s>5$.

In these equations $x=r / R=$ normalized radius, $s=$ dummy variable of integration, $\alpha=v^{\star} \rho R / \mu$, and $v^{\star}=0.1989 u / \operatorname{Re}^{1 / 8}$. These equations are solved by the TRITUBE computer code.

The superheater and evaporators in each of the three loops are exposed to tritium-depleted Flibe. Hoffman and Lee 37 recommend making the evaporators and superheaters identical units to simplify design, maintenance, and spare parts requirements. Typical superheater parameters are listed in Table 7. From the Reynolds number, the hydraulic diameter, and the viscosity, the effective Flibe flow velocity through the shell side of the superheater is estimated to be $1.43 \mathrm{~m} / \mathrm{s}$. The Flibe temperature drops from $923 \mathrm{~K}$ to $896 \mathrm{~K}$ as it passes through the superheater, and the wall temperature is about $42 \mathrm{~K}$ less than the Flibe temperature. The tube outer diameter is $21.4 \mathrm{~mm}$, the tubes are $21.2 \mathrm{~m}$ long, the tube bundle is $2.0 \mathrm{~m}$ in diameter, so the volume of Flibe in the superheater is $52.6 \mathrm{~m}^{3}$. The TRITUBE code calculated permeation fraction

Table 7. Example superheater tube parameters for the subcritical cycle.

\begin{tabular}{|c|c|c|}
\hline H & $=$ tube length & $=25.4 \mathrm{~m}$ \\
\hline $2 R$ & = hydraulic diameter & $=6.85 \mathrm{~cm}$ \\
\hline$T$ & = Flibe inlet temper ature & $=923 \mathrm{~K}$ \\
\hline A & = Flibe-side tube area & $=4471 \mathrm{~m}^{2}$ \\
\hline N & $=$ number of tubes & $=2075$ \\
\hline u & $=$ bulk Flibe velocity & $=1.43 \mathrm{~m} / \mathrm{s}$ \\
\hline$\rho$ & - Flibe mass density & $=1970 \mathrm{~kg} / \mathrm{m}^{3}$ \\
\hline$D_{F}$ & - diffusivity of $T_{2}$ in Flibe & $=6.3 \times 10^{-8} \mathrm{~m}^{2} / \mathrm{s}$ \\
\hline$\mu$ & - Flibe viscosity & $=1.16 \times 10^{-4} \exp (3755 / \mathrm{T}) \mathrm{Pa}-\mathrm{s}$ \\
\hline $\operatorname{Re}$ & - Reynolds number & $=2 \operatorname{Rv} \rho / \mu=28.810$ \\
\hline Sc & $=$ Schmidt number & $=\mu / \rho D_{F}=48$ \\
\hline
\end{tabular}


through the superheater tubes is $14.9 \%$.

For the evaporators, there are 1500 tubes, each $17.9 \mathrm{~m}$ long. Flibe enters at $896 K$ and leaves at $857 K$. For a Reynolds number of 19,938, a hydraulic diameter of $6.85 \mathrm{~cm}$, and a slightly higher viscosity at the lower temperature, the effective flow velocity of the Filibe is $1.23 \mathrm{~m} / \mathrm{s}$. The tube is about $130 \mathrm{~K}$ colder than the Flibe. The two tubes are each $2.8 \mathrm{~mm}$ thick, the tube bundle diameter is $1.7 \mathrm{~m}$, and the volume of $\mathrm{Flibe}$ in each evaporator is $28.8 \mathrm{~m}^{3}$. The calculated permeation fraction for the evaporator tubes is $8.65 \%$.

It is assumed that leaks will result in eventual loss of all the tritium that gets into the steam system. Of the $5 \mathrm{MCi}$ /day of tritium entering the Flibe system, a fraction $10^{-5}$ or $50 \mathrm{Ci} /$ day is not removed by the vacuum disengagers. Of that $50 \mathrm{Ci} /$ day, $14.9 \%(-7.5 \mathrm{ci} /$ day $)$ is 10 st through the superheater tubes, and of the remaining $42.5 \mathrm{Ci} /$ day, $8.65 \%(-3.7 \mathrm{Ci} /$ day $)$ is lost through the evaporator tubes. Thus, about $11 \mathrm{Ci} /$ day are lost through the steam generator. 


\section{Loss through the Secondary Containment}

The tritium flow rate leaving the blast chamber is

$$
\text { nQ } \quad=9.80 \times 10^{21} \text { atoms } / \mathrm{s}-40.9 \mathrm{MC1} / \mathrm{day} \text {. }
$$

The tritium leakage out of a Flibe duct with $R-1 \mathrm{~m}, L=20 \mathrm{~m}$ was previously estimated to be $0.34 \%$ of the tritium in the Flibe entering the duct. If the secondary containment system consisted of Flibe duct segments each with $R=0.5 \mathrm{~m}, L-30 \mathrm{~m}$, the loss fraction scales to $1.17 \%$ in each segment. The surface area over which secondary tritium containment is required is estimated to be $4551 \mathrm{~m}^{2}$. Since the area of one segment $-94 \mathrm{~m}^{2}$, it will take about 48 such segments to cover the active $3582 \mathrm{~m}^{2}$ area. The Flibe flow is split into about 12 parallel flow paths around the blast chamber. Each path carries about $1 / 12$ of the tritium, and consists of about 4 of the helium flow segments. The duct leakage in one of the 12 paths is

$$
\begin{aligned}
\text { Leakage (one path) }-(1 / 12)(n Q)\left[1-(1-0.0117)^{4}\right] \\
-(1 / 12)(n Q)[0.0460] .
\end{aligned}
$$

Since there are 12 parallel paths, the total leak rate is 12 times as great, or

$$
\text { Leakage }=0.0460(n Q)=4.51 \times 10^{20} \text { atoms } / \mathrm{s}=1.88 \mathrm{MCi} / \text { day }
$$

from the Flibe duct into the sweep gas. Approximating the helium flow segment as an annulus with radius $R$, gap width $\Delta r$, length $L$, and flow speed $u$, the tritium balance in the sweep gas is estimated from the equation

$$
2 \pi R \Delta r u d n / d z-2 \pi R\left(J_{1}-J_{2}\right)
$$

where $n=$ tritium concentration in the sweep gas (atoms $/ \mathrm{m}^{3}$ ), $d n / d z=$ concentration gradient, $J_{1}=$ leakage flux from Flibe duct into sweep gas, $J_{2}=$ leakage flux from sweep gas through outer shell to room air. Assuming $J_{2} \ll$ $J_{1}$, the solution of this equation is 


$$
n(z)-2 \pi R J_{1} z / 2 \pi R \Delta r u \text {. }
$$

Since $p-n k T$, the Sievert's Law loss rate through the outer shell of one segment is

$$
\begin{aligned}
\text { Loss }= & 2 \pi R \int_{0}^{L} d z \text { DS } p^{1 / 2} / x \\
& -(4 \pi R D S L / 3 x)\left(2 \pi R J_{1} L k T / 2 \pi R \Delta r u\right)^{1 / 2}
\end{aligned}
$$

where $x$ - shell thickness, $D$ - tritium diffusivity in she11, $S$-tritium solubility in shell. For stainless steel at $350 \mathrm{~K}, 0-4.05 \times 10^{-15} \mathrm{~m}^{2} / \mathrm{s}$ and $S=1.46 \times 10^{22}$ atoms $/ \mathrm{m}^{2} \mathrm{~Pa} \mathrm{a}^{1 / 2} .38$

The leak rate into each segment is

$$
2 \pi R J_{1} L-(\text { Leakage }) / 48=9.39 \times 10^{18} \text { atoms } / \mathrm{s} .
$$

Assuming, $L=33 \mathrm{~m}, R=0.5 \mathrm{~m}, \Delta r=0.02 \mathrm{~m}, x=0.002 \mathrm{~m}, u=0.1 \mathrm{~m} / \mathrm{s}$, the loss rate from one segment is found to be

$$
\text { Loss }=5.49 \times 10^{12} \text { atoms } / \mathrm{s}
$$

so the total loss rate from 48 segments is $2.64 \times 10^{14}$ atcms $/ \mathrm{s}=1.1 \mathrm{ci} /$ day. (If the outer shell were hotter, the loss rate would increase rapidly, because both $D$ and $S$ vary exponentially with reciprocal temperature.) The total tritium loss rate via the steam generators plus secondary containment is about $12 \mathrm{Ci} /$ day. 


\section{Cost Estimate}

A few representative items will be described below, followed by a table sumarizing all the cost elements.

\section{Vacuum Disengager Chambers}

The vacuum chambers are approximated by cylinders with $L-8 \mathrm{~m}, R=2.5 \mathrm{~m}$, thickness $\Delta r=0.03 \mathrm{~m}$, and mass $-30 \mathrm{t}$. At an estimated cost of $\$ 21 / \mathrm{kg}$, the cost of the 6 vacuum disengager chambers is 3.78 MS.

\section{Orifice Plates}

The spray region radius $-1.6 \mathrm{~m}$ and the chamber radius $-2 \mathrm{~m}$, so there is a plenum at the outside to facilitate azimuthal and vertical gas flow. Each stage will have 830 orifice plates, each $0.1 \times 0.1 \times 0.002 \mathrm{~m}$ with $10 \%$ of each plate's surface occupied by 32,000 holes, diameter $0.2 \mathrm{~mm}$, drilled by multiple pulsed laser beams. The cost of the steel plates and cutting is negligible. Research and development of laser drilling process is estimated to take 4 manyears. Manufacture is estimated to take 2 man-years plus $400 \mathrm{kS}$ equipment. The total estimated cost of the orifice plates is 1.0 Ms, including spares.

\section{Vacuum Duct for Vacuum Disengagers}

There are four vacuum pumping ducts (two at the middle and two at the bottom) on each stage. The middle level pumps handle most of the gas load, and the bottom level pumps minimize the pressure around the Flibe droplets near the end of their fall. There are six stages with four ducts each, for a total of 24 ducts. Each duct has $L=30 \mathrm{~m}, R=0.5 \mathrm{~m}$, and thickness $=1.3 \mathrm{~cm}$. The total mass $=233 \mathrm{t}$. At $63 \mathrm{\$} / \mathrm{kg}$, the cost is $14.65 \mathrm{MS}$.

\section{Valves and Other Vacuum Equipment}

Each vacuum duct contains a $1 \mathrm{~m}$ diameter gate valve. Large gate valves have been designed for applications such as isolation of neutral beam injection 
lines, and a valve with $0.4 \mathrm{~m}$ inside diameter has been built for the $J T-60$ tokamak. 39,10 The $1 \mathrm{~m}$ diameter gate vaives are estimated to cost $160 \mathrm{ks}$ each. A $10 \mathrm{~cm}$ tube/isolation valve will connect the cryopump to the turbopump, and a $2.5 \mathrm{~cm}$ tube/valve will connect the turbopump to a diaphragm pump. It is assumed that the costs of these other valves, baffles, tubes (not including the large duct from the chamber to the cryopump), and instrumentation will about equal the cost of a second large gate valve. Thus, the cost for the valves and baffles per duct is estimated to equal the cost of two large gate valves, or $320 \mathrm{ks}$. Since there are 24 ducts, the total cost for these items is 7.68 MS.

\section{Filbe System Components}

The estimated sizes of flibe system components are listed in Table 8 . Most of the Flibe system components are considered to be part of the primary coolant system, and are not included here as part of the tritium management system. 
Table 8. Estimated Sizes of Flibe components.

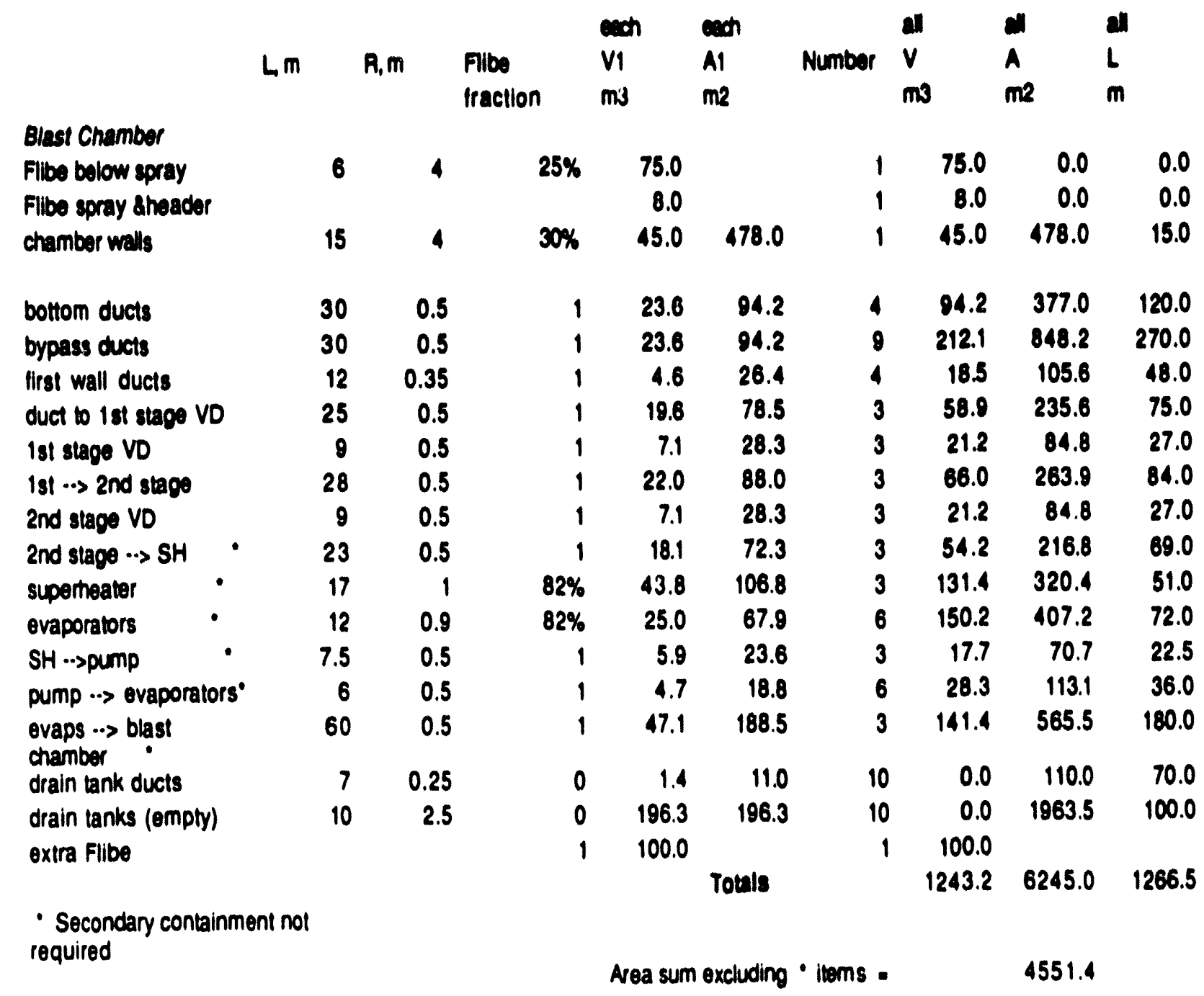




\section{Tritlua Storage Bods}

The target factory is a separate system, which has not yet been designed, and its tritium inventory has not been calculated. There will be segmented tritium storage beds at the output of the protium removal system, located in a Nuclear Grade containment bullding (perhaps the target factory). In the event of target factory fallure, the reactor could continue to operate for one day on stockpiled targets, and this storage bed would accumulate the one-day exhaust tritium from the reactor and flibe.

The tritium production rate in the flibe is

$$
B P / W-1.19 \times 10^{21} \text { atoms } / \mathrm{s}-5.84 \times 10^{20} \text { molecules } / \mathrm{s} .
$$

With a burnup fraction $\mathrm{fb}_{\mathrm{b}}-0.35$, the unburned target tritium exhausted to the vacuum system is

$$
(P / W)(1-f b) / f b-1.87 \times 10^{21} \text { atoms } / \mathrm{s}-9.34 \times 10^{20} \text { molecules } / \mathrm{s} .
$$

Both of these flows eventually reach the tritium management system, except for the small fraction which is lost. In one day, the total flow is $8.07 \times 10^{25}$ molecules - 134 moles. Each mole of uranium can practically store about 0.75 moles of $T_{2}$, so 179 moles of uranium $(43 \mathrm{~kg})$ are required. Assuming each storage bed contains $5 \mathrm{~kg}$ uranium, there will be 9 storage beds, plus 5 spares. The cost of the 14 storage beds, each $47 \mathrm{ks}$, is $660 \mathrm{ks}$.

The costs estimated for the HYLIFE-II Tritium Management System are summarized in Table 9. The total cost is $92 \mathrm{MS}$, of which the vacuum disengagers cost $-56 \%$, the blast chamber vacuum system $-15 \%$, the cryogenic plant $-9 \%$, the emergency air cleanup and waste treatment systems each $-6 \%$, the protium removal system - $3 \%$, and the fuel storage system and inert gas system each $2 \%$. 
Tab10 9. Estimated costs for the HYLIFE-II Trittum Management System, FY 1990 dollars.

\begin{tabular}{|c|c|c|c|c|c|c|}
\hline 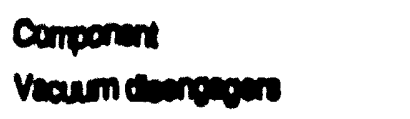 & Rol. & $9 \operatorname{man}$ & 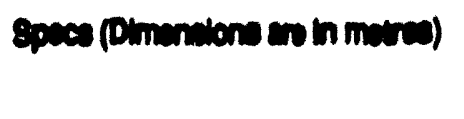 & $\cos x \cos$ & mon m & $\begin{array}{r}\text { enblothins } \\
51.44\end{array}$ \\
\hline vacuum disongepor chembers & $\operatorname{mex}$ & 6 & $D=4, L=8,1=0.03, M=301$ & 21 sko & 3.78 & \\
\hline internal structure & $\max$ & 6 & $5 \%$ of VD mass - 1.51 each & 21 skno & 0.10 & \\
\hline orlilice plates \& spares & $\max$ & 1 eet & $0.1 \times 0.1 \times 0.002,0.2 \mathrm{~mm}$ diem holes & & 1.00 & \\
\hline Utrahigh vacum gato valves & scaled & 48 & 1.0 diam, $(1+1$ equiv)touct, & $100 \mathrm{ks}$ & 7.68 & \\
\hline cryogonic pumps & est. & 24 & 50 m3/s, enall type & $24 \mathrm{ks}$ & 2.26 & \\
\hline urtomolocular pumps & Baizor & 24 & $5 \mathrm{~m} 3 / \mathrm{s}$, rated tor trittium senvice & $131 \mathrm{kS}$ & 3.14 & \\
\hline $\begin{array}{l}\text { vacuum ducts of disenpagers } \\
\text { engr., install,fost }\end{array}$ & $\operatorname{man}$ & 24 & $D=1, L=30,1=0.013,10 \mathrm{ta} \mid=232,61$ & 63 kPskg & $\begin{array}{l}14.65 \\
18.74\end{array}$ & \\
\hline huw stornges syatem & & & & & & 2.10 \\
\hline Iritium storago beds & est. & 14 & $5 \mathrm{~kg}(U)$ por bed. & $47 \mathrm{ks}$ & 0.66 & \\
\hline fubing/valves/pumps & est. & 14 & & $28 \mathrm{ks}$ & 0.39 & \\
\hline glove box +1 year labor & est. & 2 & & $24 \mathrm{ks}$ & 0.18 & \\
\hline engr..install,test & & & & & 0.86 & \\
\hline redistion montioring syeien & & & From BPX cost estimave & & & 0.53 \\
\hline 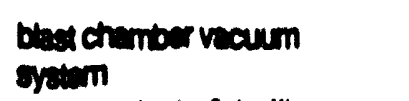 & & & & & & 13.80 \\
\hline $\begin{array}{l}\text { vacuum ducts \& baltles } \\
\text { cryogenic pumps }\end{array}$ & $\begin{array}{l}\text { mass } \\
\text { scalod }\end{array}$ & 4 & $\begin{array}{l}L=17, D=1.5,1=.01,0 a \mathrm{ch}=6.341 \\
\text { snail type, } 100 \mathrm{~m} 3 / \mathrm{s}\end{array}$ & $\begin{array}{l}62.8 \\
\mathrm{k} 5 / \mathrm{kg} \\
133 \mathrm{ks}\end{array}$ & $\begin{array}{l}1.59 \\
0.53\end{array}$ & \\
\hline hurbomolecular pumps & Balzer & 4 & tritium service, $5 \mathrm{~m} 3 / \mathrm{s}$ & $131 \mathrm{ks}$ & 0.52 & \\
\hline gale values & scalod & 12 & $1.5 \mathrm{~m}$ & $208 \mathrm{ks}$ & 2.50 & \\
\hline scroll pumps & est. & 4 & & $542 \mathrm{ks}$ & 2.17 & \\
\hline instrumentation & est. & sol & vacum gages. AGA & 89 kS & 0.09 & \\
\hline engr.,install, test & & & & & 5.10 & \\
\hline leak detection system & & & Irom BPX cost estimalt & & 1.30 & \\
\hline
\end{tabular}




\begin{tabular}{|c|c|c|c|c|c|c|}
\hline Component & Ret. & quent & Specs (Dimensions are in metres) & unt cost & $\begin{array}{l}\text { Men cost } \\
\text { MS }\end{array}$ & $\begin{array}{l}\text { abtotals } \\
\text { MS }\end{array}$ \\
\hline Inert gas system & & & & & & 1.95 \\
\hline gas supply \& storage system & & $9 \mathrm{m3}$ & helium tank, gages, regulators, & 0.08 & 0.08 & \\
\hline accumulator & & $9 \mathrm{m3}$ & & 0.08 & 0.08 & \\
\hline tubes, ducts \& valves & & set & & 0.07 & $0.0 ?$ & \\
\hline pumps & & 4 & & & 0.23 & \\
\hline hot getter bed & & 1 & & 0.09 & 0.09 & \\
\hline cold getter tods & & 3 & & & 0.28 & \\
\hline $\begin{array}{l}\text { D2 storage bed \& ref. } \\
\text { volume } \\
\text { instrumentation }\end{array}$ & & se! & & & $\begin{array}{l}0.38 \\
0.05\end{array}$ & \\
\hline engr.,install,test & & & & & 0.69 & \\
\hline protlum removal system & est. & & based on BPX isotope sep.system & & & 2.93 \\
\hline $\begin{array}{l}\text { emergency air cleanup } \\
\text { system }\end{array}$ & est. & & $\begin{array}{l}\text { Based on BPX atmos.detritiation } \\
\text { syst. }\end{array}$ & & & 5.37 \\
\hline cryogenic plant & & & & & & 8.57 \\
\hline $\begin{array}{l}\text { helium cryogenic refrig. } \\
\text { plant }\end{array}$ & scale & $.13 \mathrm{~kW}$ & $C=24.8(2.6 / 15)^{\wedge} 0.6$ & & 8.16 & \\
\hline $\begin{array}{l}\text { nitrogen cryogenic refrig. } \\
\text { plant }\end{array}$ & est. & & $5 \%$ of LHe cost & & 0.41 & \\
\hline $\begin{array}{l}\text { waste treatment \& } \\
\text { packaging } \\
\text { fume hoods }\end{array}$ & est. & 3 & & 0.05 & 0.14 & 5.30 \\
\hline glove boxes & est. & 2 & & 0.09 & 0.19 & \\
\hline remote handling equipment & est. & & & & 0.47 & \\
\hline room air cleanup equipment & est. & & & & 1.41 & \\
\hline packaging equipment & est. & & & & 0.94 & \\
\hline \multirow[t]{2}{*}{ engr.,install, test } & & & & & 2.15 & \\
\hline & & & & Total Cost & (\$) $=$ & 91.9 \\
\hline
\end{tabular}




\section{Summary}

A two-stage vacuum disengager is used in each of the three Flibe loops for tritium removal. Each stage has a chamber about $4 \mathrm{~m}$ in diameter and $7 \mathrm{~m}$ high. The optimum Flibe droplet diameter is $0.4 \mathrm{~mm} ; 1$ arger droplets release tritium more slowly, and smaller droplets impede tritium gas flow out of the spray region. The tritium leakage into the steam system is about $11 \mathrm{ci} /$ day, and leakage through the secondary containment is about $1 \mathrm{Ci} /$ day. The Flibe pumping power associated with the vacuum disengagers is $6.6 \mathrm{MW}$.

The present design assumes that the calculated tritium removal fraction per stage is degraded a factor of two by nonuniform vacuum pumping and other undesirable effects. The design does not take credit for

* Flibe droplet oscillations and internal circulation

* reduced tritium backpressure in the spray region from the use of flow channels (Figure 11).

Experimental confirmation of the vacuum disengager concept for molten salt is needed. Because the vacuum disengager removes tritium effectively from the Flibe, an intermediate coolant loop is not needed to prevent tritium leakage into the steam system. The HYLIFE-II design has evolved to a configuration with no intermediate coolant loop, using a double-wall steam generator to reduce the probability of steam penetration into the Flibe system.

\section{Acknow ledgments}

This work was supported by the US Department of Energy, Office of Energy Research, under contract DE-AC07-76ID01570. The costs were estimated by J. C. Commander. The authors are grateful to J. DeVan, P. A. Finn, E. Garcia-Otero, P. Gierszewski, C. D. Hendricks, M. A. Hoffman, R. W. Moir, H. Moriyama, D. K. Sze, W. Williams, and L. J. Wittenberg for helpful discussions. 


\section{References}

1 R. W. Moir, "HYLIFE-II inertial confinement fusion reactor design, "Fusion Technology 19, 617-624 (1991).

2 R. W. Moir, "HYLIFE-II inertial fusion energy power plant design," Fusion Technology 21, 1475-1486 (1992).

3 T. J. Dolan and G. R. Longhurst, "Safety and Environmental Aspects of HYLIFE-II, " Fusion Technology 19, 1392-1397 (1991).

4 A. Sherwood, "Process concepts for tritium recovery from fluid loops," Section 3.7 of LLNL Report UCID-20153 (1984); A. Sherwood, "Tritium permeation and recovery for He-cooled molten salt breeder," UCID-20141 (1974).

5 R. W. Moir et a1, "HYLIFE-II Progress Report," UCID-21816 (1991) Chapter 5 .

6 M. Hoffman, University of California, Davis, CA, letter February 1, 1992, to HYLIFE-II Design Team.

7 G. R. Longhurst and T. J. Dolan, "Tritium Permeation Losses in HYLIFE-II Heat Exchanger Tubes, " Fusion Technology 19 (1991) 820-82567.

8 R. W. Moir et a1, "HYLIFE-II progress report," UCRL-ID-21816 (1991), P.14.

9 J. F. O'Hanion, A User's Guide to Vacuum Technology, John Wiley \& Sons, New York, 1980, Fig. 6.6.

10 R. W. Moir et al, "HYLIFE-II progress report," UCRL-ID-21816 (1991), Section 4.5.

11 A. Roth, Vacuum Technology, North-Holland, New York, 1976, p.165.

12 T. J. Dolan, Fusion Research, Pergamon Press, Elmsford, NY, 1982, Ch. 19.

13 A. Roth, Vacuum Technology, North Holland, New York, NY, 1976.

14 J. H. Pitts and H. G. Patton, "Vacuum pumping for inertial-confinementfusion reactors," Journal of Vacuum Science and Technology A 8, 3052-3057 (1990).

15 J. L. Hemmerich, "The cryogenic diffusion pump - an advanced design for fusion reactor primary pumping and fuel processing," 4th Topical Meeting on Tritium Technology in Fission, Fusion and Isotopic Applications, 
September 29-0ct 4, 1991, Albuquerque, NM.

16 C. A. Foster, "High-throughput continuous cryopump," Journạl of Vacuum Science and Technology A 5, 2558-2562 (1987).

17 R. W. Moir et a7, "HYLIFE-II Progress Report," UCRL-ID-21816 (1991), Ch. 6 .

18 G. Pierini, R. Baratti, A. M. Polcaro, P. F. Ricci, and A. Viola, "Mass transfer operational units applied to the liquid breeding material of fusion reactors for tritium recovery," Fusion Technology 8, 2121-2126 (1985).

19 R. G. Clemmer, D. K. Sze, P. E. Blackburn, E. VanDeventer, and $\dot{V}$. A. Maroni, "Flibe chemistry studies," Fusion Technology 19, 1612-1618 (1991).

20 G. R. Longhurst, "Gas evolution from spheres," EGG-FSP-9634, 1991.

21 R. Clift, J. R. Grace, and M. E. Weber, Bubbles, Drops, and Particles, Academic Press, New York, NY, 1978.

22 P. F. Peterson, R. Y. Bai, V. E. Schrock, and K. Hijikata, "Droplet condensation in rapidly decaying pressure fields, " Transactions of the ASME 114, 194-200 (1991).

23 J. Oishi, H. Moriyama, S. Maeda, and $Y$. Asaoka, "Tritium recovery from molten LiF-BeF2 salt, Fusion Engineering and Design 8, 317-321 (1989).

24 R. B. Bird, W. E. Stewart, and E. N. Lightfoot, Transport Phenomena, Wiley, New York, 1960.

25 V. L. Streeter, Editor Handbook of Fluid Dynamics, McGraw-Hill, New York, NY, 1961 .

26 R. H. Perry and C. H. Chilton, Chemical Engineer's Handbook, 5th Edition, McGraw-Hi11, New York, NY 1973, p. 18-59.

27 C. D. Hendricks, "Micron and submicron particle production," IEEE Transactions on Industry Applications IA-10, No. 4, 508-510 (July/August 1974).

28 R. C. Weast and S. M. Selby, Editors, Handbook of Chemistry and Physics, 47th Edition, The Chemical Rubber Company, Cleveland, OH, 1966, P. F-123.

29 E. W. McDaniel, Collision Phenomena in Ionized Gases, Wiley, New York, NY, 1964, P. 164.

30 W. H. Press, B. P. Flannery, S. A. Teukolsky, and W. T. Vetterling, Numerical Recipes, Cambridge University Press, 1986. 
31 A. P. Malinauskas and D. M. Richardson, "The solubilities of hydrogen, deuterium, and helium in molten Li2BeFA," Ind. Eng. Chem. Fundam. 13, 242-245 (1974).

32 K. Yajima, H. Moriyama, J. Oishi, and Y. Tominaga, "Surface tension of lithium fluoride and beryllium fluoride binary melt," Journal of Physical Chemistry 86, 4193-4196 (1982).

33 P. A. House, "HYLIFE-II Reactor Chamber Mechanical Design," Fusion Technology 21, 1487-1491 (1992).

34 R. W. Moir, et al., "HYLIFE-II Progress Report," UCRL-ID-21816, December 1991, Ch. 5.

35 Using essentially tritium-free Flibe coming from the heat exchangers to cool the space between shells 2 and 3 and all required cooling exterior of that may mean that the blast chamber need not be strictly doubly contained.

36 R. Leber, Lawrence Livermore National Laboratory, March 26, 1992.

37 M. A. Hoffman and Y. T. Lee, "Performance and cost of the HYLIFE-II Balance of Plant," Fusion Technology 21, 1557-1568 (1992).

38 T. J. Dolan, Fusion Research, Pergamon Press, Elmsford, NY, 1982, Table $28 B 3$.

39 S. R. Thomas, Jr., T. H. Batzer, M. O. Calderon, R. H. Hawkins, and R. J. Nage 1, "A large rectangular gate valve," Proceedings of the Seventh Symposium on Engineering Problems of Fusion Research, Volume II, Knoxville, TN, October 25-28, 1977, published by IEEE, 1978, pages 985988.

40 N. Ogiwara, T. Arai, M. Shimizu, T. Takizawa, and F. Kimijima, "Reliability tests of $40 \mathrm{~cm}$ ID all metal gate vale and $54 \mathrm{~cm}$ ID ceramic break for JT-60," Proceedings of the 10th Symposium on Fusion Engineering, Volume 2, Philadelphia, PA, December 5-9, 1983, published by the IEEE, Catalog No. 83CH1916-6 NPS, 1984, pages 1058-1062. 
$\forall$
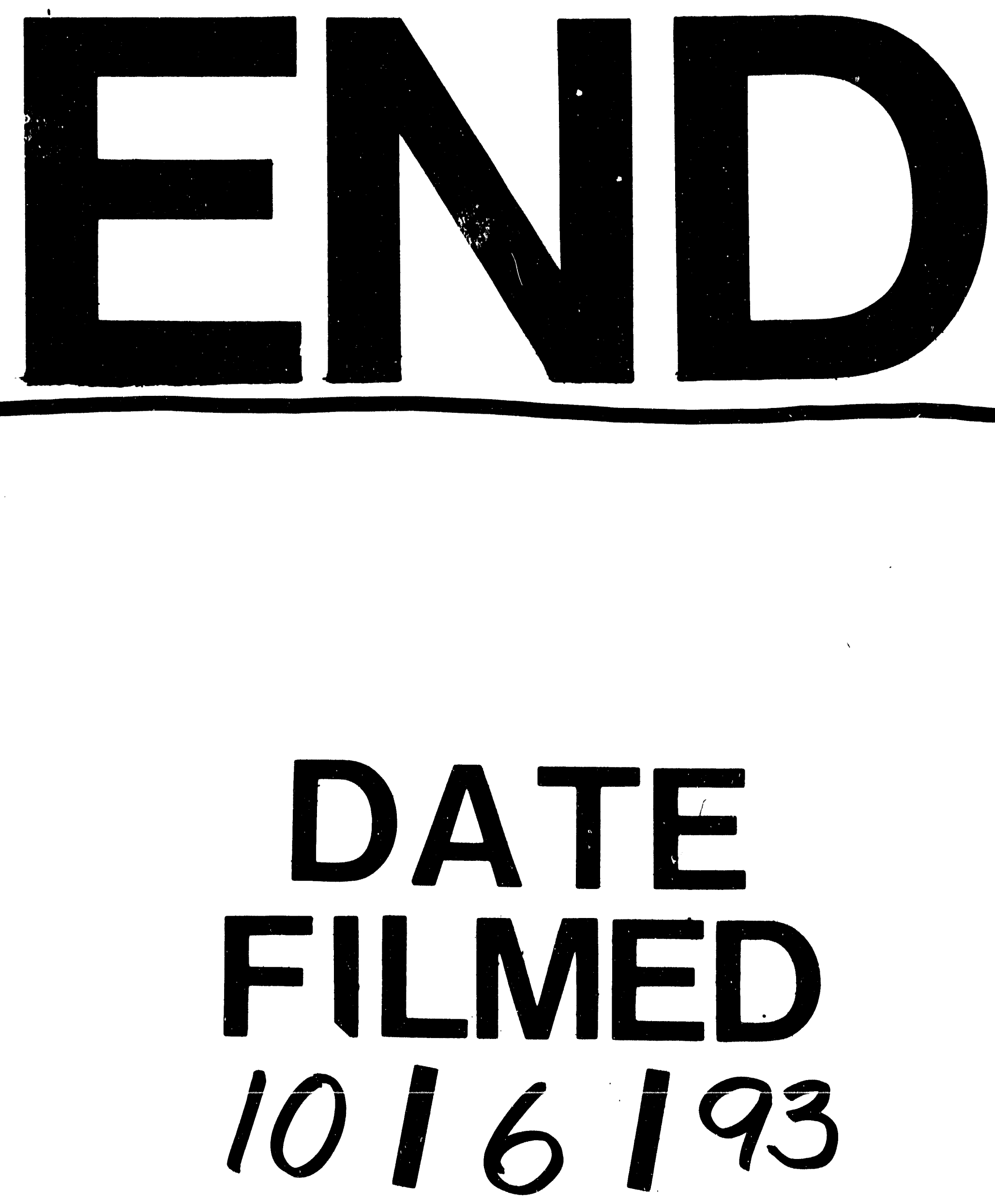
